US Army Corps of Engineers ${ }_{\circledast}$ Engineer Research and Development Center

\title{
Evaluation of the Air Void Analyzer
}

Peter G. Bly and Luis A. Ventorini

July 2013

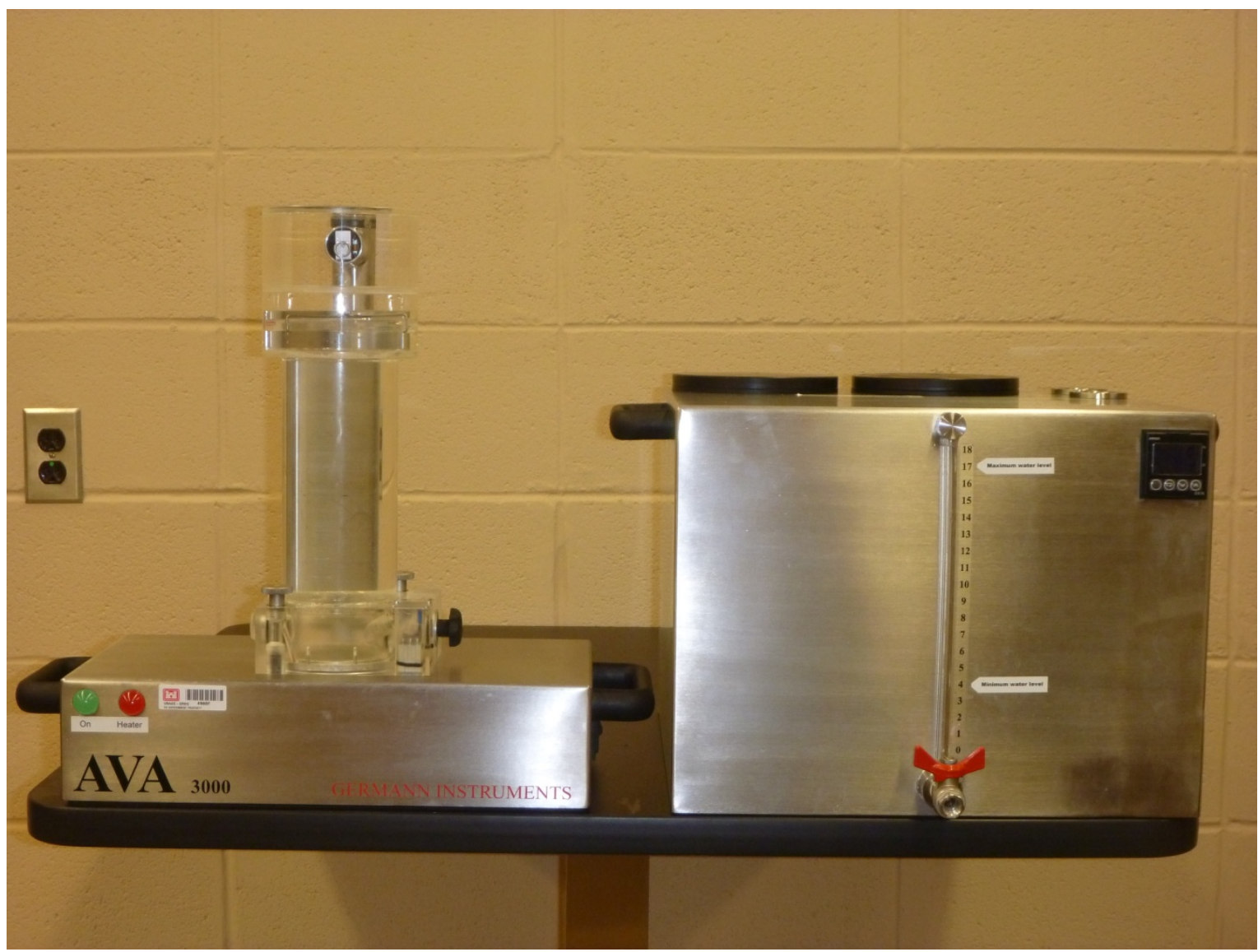


The US Army Engineer Research and Development Center (ERDC) solves the nation's toughest engineering and environmental challenges. ERDC develops innovative solutions in civil and military engineering, geospatial sciences, water resources, and environmental sciences for the Army, the Department of Defense, civilian agencies, and our nation's public good. Find out more at www.erdc.usace.army.mil.

To search for other technical reports published by ERDC, visit the ERDC online library at http://acwc.sdp.sirsi.net/client/default. 


\title{
Evaluation of the Air Void Analyzer
}

\author{
Peter G. Bly and Luis A. Ventorini \\ Geotechnical and Structures Laboratory \\ U.S. Army Engineer Research and Development Center \\ 3909 Halls Ferry Road \\ Vicksburg, MS 39180-6199
}

Final report

Approved for public release; distribution is unlimited.

Prepared for Headquarters, Air Force Civil Engineer Support Agency

Tyndall Air Force Base, FL 32403-5319 


\section{Abstract}

The U.S. Army Engineer Research and Development Center (ERDC) conducted an evaluation of the Air Void Analyzer (AVA) to determine the machine's ability to accurately and precisely measure the air void structure of freshly prepared portland cement concrete (PCC). This evaluation consisted of producing multiple batches of PCC in the laboratory and measuring each batch's air void structure with the AVA and other commonly used ASTM International testing procedures. A statistical analysis was conducted on sixty batches of concrete, covering a range of entrained air and fly ash contents. Air contents and fly ash replacement ranged from 3 to 8 percent and o to 20 percent, respectively. The freezethaw resistance of the PCC produced was also evaluated to verify the machine's ability to reveal poorly performing mixtures.

The laboratory evaluation was conducted from May 2011 to January 2012. Laboratory mixtures were batched and concrete specimens were prepared and tested at the ERDC Materials Testing Center. A certified petrographer determined the air void structures were in accordance with ASTM C457. A statistical analysis of the air void structure measurements taken by the AVA was completed using the results of five ASTM International standard test methods.

This report summarizes the laboratory performance of the AVA, and the pertinent conclusions from the testing performed. Recommendations for implementation and future testing are provided.

DISCLAIMER: The contents of this report are not to be used for advertising, publication, or promotional purposes. Citation of trade names does not constitute an official endorsement or approval of the use of such commercial products. All product names and trademarks cited are the property of their respective owners. The findings of this report are not to be construed as an official Department of the Army position unless so designated by other authorized documents. 


\section{Contents}

Abstract...................................................................................................................................... if

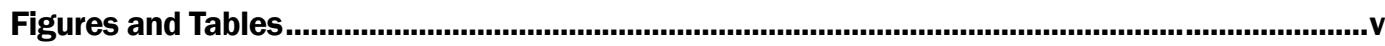

Preface ................................................................................................................................................vii

Unit Conversion Factors.........................................................................................................viif

1 Introduction...................................................................................................................... 1

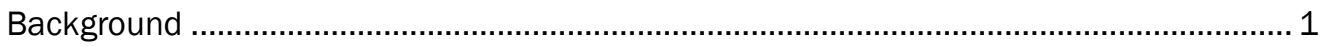

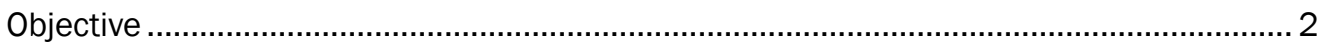

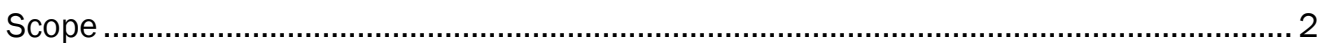

2 Literature Review ........................................................................................................... 4

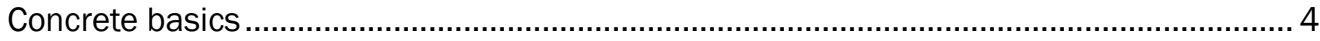

Void types within concrete ..................................................................................... 4

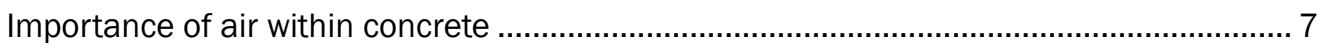

Air void structure characteristics ................................................................................ 8

Air void structure measurement methods .................................................................... 9

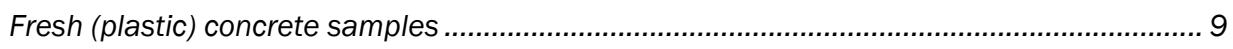

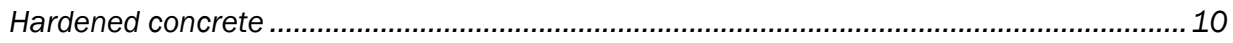

New techniques to analyze air void system ................................................................. 11

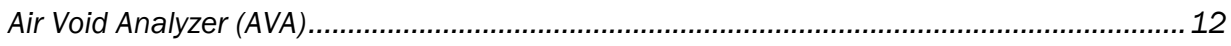

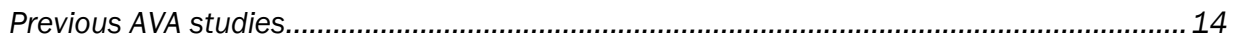

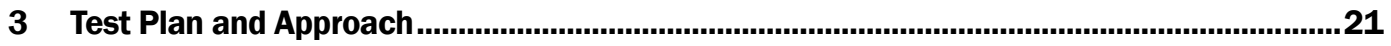

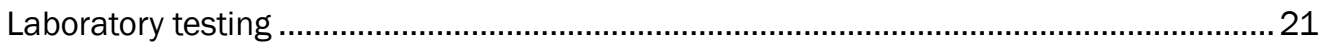

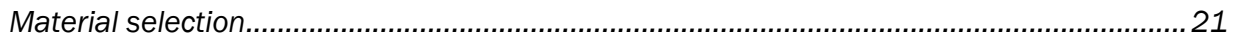

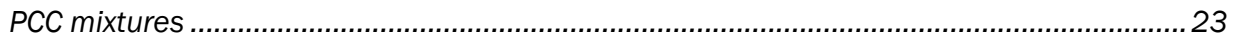

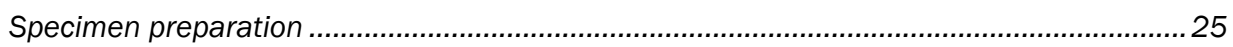

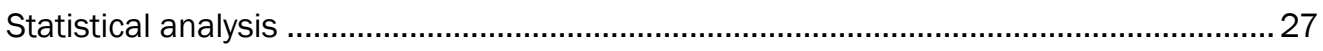

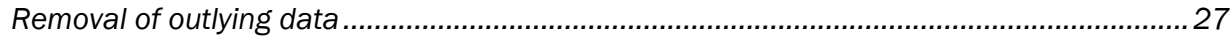

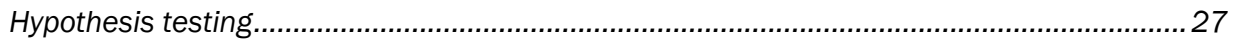

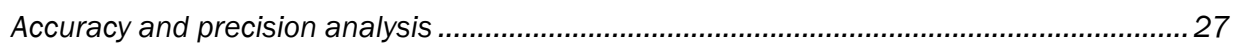

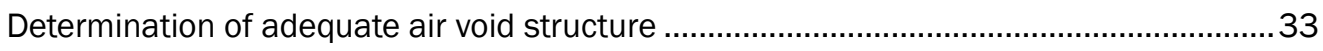

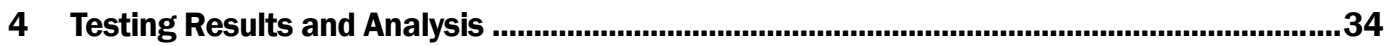

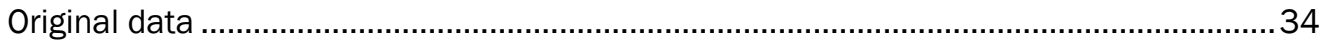

Outlying data detection and descriptive statistics .......................................................... 34

Bivariate analysis on testing methods .........................................................................4 45

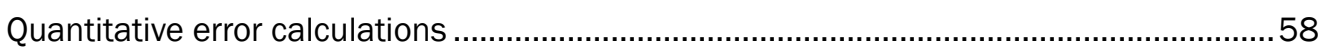

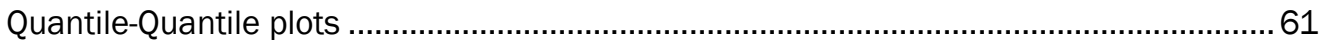

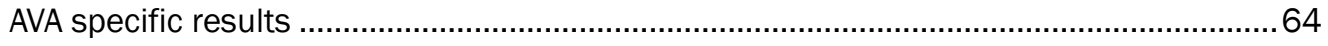




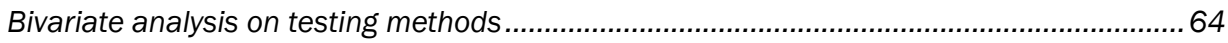

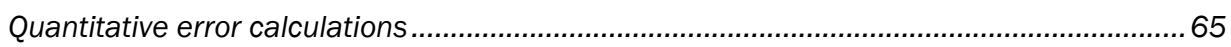

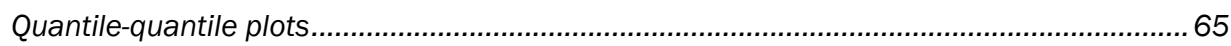

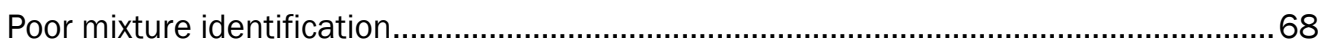

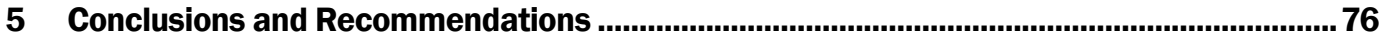

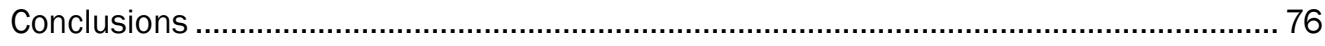

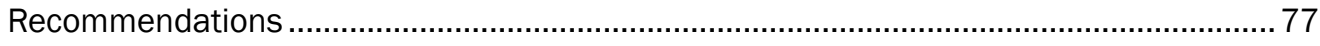

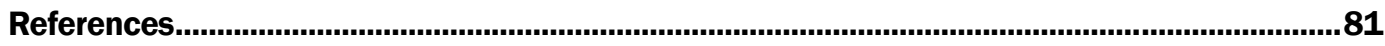

Appendix A: Detailed Material Testing Reports .......................................................................85

Report Documentation Page 


\section{Figures and Tables}

\section{Figures}

Figure 1. Component breakdown of basic portland cement concrete by volume.............................. 5

Figure 2. Typical range of PCC mixture component sizes................................................................... 5

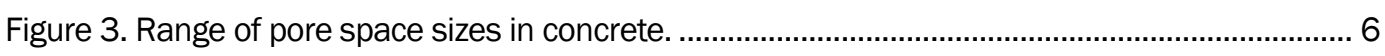

Figure 4. Air voids within concrete. ........................................................................................ 6

Figure 5. Freeze-thaw damage from non-air entrained and air entrained concrete........................... 8

Figure 6. AVA water column.................................................................................................... 13

Figure 7. Rise velocity of air bubbles in water at $70^{\circ} \mathrm{F}$............................................................ 13

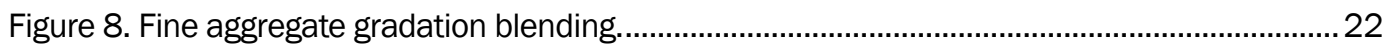

Figure 9. Generalized results for the accuracy and precision analysis............................................ 31

Figure 10. Total air content measured by ASTM C231 for each mixture design...............................35

Figure 11. Total air content measured by ASTM C173 for each mixture design.................................35

Figure 12. Total air content calculated by ASTM C138 for each mixture design. ..............................36

Figure 13. Total air content measured by ASTM C457-A for each mixture design. ...........................36

Figure 14. Total air content measured by AVA (less than $2 \mathrm{~mm}$ ) for each mixture design................. 37

Figure 15. Total air content measured by AVA (less than $1 \mathrm{~mm}$ ) for each mixture design. ............... 37

Figure 16. Specific surface measured by ASTM C457-A for each mixture design. ...........................38

Figure 17. Specific surface measured by AVA (less than $2 \mathrm{~mm}$ ) for each mixture design. ................38

Figure 18. Specific surface measured by AVA (less than $1 \mathrm{~mm}$ ) for each mixture design..................39

Figure 19. Spacing factor measured by ASTM C457-A for each mixture design. ..............................39

Figure 20. Spacing factor measured by AVA (less than $2 \mathrm{~mm}$ ) for each mixture design. .................. 40

Figure 21. Spacing factor measured by AVA (less than $1 \mathrm{~mm}$ ) for each mixture design. ................. 40

Figure 22. Q-Q plots comparing ASTM C457-A to other fresh property measurements...................46

Figure 23. Comparison of air void perimeter damage on measurement. ..........................................50

Figure 24. Examples of samples that were not ground flat. .............................................................52

Figure 25. Comparison of ASTM C457 Procedures (Lamond and Pielert 2006)..............................53

Figure 26. Q-Q plot comparing ASTM C457-A and ASTM C138 results.........................................56

Figure 27. Q-Q plot comparing ASTM C457 Procedure A and B air void structure results................5 57

Figure 28. Q-Q plot comparing ASTM C457-B and C231 results.................................................58

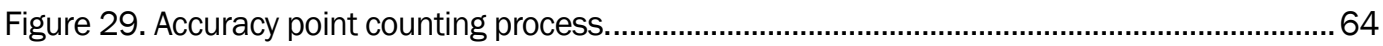

Figure 30. Q-Q plots made for comparison of ASTM air content tests against the AVA. ...................66

Figure 31. Comparison of additional ASTM C457 air void structure properties compared to AVA results.

Figure 32. Breakdown of specific surface measurements by mixture design for AVA data

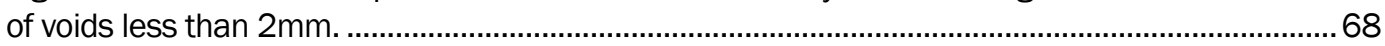

Figure 33. Tested freeze-thaw specimens........................................................................... 70

Figure 34. Freeze-thaw durability results by air content for all concrete batched. ............................ 70 
Figure 35. Freeze-thaw durability results by air spacing factor for all concrete batched.................. 71

Figure 36. Freeze-thaw durability results against AVA (less than $2 \mathrm{~mm}$ ) air content measurements by mixture design.

Figure 37. Freeze-thaw durability results against AVA ( $2 \mathrm{~mm}$ and less) spacing factor measurements by mixture design. .............................................................................................

Figure 38. Historical freeze-thaw durability results of different concretes by (a) air content (Cordon 1966) and (b) spacing factor (Backstrom 1956)................................................ 73

Figure 39. Plot of measured spacing factors against air content................................................... 75

Figure A1. \#67 Limestone test results.................................................................................... 85

Figure A2. Bagged sand test results....................................................................................... 86

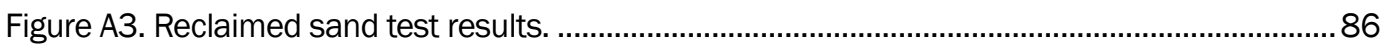

Figure A4. Portland cement mill testing report. ......................................................................... 87

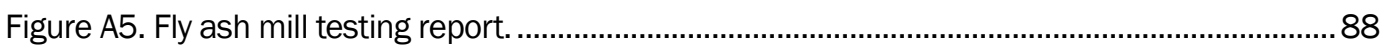

Figure A6. Air entraining admixture manufacturer's information. ................................................... 89

Figure A7. Air entraining admixture manufacturer's information. ................................................... 91

\section{Tables}

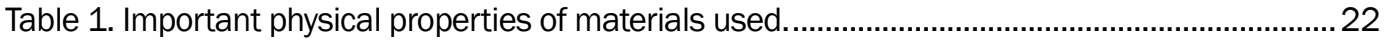

Table 2. Mixture design constants................................................................................................ 23

Table 3. Material usage per cubic yard of concrete...................................................................... 24

Table 4. Concrete properties measured during mixture design determination. ................................. 24

Table 5. Required calculated AVA mixture design input data........................................................... 25

Table 6. Descriptive statistics for air content by testing method. ...................................................... 41

Table 7. Descriptive statistics for specific surface by testing method............................................... 43

Table 8. Descriptive statistics for spacing factor by testing method. .................................................4

Table 9. Total air content descriptive statistics by testing procedure................................................46

Table 10. Consolidation effort used for sample construction.......................................................... 48

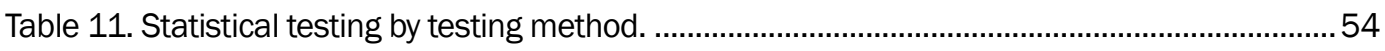

Table 12. Accuracy error calculations made.............................................................................59

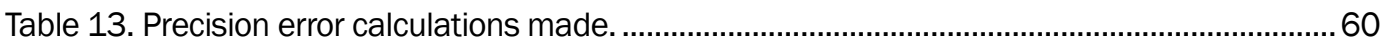

Table 14. Q-Q plot regression equation analysis values............................................................... 62

Table 15. Determination of appropriate error............................................................................. 63

Table 16. ASTM C666-A (2008c) testing data..............................................................................69

Table A1. Measured fresh and hardened concrete properties........................................................93

Table A2. ASTM C666-A testing data............................................................................................... 95 


\section{Preface}

Personnel of the U.S. Army Engineer Research and Development Center (EDRC), Geotechnical and Structures Laboratory (GSL), Vicksburg, MS, were tasked to evaluate the accuracy and precision of the Air Void Analyzer (AVA) in measuring the air void system of portland cement concrete (PCC). Users of the information presented within this report include the U.S. Air Force, base civil engineers, and major command pavement engineers. Additional users include members of the Army, the Navy and the Marine Corps assigned with concrete construction.

The findings and recommendations presented in this report are based on laboratory tests conducted at the EDRC during May 2011 to January 2012. The principal investigators for this study were Peter G. Bly and Lt. Colonel Luis A. Ventorini (Brazil), Airfield and Pavements Branch (APB), GSL. Other research team members included personnel of the Material Testing Center (MTC) at ERDC. Bly and Ventorini prepared this report under the supervision of Dr. Gary L. Anderton, Chief, APB, GSL; Dr. Larry N. Lynch, Chief, Engineering Systems and Materials Division, GSL; Dr. William P. Grogan, Deputy Director, GSL; and Dr. David W. Pittman, Director, GSL.

Col Kevin J. Wilson was the Commander and Executive Director of EDRC. Dr. Jeffery P. Holland was the Director.

Recommended changes for improving this publication in content and/or format should be submitted on DA Form 2028 (Recommended Changes to Publications and Blank Forms) and forwarded to Headquarters, U.S. Army Corps of Engineers, ATTN: CECW-EW, 441 G Street NW, Washington, DC 20314 . 


\section{Unit Conversion Factors}

\begin{tabular}{|l|c|l|}
\hline Multiply & By & To Obtain \\
\hline cubic feet & 0.02831685 & cubic meters \\
\hline cubic yards & 0.7645549 & cubic meters \\
\hline degrees Fahrenheit & $($ F-32)/1.8 & degrees Celsius \\
\hline feet & 0.3048 & meters \\
\hline gallons (U.S. liquid) & 3.785412 E-03 & cubic meters \\
\hline inches & 0.0254 & meters \\
\hline ounces (U.S. fluid) & 2.957353 E-05 & cubic meters \\
\hline poise & 0.1 & pascal-seconds \\
\hline pounds (force) & 4.448222 & newtons \\
\hline pounds (force) per square inch & 6.894757 & kilopascals \\
\hline pounds (mass) per cubic foot & 16.01846 & kilograms per cubic meter \\
\hline
\end{tabular}




\section{Introduction}

\section{Background}

U.S. Air Force engineers are under constant pressure to design and build high-quality yet economical portland cement concrete (PCC) airfield pavement to support each airfield's intended mission. The PCC is an essential airfield paving material because its usage is required in specific airfield features, according to Unified Facilities Criteria pavement design guidance for precise construction and the prevention of damage to asphalt pavements from heavy loads, extreme heat, spilt petroleum products, long term parking, routine turning and braking, and the handling of hazardous items (UFC 2001).

One of the most important characteristics of PCC is its air void system. Air, which occurs naturally in PCC after its constituent materials are mixed, ranges between 2 to 4 percent of the mixture's total volume. Additional air can be trapped (entrained) into a mixture by the use of air entraining admixtures when mixing to provide a network of small bubbles throughout its paste, raising the total air volume to 4 - 8 percent. Air affects both the plastic and hardened properties of concrete, from its ease of placement (workability) to its strength and durability. Ultimately, increased air contents decrease strength; however, adding resistance to freeze-thaw and salt scaling associated damage increases long-term durability. The tolerances used for mixture proportioning studies and construction specifications ensure that both strength and durability are achieved with the concrete used.

Quality assurance and quality control (QA/QC) procedures require that PCC delivered for projects have its air content measured to ensure the material delivered follows the mixture design used. Current Unified Facilities Guide Specifications (UFGS 2010) for structural and paving PCC allows the use of ASTM C231 ${ }^{1}$ and $\mathrm{C}_{173}{ }^{2}$ for air content determination of plastic normal weight and lightweight concrete, respectively. The ASTM C173 can also be used on normal weight concrete, but is not typically used because of the amount of effort required to perform the test. These field tests are quick and

1 C231 can be found in the references as ASTM $2009 \mathrm{f}$ and will be cited throughout the report as C231.

2 C173 can be found in the references as ASTM 2009e and will be cited throughout the report as C173. 
inexpensive to conduct, but they provide limited data. The output of these tests yields only a total air content that cannot delineate between entrapped and entrained air or provide an indication of the spacing and size distribution of the air voids within the cementitious paste. This additional data can be obtained from specimens examined by a petrographer following ASTM $\mathrm{C} 457^{1}$, but this examination requires hardened specimens, extensive preparation, and visual analysis under a microscope; steps which preclude its use for a rapid field test. Typically these specimens are taken and analyzed when damage is discovered after a structure is in service.

Currently, there is increasing interest in the concrete industry use the Air Void Analyzer (AVA) for quickly measuring the air void structure. The system is capable of rapidly measuring the total air content, size distribution, and spacing of air voids in a sample of plastic concrete in less than $30 \mathrm{~min}$. These rapid measurements can be used to detect deficient air void systems of delivered PCC and correct material with on-the-fly mixture modifications before the batch is placed in the structure.

\section{Objective}

The overall objective of this project was to evaluate the accuracy and precision of the AVA equipment for use in Department of Defense (DoD) projects as a QA/QC tool for air void structure measurement of fresh PCC.

\section{Scope}

This project consisted of evaluating the accuracy and precision of the AVA compared to standard PCC test methods. The laboratory study investigated the sensitivity of the machine to PCC mixtures designed with differing fly ash and entrained-air combinations. The characteristics of the air voids within various PCC mixtures were measured by different standard PCC testing methods, and the test results were compared to AVA test results taken from the same mixture. The laboratory investigation measured the effects of varying amounts of entrained air and fly ash on different PCC mixtures. A literature review on current testing methodologies used for measuring air content in concrete was also completed.

Chapter 2 gives a literature review on current methods used to measure the air void structure in fresh and hardened concrete and its importance

${ }^{1}$ C457 can be found in the references as ASTM 2010c and will be cited throughout the report as C457. 
for PCC design and construction. Chapter 3 describes the experimental program used for this study. Chapter 4 presents the results and analysis of the laboratory study conducted. Chapter 5 presents conclusions and recommendations. 


\section{Literature Review}

This chapter presents the current methods employed to analyze the air void system in fresh and hardened concrete. Descriptions of the testing methods used to monitor air voids in construction and a detailed discussion of the history of, the principals behind, and the previous studies with the AVA are provided.

\section{Concrete basics}

Concrete is a blend of aggregate held together with a binding material. Its basic composition and a description of its component materials are shown in Figure 1. For PCC, the typical binder is portland cement, but supplementary cementitious materials, like fly ash and ground granular blast furnace slag, can be used. When portland cement comes in contact with water, they chemically combine (hydration reaction), and this paste hardens over time. When mixed with aggregates, the paste coats the aggregates and bonds them together as the paste hardens. Concrete continues to gain strength over time until the material has no remaining water or un-hydrated cement to interact.

\section{Void types within concrete}

Voids occur naturally in PCC after all of its constituent materials are mixed. Figures 2 and 3 depict the typical size range of PCC air voids in relation to the other components used and other pore spaces, respectively. Figure 4 details the larger pore types seen in a typical sample of concrete. The pore space components are broken down as follows (Carlson 2005; Mindess et al. 2003; Mehta and Monteiro 2006; Taylor et al. 2007):

- Entrapped air voids

o Are unintentionally created within the concrete during the mixing and placement process,

o Range between 2 and 4 percent of the mixture's total volume and increase with increasing aggregate size,

o Increase with decreasing maximum aggregate size, since more paste is required to maintain workability,

o Typically have entrapped air void diameter sizes greater than 0.04 in., 


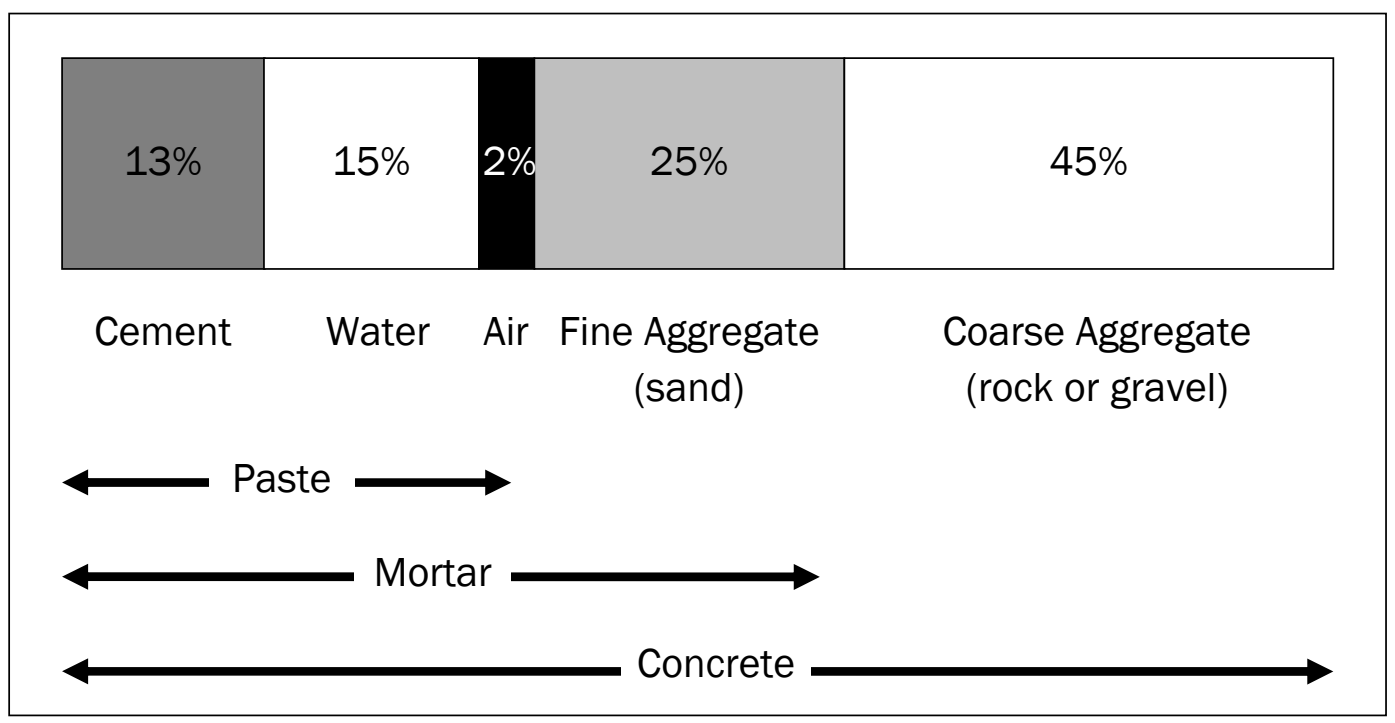

Figure 1. Component breakdown of basic portland cement concrete by volume.

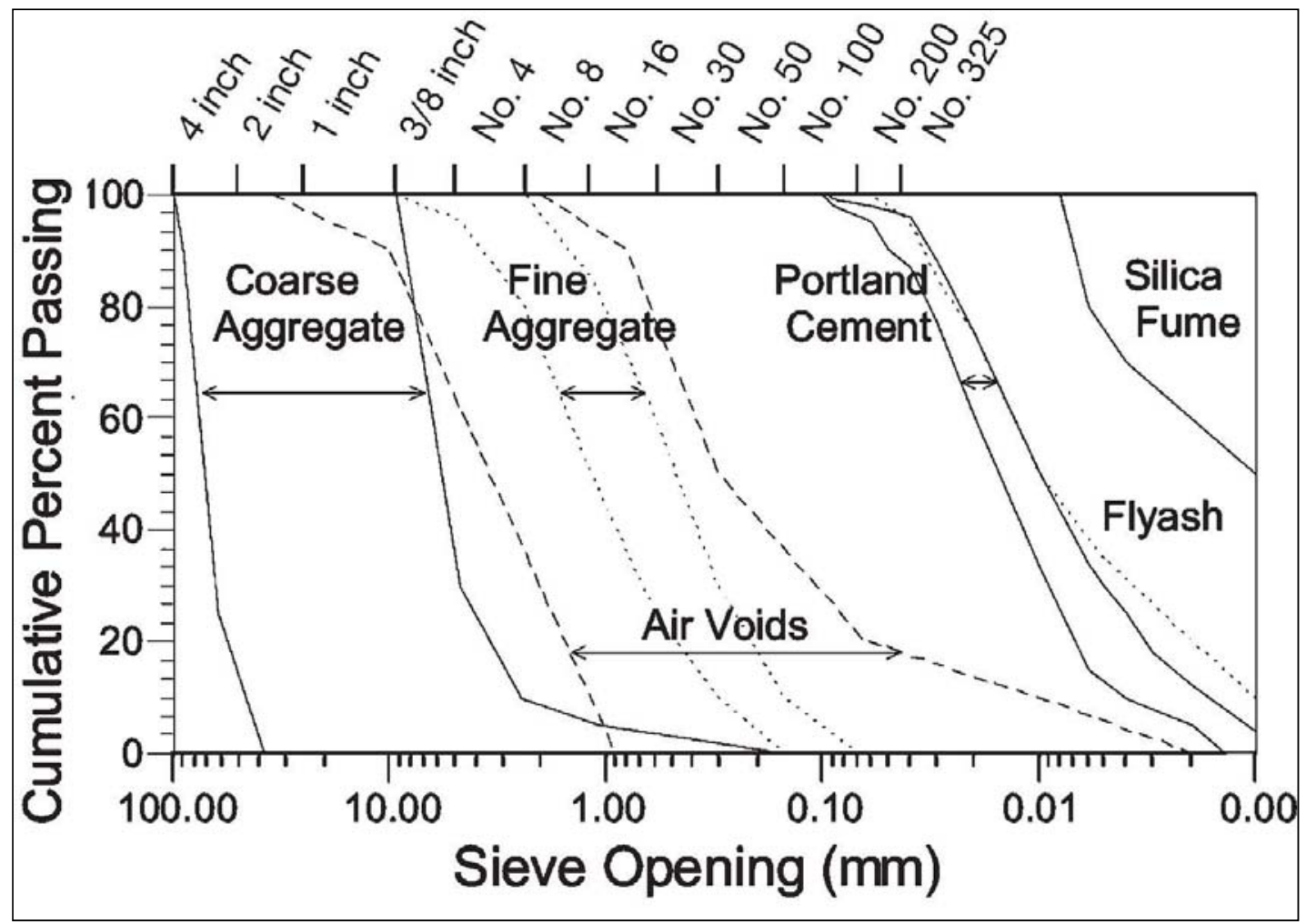

Figure 2. Typical range of PCC mixture component sizes (Lamond and Pielert 2006). 


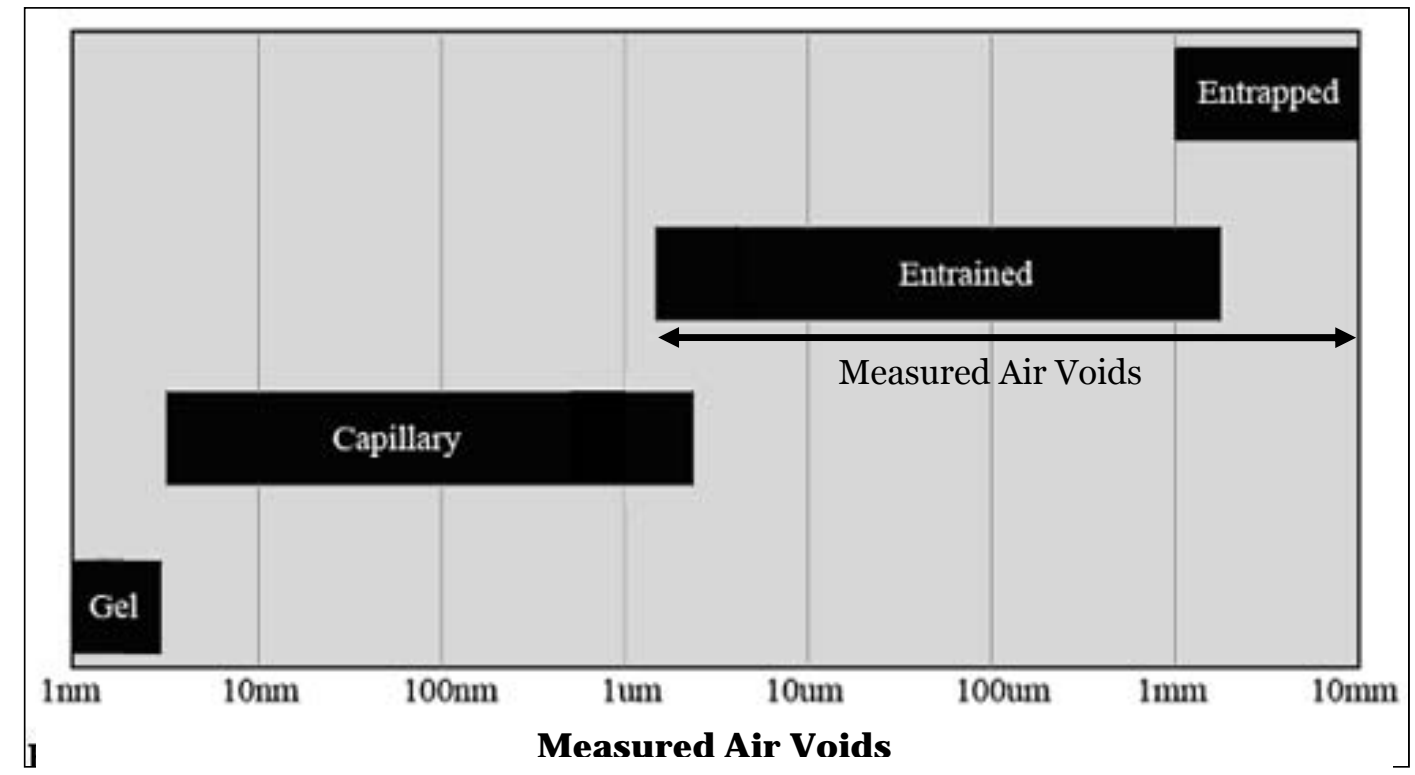

Figure 3. Range of pore space sizes in concrete (Carlson 2005).

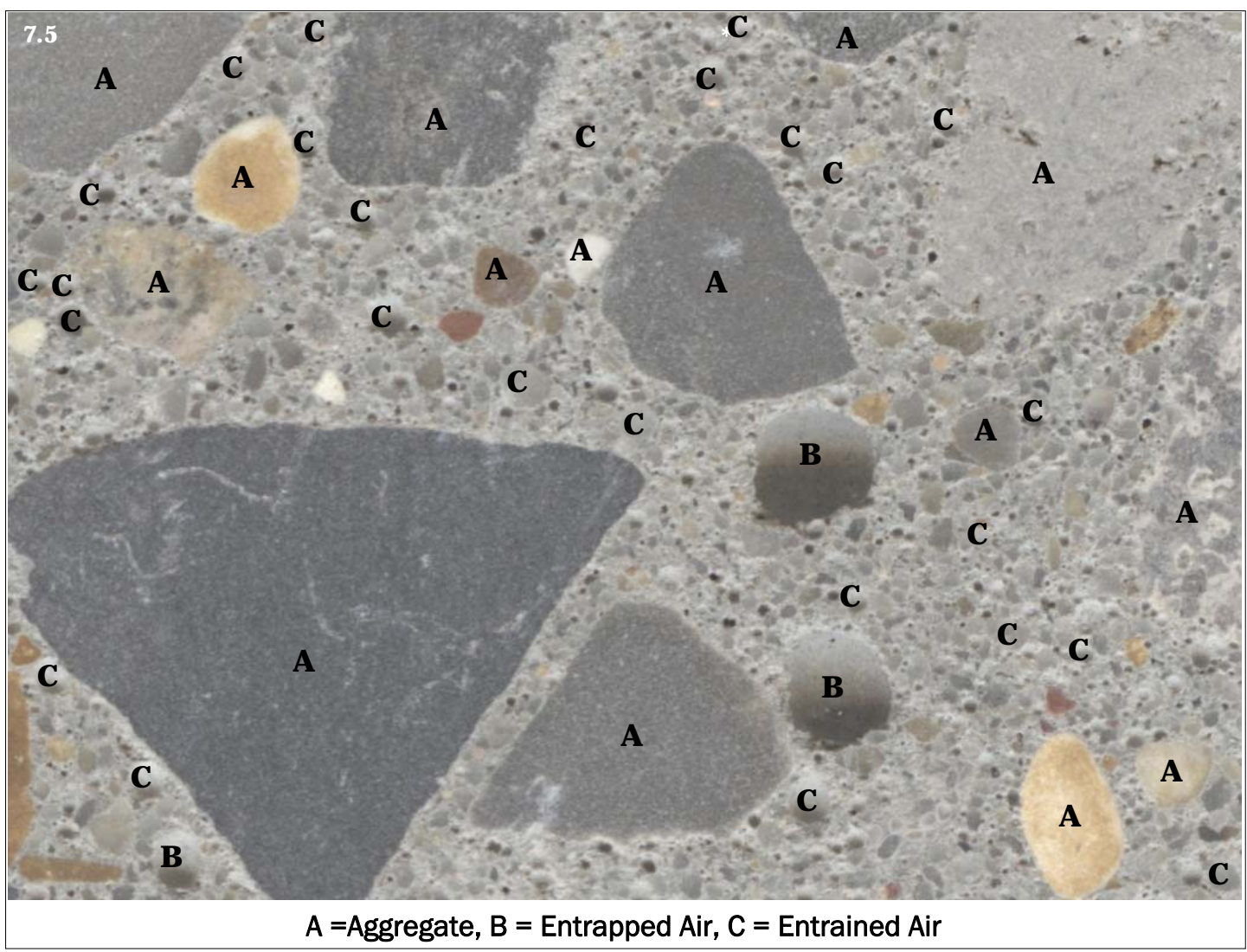

Figure 4. Air voids within concrete.

o Are irregularly shaped, and

o Are poorly dispersed throughout the mixture. 
- Entrained air voids

o Are created by the addition of an entraining admixture to the concrete,

o Provide a network of small bubbles throughout the paste and provide for total air volume between 4 and 8 percent,

o Range in diameter from $2.0 \cdot 10^{-3}$ to 0.04 in.,

o Are typically spherical in shape, and

o Are well dispersed throughout the mixture.

- Capillary pores are created by mixture water that is not used for cementitious hydration and that leaves the concrete by draining out or evaporating.

- Gel pores are the voids between the calcium silicate hydrate (CSH) layers bound by Van Der Waals forces and hydrogen bonding.

\section{Importance of air within concrete}

In the design of a concrete mixture, the volume of air within the mixture is specified to provide workability to help in placement when the mix is plastic and to increase the durability of the placed material. When used for workability, the air bubbles act as small, compressible ball bearings that reduce friction between aggregates in the mixture (Mindess et al. 2003). Air also prevents damage caused by cyclic freezing and thawing of water as its volume expands when freezing into ice or from the growth of salt crystals. The air provides additional void space within the structure that can provide the additional volume needed for the expanding materials. Figure 5 shows typical examples of concrete damage from improper air void structure from freeze-thaw. Korhonen (2002) provides a very detailed literary review of the theory and mechanisms behind concrete freezethaw-related damage.

When air entrained concrete is made for durability, voids are deliberately generated into the concrete, and this affects its mechanical properties. Air voids do not offer mechanical resistance to loading and can affect the way stresses are distributed throughout the structure. Concrete strength is reduced approximately 2 to 9 percent for each additional percent of air entrained (Kerkhoff 2002). The mixture must be designed to counteract this strength loss to ensure both strength and durability. 


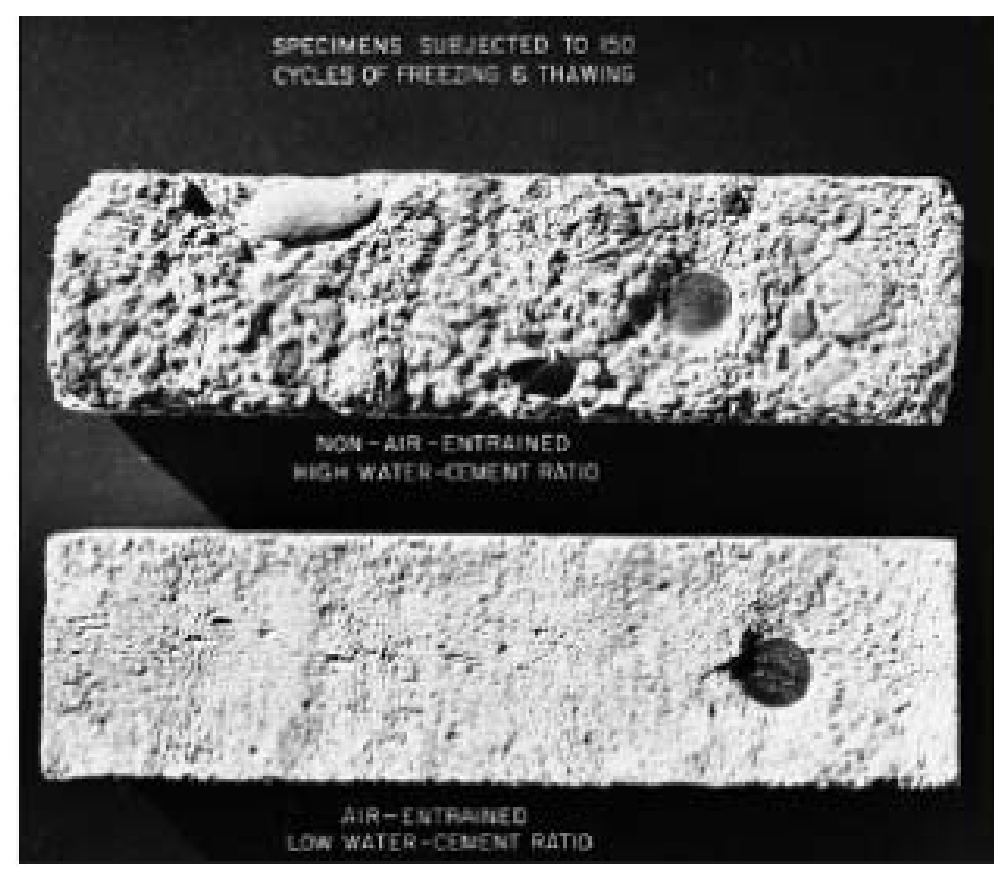

Figure 5. Freeze-thaw damage from non-air entrained and air entrained concrete (Taylor et al. 2007).

\section{Air void structure characteristics}

The durability of concrete results from more than just having air within the placed material. The structure of the voids dictates concrete's durability. The most important characteristics include the total air content, the specific surface, and the spacing factor. These characteristics are defined below for clarity, and their effects on concrete are described as follows:

- Total air content

o Measure of the entire volume of air per unit volume of concrete.

o No distinction between entrained and entrapped air with common, quick field tests.

- Specific surface

o Measure of the total amount of surface area provided by the air voids per unit volume of concrete.

o Smaller air voids indicated by higher values, since smaller voids have larger surface area-to-volume ratios.

o Void frequency determined from the number of voids intercepted by a traversed line during petrographic analysis. The combination of specific surface and air void frequency gives an idea of the size distribution of air voids in the concrete specimen (Carlson 2005). 
- Spacing factor (Lamond and Pielert 2006)

o Maximum theoretical distance between any points in the paste to the nearest air void.

o An index of effectiveness against frost resistance, since other methods may be more accurate but difficult to implement.

- Assumes a single void size is arranged in a simple cubic lattice structure, unlike the random distribution of various sized voids actually present.

- Represents the average half distance between two diagonal entrained air void surfaces (Carlson 2005).

For mitigating freeze-thaw damage, air void systems are believed to be sufficient when the spacing factor is less than $0.008 \mathrm{in}$. and have a specific surface greater than 600 in..$^{-1}$ (Kerkhoff 2002). However, typical project specifications require only the total air content. There is little or no correlation between the air content in fresh concrete and both the spacing factor and the size distribution of the air voids in hardened concrete. Additionally, there is no guarantee the service life of the placed and consolidated concrete will be met or exceeded when only the total air content of the fresh, delivered concrete is considered (Wang et al. 2008).

\section{Air void structure measurement methods}

Various testing methods are used to measure the air void structure of PCC. A brief overview of the testing methods currently used is presented below. The full procedure for conducting each standardized test described can be found in the cited standard.

\section{Fresh (plastic) concrete samples}

- Chace Air Indicator (AASHTO 2004)

o Yields an indication of total air void content on a mortar sample,

- Is semi-qualitative and

- Measures the degree of air content (low, medium, or high) or deviation between batches.

o Uses a considerably smaller sample size, compared to other test methods,

o Requires isopropyl alcohol, but 
o Is not a substitute for more accurate methods, ASTM C231 and C173, and should not be used for compliance to specifications (Wilson 2010).

- Gravimetric (ASTM C1381)

o Indirect determination of the total air content based on calculations

- Requires measurement on a sample and knowledge of mixture components and

- Depends on measured batch weights and material properties for accuracy.

o It is essentially a percent error calculation using the measured density of the sample and the calculated air free density from the mixture design submittal.

- Volumetric (ASTM C173)

o Is a physically demanding test in terms of sample processing effort,

o Determines total air content by shaking and rolling air out of a sample,

o Can be used with all aggregate types,

o Requires isopropyl alcohol, and

o May underestimate the air content with PCC containing more than $600 \mathrm{lb} / \mathrm{yd} 3$ of cementitious material because voids may take up to 60 min to reveal a stable reading.

- Pressure method (ASTM C231)

o Most common field measurement taken,

o Total air content determined by compressing the air volume within a sample and measuring the pressure difference within a sealed container,

- Pressure related to volume by Boyle's gas law

o Dense aggregates required; cannot be used with lightweight, highly porous, and slag aggregates or non-plastic concrete, and

o Correction factor required for the aggregate blend used.

\section{Hardened concrete}

- Petrographic (ASTM C457)

${ }^{1}$ C138 can be found in the references as ASTM 2009d and will be cited throughout the report as C138. 
o Visual observation of the voids by a trained professional with an optical microscope,

o Statistical approach to determining air void structure,

- Measurements record either the chord lengths of the voids observed or point count of a superimposed grid.

- Fraction of voids found per row traversed is determined.

o Hardened concrete and a flat surface ground until almost polished required for specimens,

- The total air, void size distribution (specific surface), and void spacing (spacing factor) within a specimen determined, and

o Standard method for measuring air void characteristics (Magura 1996).

\section{New techniques to analyze air void system}

To analyze air void systems, new automated techniques that greatly reduce the measurement time needed and operator-induced error have been developed. Previous studies have shown the suitability and ease of operation of these methods compared to standard tests.

- Hardened specimens with black and white contrast enhancement (Jana 2007):

o Digital imaging processing of hardened ASTM C457 specimens with additional staining for contrast enhancement,

o Black stain used to coat the paste and aggregates and white filler added to the surface to fill the air voids,

o Multiple imaging sources used where individual images can be spliced together, and

- High resolution flatbed scanner

- Camera with charge coupled device (CCD) image sensor

- Scanning electron microscope

- Calculations from the processed images for air void structure properties based on those of ASTM C457.

- Hardened specimens without black and white contrast enhancement (Jana 2007):

o Digital image processing of hardened ASTM C457 specimens with as-ground sample images, 
o Images analyzed by systems measuring the differences in shadowed areas of a specimen when subjected to light at various angles, similar to what a human operator does, and

o ASTM C457 based calculations.

- Computer tomography x-ray scanning (Caliskan 2007):

o Can be used on both fresh samples and hardened specimens,

o Must use small samples because of the amount of data collected,

o Can achieve resolutions of up to $4 \cdot 10^{-4} \mathrm{in}$., and

o Makes a 3D representation of the sample by taking multiple twodimensional cross sections through the sample or specimen.

\section{Air Void Analyzer (AVA)}

History

The AVA was developed in the early 1990 s under a BRITE/EURAM project led by Dansk Beton Teknik. In August 1993, the Federal Highway Administration (FHWA 2006) Office of Technology Applications purchased an AVA machine for evaluation and modified the software in November 1993. In April 1994, another software upgrade was made along with a formulation change to the glycerin-based blue viscous release fluid. This version was first used in June 1994 for testing in Michigan, Wisconsin, Texas, and Iowa; and the results of this study were published in 1996 by the FHWA (Magura 1996). Additional studies, conducted by Kansas DOT and National Concrete Pavement Technology Center (NCPTC); Iowa State University among others, have added considerable knowledge concerning the AVA since the first evaluation regarding implementing the use of the machine into project specifications, standardization of the testing method, and machine and process modifications. Germann Instruments purchased the rights of the AVA system in 2005 from Dansk Beton Teknik (Germann Instruments 2011). The AVA (3000 model), currently the top-of-the-line model available for purchase, was developed from modification recommendations given in the NCPTC's 2008 report concerning robustness and reliability of the previous AVA (2000 model).

\section{Concept and mechanics of testing}

The concept behind the AVA is very different from those of the photoimagery and visual counting techniques previously described. Instead of counting the voids while intermixed in a sample, the machine collects and records the voids as they rise out of a column of water from a fresh mortar 
sample (Figure 6). The voids rise at different speeds, depending on their size: larger voids rise faster than smaller voids. The process follows Stokes' law, and the frictional resistance (drag) on the various sizes (diameters) of spherical voids causes the voids to rise at different rates (Figure 7). This concept is similar to the settlement of small particles in clarification tanks in water and wastewater treatment plants, just in the opposite direction.

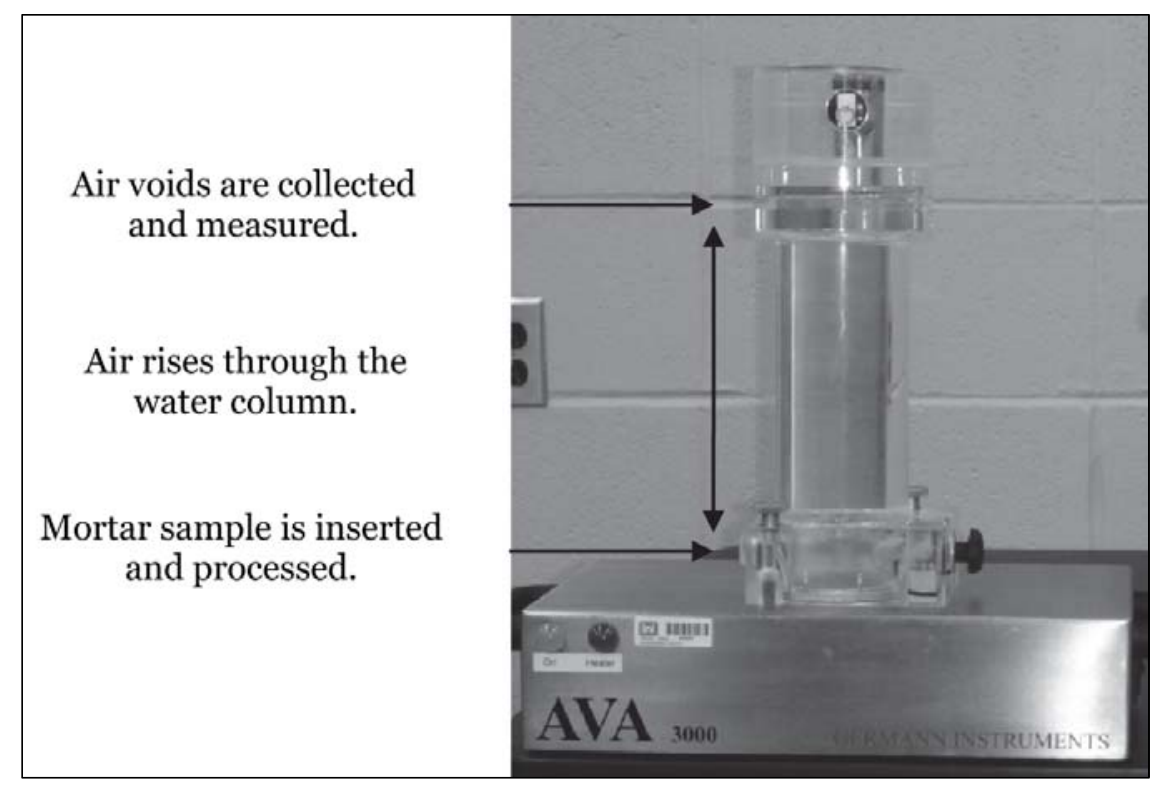

Figure 6. AVA water column.

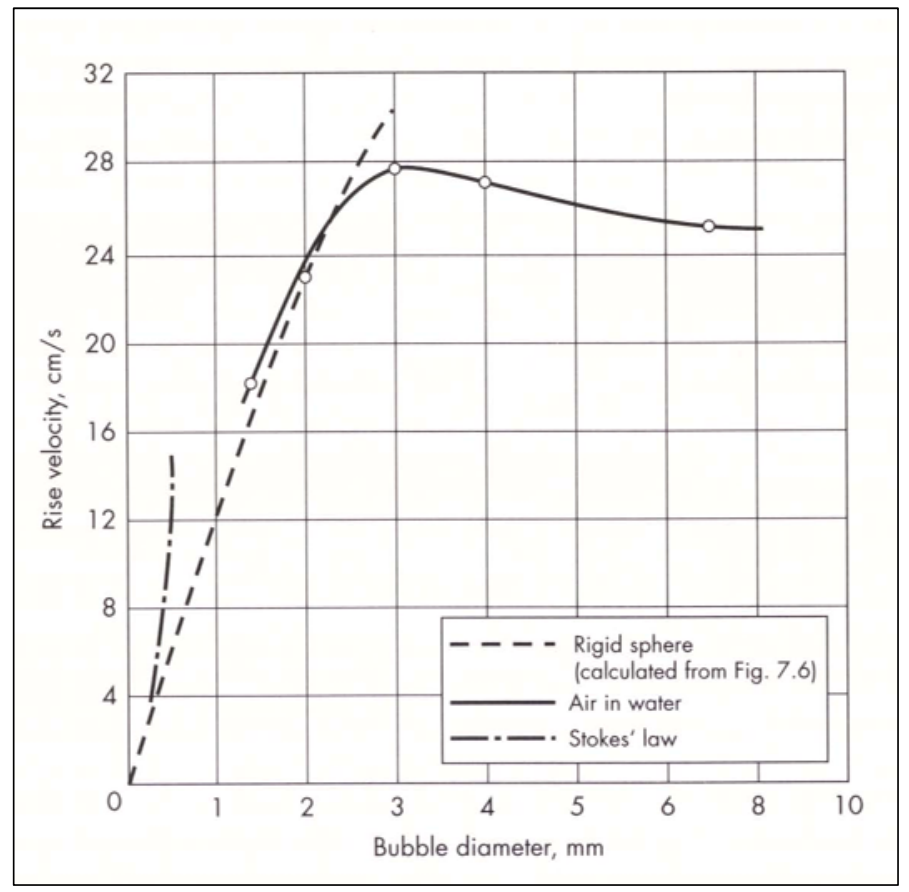

Figure 7. Rise velocity of air bubbles in water at $70^{\circ} \mathrm{F}$ (McAbe et al. 2001). 
Once a screened $0.67 \mathrm{oz}\left(20 \mathrm{~cm}^{3}\right)$ sample of mortar is obtained from concrete, it is injected into the base of the column with the glycerin-based blue release fluid, and the mortar sample is mixed into the release fluid with an impeller for $30 \mathrm{sec}$. The fluid is required to keep the voids at their original size when mixed, as if they were still in the mortar. The fluid prevents the voids from coalescing into larger voids or breaking up into smaller voids (Germann Instruments 2011). The fluid also assists the air void measurement process by slowing the rise of all the air voids released from the mortar for greater void size separation when measuring. Void rise speeds are reduced in the higher viscosity glycerin solution. Once the voids are freed from the mortar, the voids begin to rise to the top of the water column for measurement. A glass plate is used to capture the released air voids at the top of the water column, and the plate's buoyancy is monitored over time by the computer and corresponding software. The measurement intervals used by the software correspond to ranges of air void sizes that arrive to the plate. Larger voids arrive first followed by progressively smaller voids over the 25-min monitoring time. Voids may still rise after $25 \mathrm{~min}$, but it is believed these voids will not be seen in ASTM C457 testing on hardened specimens. The software calculates the air void structure parameters corresponding to the assumptions detailed for a linear traverse measurement (Procedure A) in ASTM C457 (Germann Instruments 2011).

\section{Previous AVA studies}

Multiple studies have been conducted on the AVA to determine its reliability, since its creation in the 1990s. Multiple DOTs, concrete admixture companies, and others had purchased and used this equipment by 2008, but limited published data were available (Wang et al 2008, Distlehorst and Kurgan 2007). This section summarizes the relevant results from previous work for any future comparisons against this study.

\section{Dansk Beton Teknik}

This study used approximately 270 specimens from 27 different batches of concrete and a wide range of air void structures. Five AVA samples were taken from a cast flexure beam for each mixture batched. ASTM C457 samples were taken from undisturbed areas of the beam, and ASTM C231 results were reported for each mixture. The findings determined that the specific surface and spacing factor measured by the AVA (model 1000) were reliable, since the measurements were within the 95 percent confidence limits and the regression equation results yielded slopes of 1 . The air 
contents were lower than ASTM C457 as expected, since the machine did not measure entrapped air voids; and the authors speculated the AVA's small sample size was not large enough to take this measurement compared to the ASTM C231 specimen. The authors believed the "measurement principle" was accurate for European concrete with slumps greater than 0.4 in. and the sampling technique used might not have been appropriate for zero-slump mixtures because of the scatter in the results obtained (Dansk Beton Teknik 1994).

\section{FHWA}

The FHWA study used laboratory and field results of 33 mixtures in four states. The individual state studies also tracked software modifications made to the AVA equipment during the time of testing; however, the results for the Iowa tests were not comparable, since both the software and the viscosity of the blue release fluid had changed. Results from the study were similar to those described by Dansk Beton Teknik. The air content results were "always on the order of $2 \%$ less" than those shown by ASTM C231 and C457. The AVA specific surface values were higher than ASTM C457 results, indicating a smaller air void structure was found. The spacing factor results were very comparable, and values were about the same. The authors concluded that the machine "can provide information that characterizes the air void system of concrete" and the system requires additional calibration. Additionally, useful comments concerning the operation of the AVA were also collected from the participating state representatives. Operational issues, such as maintaining the correct testing environment, the sensitivity of the system to vibration, and sampling of difficult mortar samples or those from a finished structure, were mentioned for future research and equipment package optimization.

\section{Kansas DOT}

In 2002, the Kansas DOT was the first American organization to incorporate the AVA into project specifications as Kansas Test Method KT 71: Air Void Analyzer. In 2001, premature joint deterioration that required additional, unplanned joint seal replacement over the 10-year-old pavement's remaining lifespan was observed. To prevent future material failures, Kansas DOT began using the AVA to pre-qualify PCC mixtures for use and for on-site testing. Implementation of the machine led to a cost savings of $\$ 1.1$ million between 2001 and 2002 (FHWA 2006). The KT-71 testing standard was later taken by FHWA and formed the basis of the 
American Association of State Highway Transportation Officials (AASHTO) provisional standard TP 75-08: Air-Void Characteristics of Freshly Mixed Concrete by Buoyancy Change. The Kansas trends look accurate and precise; however, limited data were used in the studies. Particularly interesting is the mixture freeze-thaw resistance data collected compared against the spacing factors measured by both the AVA and ASTM C457 results. The results fall nicely within the original curve given by Backstrom (1956).

In February 2006, an AVA inter-laboratory test event was held at the Kansas DOT research facility to develop a precision statement by ASTM C802 for the draft AASHTO test method. Two hundred sixty-six AVA samples were taken over seven mixture designs and tested with nineteen different machines simultaneously to compare the resulting spacing factor and specific surface values collected. The data for the specific surface and spacing factor showed significantly different patterns between the mixture designs used, and ASTM C802 required that the causes of the variability or interaction of variables be identified and removed. It was believed that the mixtures used might have been a major source of the variability seen in the results. Mixtures with a low spacing factor and a large quantity of smaller air voids were used. Since smaller voids are the slowest to rise out of the water column, variability in detecting voids this small was believed to significantly affect the results. The spacing factor and specific surface measurements showed a constant standard deviation and coefficient of variation over the mixtures used, respectively, and the precision statements were written to reflect this for mixtures with spacing factors less than $6 \cdot 10^{-3}$ in. Additional testing is required for larger spacing factors than those used here (Distlehorst and Kurgan 2007).

National Concrete Pavement Technology Center; lowa State University

Zhang and Wang (2006) investigated the air void structure of PCC with different materials and mixes using different procedures from that typically completed under ASTM C192 laboratory testing. Three different concrete mixtures were used and produced by five different mixing procedures. The majority of the mixtures were batched with a $0.5 \mathrm{ft}^{3}$ pan mixer at 75 percent of its capacity, but some mixtures were also batched in a $1.5 \mathrm{ft}^{3}$ pan mixer to investigate the effect of mixer size. Air void structure measurements taken by the AVA (2000 model), ASTM C231 (Type B), and the computerized RapidAir 457 were compared from the 27 mixtures batched. AVA specific results from the study showed that fly ash (Class C 
at 15 percent replacement) did not reduce the total air content, and did reduce the spacing factor. The water reducer (lignin-based) significantly reduced the spacing factor and increased the specific surface of the air within the mixtures. The total air content measured by the AVA correlated well to the ASTM231 measurements $\left(R^{2}=0.81\right)$; however, RapidAir 457 measurement comparisons to the AVA and C231 were not as strong.

Grove et al. (2008) evaluated current and new PCC testing methods to refine a suite of tests to accurately evaluate PCC pavement properties. The goal of the project was to develop a testing protocol that prevented premature distress caused by material and construction problems and develop a mobile, trailer mounted, concrete testing laboratory. The AVA (2000 model) was included in the study and a specially developed area inside the mobile testing trailer was developed to minimize the effects of external vibrations. Results from the AVA specific testing showed the machine gave a good indication of the air void structure in fresh concrete, but there was some variation in the results. A better relationship was obtained between the air content and spacing factor using data collected on void sizes less than $0.012 \mathrm{in}$. (300 $\mu \mathrm{m})$ compared to $0.08 \mathrm{in}$. $(2 \mathrm{~mm})$, and sampling location did not appear to significantly affect the measurements reported for both before and after the paver and on and between the vibrators for smaller voids. Monitoring the smaller stable air voids appeared to be more effective than monitoring the large voids (Grove et al. 2008).

Wang et al. (2008) analyzed previously collected AVA data from three DOT studies with the intent of improving the precision of the machine and developing practical specification limits based on AVA measurement to control freeze-thaw damage. Phase 1 of the study focused on a literatary review and statistical analysis of data from previous projects. Common issues with the AVA (2000 model) were the rejection of concrete known to have good field performance and precision and accuracy problems when compared to multiple AVA tested samples and ASTM C457 testing, respectively. These major issues stemmed from the equipment setup, the control over the viscosity of the blue viscous fluid between batches made by the manufacturer, and the testing procedure used. Major findings from the literary review concluded that (1) the AVA typically measured lower air contents and was more variable than other ASTM measurements, (2) there was a weak relationship between the laboratories' determined AVA and ASTM C457 results, and (3) there was a poor relationship between the fieldcollected AVA samples and the ASTM C457 laboratory data. The statistical 
analysis showed the AVA variability was acceptable compared to ASTM $\mathrm{C} 231$ and $\mathrm{C} 457$ tests, and various regression equations were reported. The majority of the equations were linear models, and the highest coefficient of determination $\left(R^{2}\right)$ value calculated was 0.67 . Results of the trial testing completed showed (1) high variation in single operator measurements, (2) lower variation in multiple operator measurements where a standardized procedure would help further reduce test variation, (3) the need for variable stirring energy for testing different slump concretes, and (4) maximization of air measurement readings when the blue release fluid viscosity's ranged from 0.75 to 1.30 P. Phase 2 of the study was completed by December 2010; however, no information on the results has been published or is available at this time.

\section{Oklahoma DOT}

Trost (2008) was tasked to evaluate the AVA against standard state PCC mixtures across Oklahoma, quantify the error in the measurements, and recommend any modifications to the procedures and equipment to improve their precision. Three hundred AVA specimens from 54 mixtures were tested on paving and bridge PCC mixtures. Paving and bridge mixtures were tested before and after consolidation and pumping, respectively. No additional ASTM standard tests on the air void structure or freeze-thaw testing was completed in conjunction with the AVA testing to verify the results presented. The results showed that the majority (75 percent) of the mixtures tested had spacing factors larger than $0.010 \mathrm{in}$. and pumping of the bridge concrete removed a portion of the entrained air. The most significant source of error was the variable temperature within the water column, and this could not be controlled well with the model considered in the study. Additional error was believed to have been introduced from the equipment and procedure used to accurately add the stated amount of the blue release fluid to the water column (Trost 2008).

\section{Pennsylvania DOT}

Pennsylvania State University conducted a study on incorporating the AVA into state PCC construction specifications. The study statistically evaluated multiple topics from the consistency of the units between similar and different models to comparison of results against other standard test methods. The results of the study showed consistent measurements for all three air void parameters. When values taken from two different AVA (2000 models) were compared, the FHWA operated machine showed a 
considerable difference and measured a smaller air void system. Less difference was observed between AVA (2000 and 3000 models); however, a smaller air void system was measured with the AVA (3000 model). The ASTM C231 comparisons were consistent with previous testing and indicated the entrapped air is not measured by the AVA. The majority of the freeze-thaw measurements did not correlate well with the AVA results, but the ASTM C457 measured values (from a RapidAir 457 machine) compared much better (Desai et al. 2007). Based on the findings presented in the report, use of the AVA in the Pennsylvania DOT's specification requirements for quality control operations was not recommended.

One item not discussed in sufficient detail was how the RapidAir 457 data were analyzed. This issue was also reported by NCPTC, and the research team believed the AVA yielded "more conservative" results (Grove et al. 2008). The 426 in.-1 difference seen between the AVA and the automated ASTM C457 specific surface measurements is very significant, and the cause of the error may not be described correctly by the authors. The authors indicated the deviation in the results was caused by the AVA's not measuring the larger voids; however, the data suggest the opposite may be true, and the AVA is not measuring an air void system as small as the RapidAir 457 machine. Differences in measuring larger air voids would be better shown in the air content values. The 1 percent difference observed is fairly small compared to results from others regarding air content measurements against AVA testing. The 2.7 percent difference shown between the AVA and ASTM C231 results mentioned is much more typical (Desai et al. 2007). Smaller air voids do not take up as much volume and not measuring them would not affect the results as much as measuring larger voids. The higher spacing factors and lower specific surface values compared to the RapidAir 457 indicate that the smaller air voids are not being measured by the AVA. One report that utilized the RapidAir 457 said the machine can measure air voids as small as $1.2 \cdot 10^{-4} \mathrm{in} .(3 \mu \mathrm{m})$, an order of magnitude smaller than the average human can observe for ASTM C457 testing. The RapidAir machine has an analysis option that does not consider voids smaller than $1.2 \cdot 10^{-3}$ in. $(30 \mu \mathrm{m})$ and provides results much closer to a typical petrographer; determined ASTM C457 test (Ramezanianpour and Hooton 2010). Since smaller voids affect the specific surface and spacing factor calculations much more than the air content does, the results obtained in this section of the study suggest that very small voids were not 
measured by the AVA. This lack of measurement would help explain the difference in values shown.

Brief descriptions of other unpublished testing (Wang et al. 2008)

- CTL Group

- 50 percent agreement between AVA and ASTM C457 spacing factors if an $8 \cdot 10^{-3}$ in. pass/fail criteria is used.

- W.R. Grace

- 56 percent agreement between AVA and ASTM C457 spacing factors if an $8 \cdot 10^{-3} \mathrm{in}$. pass/fail criteria is used.

- Michigan Paving Contractors (2007):

o More than 200 samples taken over 30 projects showed the AVA was "generally successful" in indentifying mixtures with poor air void structures and could be used to correct mixtures on the fly.

o The study could not explain differences in the results from "material incompatibilities."

o AVA results were more variable than ASTM C457 cores.

General conclusions from AVA tests

The AVA has demonstrated potential as a quality control and assurance tool in PCC construction. It has the ability to measure more information on the air void structure of fresh concrete much sooner than typical tests that produce the same type of data. Previous studies of its use report varying results, but they all document significant variability in the measurements taken by the AVA as compared to other standard methods. 


\section{Test Plan and Approach}

This project investigated the air void structure of PCC mixtures measured by different standard testing methods for comparison against those measured by the AVA. To evaluate the accuracy and precision of the AVA, multiple mixtures were batched with varying amounts of fly ash and entrained air at the ERDC's Material Testing Center (MTC) laboratory. The freeze-thaw resistance of each of the mixtures was also evaluated to determine if the AVA could identify mixtures with poor air void structures.

\section{Laboratory testing}

\section{Material selection}

Multiple concrete mixtures were prepared with varying amounts of fly ash and air entrainment. A locally sold \#67 western Kentucky limestone was selected for the coarse aggregate. Bagged ASTM C150 (2009c) Type I/II/V portland cement and ASTM C618 (2008b) Class F fly ash from Arizona were used as the cementitious binder materials for the concrete. Tap water was used as the mixing water. Proprietary chemical admixtures were added to provide workability and entrained air. A polycarboxylate based water reducer and saponified rosin based air entrainer were used. These materials conformed to ASTM C494 (2008a) Type A/F and C26o (2006a), respectively. The ADVA 140M and Daravair 1000 were selected from W.R. Grace Construction Products' line of concrete admixtures and procured from a local representative. Detailed testing reports and manufacturer information on these materials used can be found in Appendix A.

Some difficultly was encountered in selecting the fine aggregate. The plan was to use local bagged natural concrete sand because it was easy to transport and store. However, a sieve analysis of the material showed that it did not comply with ASTM C33 (2007b) specifications in several respects. The bagged sand was a very fine, clean material with a uniform gradation. More than 45 percent of the material was retained on the \#50 sieve. The gradation was also outside the specification limits for two of the sizes specified (\#16 and \#30 sieves) and had a fineness modulus of 2.07, less than the minimum specified value of 2.3. Locally available natural sand, sold in bulk by the Buford-Runyan pit, purchased and used for previous test section work was recycled and mixed with the bagged sand in a 50-50 percent blend 
to help bring the gradation closer to the specifications. Table 1 gives the important physical properties of the materials required for mixture design calculations. Figure 8 shows the gradation of the blended sand used compared to its constituents.

Table 1. Important physical properties of materials used.

\begin{tabular}{|l|l|l|l|}
\hline Material & Bulk Specific Gravity & Absorption, \% & Fineness Modulus \\
\hline Portland Cement & 3.15 & - & - \\
\hline Fly Ash & 1.96 & - & - \\
\hline Bagged Sand & 2.63 & 0.2 & 2.07 \\
\hline Runyan Sand & 2.61 & 0.4 & 2.25 \\
\hline Limestone & 2.65 & 0.8 & 3.59 \\
\hline
\end{tabular}

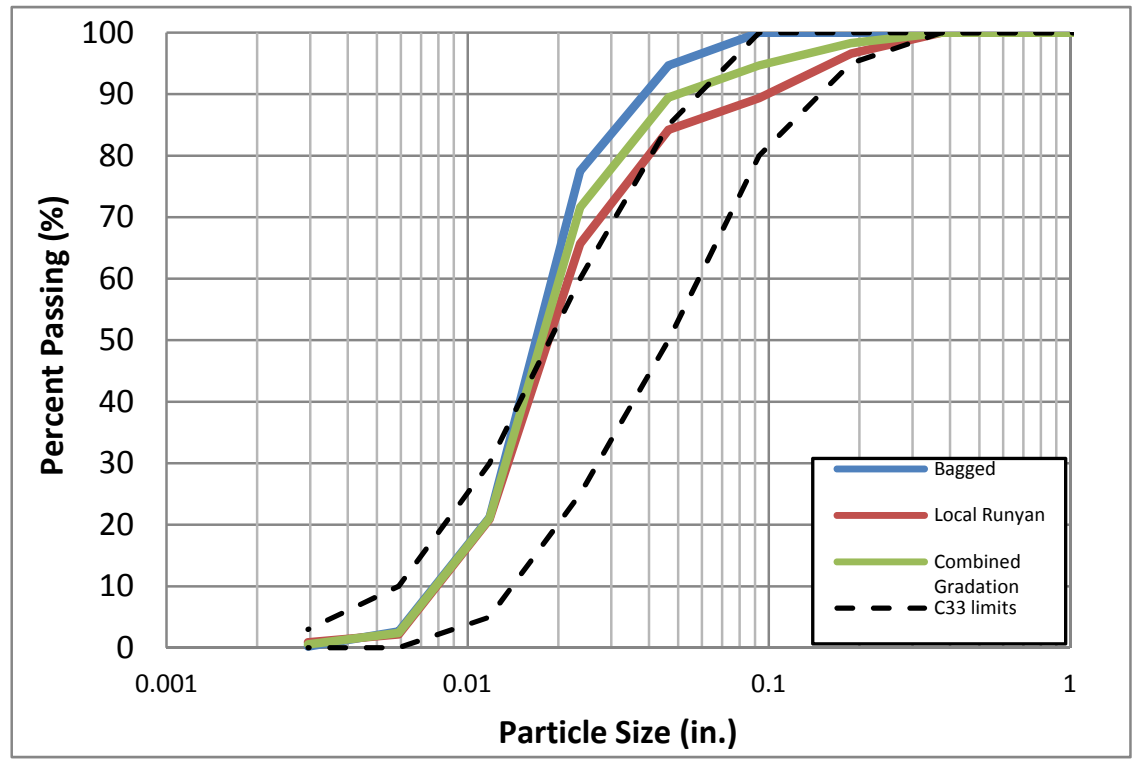

Figure 8. Fine aggregate gradation blending.

The sieve analysis of the bulk local sand shows it is significantly closer to the ASTM C33 (2007b) specification than the blend actually used and could have been used outright; however, there were concerns about its cleanliness. The bulk sand used was recycled from demolished aluminum matting and clay brick paver test sections. When the sand was excavated from the previous test sections and stockpiled, small amounts of subgrade soil (+95 percent passing the \#200 sieve) used underneath the sand base layer were taken up by the excavator bucket and mixed into the sand when stockpiled. Additionally, a small amount of "ceramic" material was reported in the sieve analysis results. Upon examination, the ceramic material was determined to be pieces of spalled brick that had mixed into the sand when 
it was used as the base and joint filler for the brick paver test section. New natural sand could not be purchased, since the Buford-Runyon pit had recently closed, and no other replacement natural sand was locally available. To balance the need for correctly blended concrete sand and minimize the potential for contamination, the $50-50$ percent proportioning used was deemed appropriate and clean sand without deposits of balled subgrade was taken from the stockpile. A stockpile of clean Buford-Runyan sand was found on the ERDC facility after mixture design development was used for the laboratory batching.

\section{PCC mixtures}

Twelve custom mixture designs were developed for testing following American Concrete Institute (ACI) specification 211, volumetric method (ACI 2009). Table 2 documents the design parameters held constant between the mixtures. Forty-seven total trial batches were made to determine the admixture dosage rates required to achieve the correct workability and air content. Tables 3 and 4 give each mixture's batching summary and final trial batching measured properties, respectively. Table 5 gives the calculated mixture proportioning properties the AVA computer software requires as an input parameter. The mixture design criteria for slump, $\mathrm{w} / \mathrm{c}$ ratio, and cementitious content are towards the extremes allowed for DoD hand-placed paving mixtures.

Table 2. Mixture design constants.

\begin{tabular}{|l|l|l|}
\hline Component/Property & Quantity & Material \\
\hline Slump & $2 \pm 1 \mathrm{in}$. & - \\
\hline Water/Cementitious Ratio & 0.45 & - \\
\hline $\begin{array}{l}\text { Cementitious Material } \\
\text { Content }\end{array}$ & $517 \mathrm{lb} / \mathrm{yd}^{3}$ & - \\
\hline Fly Ash & $\begin{array}{l}\text { Varied from 0 to } 20 \% \\
\text { replacement of PCC by mass }\end{array}$ & - \\
\hline Air Content & $\begin{array}{l}\text { Varied from 3 to } 8 \pm 0.5 \% \text { by } \\
\text { design }\end{array}$ & $\begin{array}{l}\text { Grace Construction- } \\
\text { Daravair 1000 } \\
\text { Measured by ASTM C231 }\end{array}$ \\
\hline $\begin{array}{l}\text { Water Reducing } \\
\text { Admixture }\end{array}$ & Varied to maintain slump & $\begin{array}{l}\text { Grace Construction- } \\
\text { ADVA 140M }\end{array}$ \\
\hline Coarse Aggregate & $1900 \mathrm{lb} / \mathrm{yd}^{3}$ & $\begin{array}{l}\text { ASTM 67 } \\
\text { Crushed Limestone }\end{array}$ \\
\hline
\end{tabular}


Table 3. Material usage per cubic yard of concrete.

\begin{tabular}{|l|l|l|l|l|l|l|l|l|l|}
\hline Mixture & $\begin{array}{l}\text { Design Air } \\
\text { Content, } \%\end{array}$ & $\begin{array}{l}\text { Portland } \\
\text { Cement, lb }\end{array}$ & $\begin{array}{l}\text { Fly Ash, } \\
\text { Ib }\end{array}$ & $\begin{array}{l}\text { Limestone, } \\
\text { lb }\end{array}$ & $\begin{array}{l}\text { Bagged } \\
\text { Sand, lb }\end{array}$ & $\begin{array}{l}\text { Reclaimed } \\
\text { Sand, lb }\end{array}$ & Water, lb & $\begin{array}{l}\text { Water } \\
\text { Reducer, } \mathrm{mL}\end{array}$ & $\begin{array}{l}\text { Air Entrainer, } \\
\mathrm{mL}\end{array}$ \\
\hline 1 & 3 & 517 & 0 & 1900 & 681.2 & 681.2 & 232.7 & 69.9 & 0 \\
\hline 2 & 4 & 517 & 0 & 1900 & 659.2 & 659.2 & 232.7 & 63.7 & 2 \\
\hline 3 & 6 & 517 & 0 & 1900 & 615.2 & 615.2 & 232.7 & 56.6 & 10 \\
\hline 4 & 8 & 517 & 0 & 1900 & 571.2 & 571.2 & 232.7 & 58.4 & 21.2 \\
\hline 5 & 3 & 465.3 & 51.7 & 1900 & 668.2 & 668.2 & 232.7 & 56.6 & 0 \\
\hline 6 & 4 & 465.3 & 51.7 & 1900 & 646.2 & 646.2 & 232.7 & 63.7 & 2 \\
\hline 7 & 6 & 465.3 & 51.7 & 1900 & 602.1 & 602.1 & 232.7 & 39 & 10 \\
\hline 8 & 8 & 465.3 & 51.7 & 1900 & 558.1 & 558.1 & 232.7 & 46 & 21.2 \\
\hline 9 & 3 & 413.6 & 103.4 & 1900 & 655.1 & 655.1 & 232.7 & 56.6 & 0 \\
\hline 10 & 4 & 413.6 & 103.4 & 1900 & 633.1 & 633.1 & 232.7 & 56.6 & 2 \\
\hline 11 & 6 & 413.6 & 103.4 & 1900 & 589.1 & 589.1 & 232.7 & 28.3 & 10 \\
\hline 12 & 8 & 413.6 & 103.4 & 1900 & 545.1 & 545.1 & 232.7 & 41.2 & 21.2 \\
\hline
\end{tabular}

Table 4. Concrete properties measured during mixture design determination.

\begin{tabular}{|l|l|l|l|l|l|l|}
\hline \multirow{2}{*}{ Mixture } & \multirow{2}{*}{ Slump, in. } & \multicolumn{3}{|c|}{ Air Content by ASTM Test, } & \multicolumn{2}{c|}{ Compressive Strength, psi } \\
\cline { 3 - 7 } & C231 & C173 & C138 & 7 day & 28 day \\
\hline 1 & 1 & 3.4 & 3.5 & 3.9 & 5560 & 6810 \\
\hline 2 & 1.75 & 3.6 & 4 & 4.1 & 5600 & 6810 \\
\hline 3 & 2.5 & 6.3 & 7.5 & 7.7 & 3970 & 4890 \\
\hline 4 & 3 & 7.8 & 9.5 & 8.2 & 3370 & 4340 \\
\hline 5 & 1.5 & 2.8 & 3.5 & 3 & 5310 & 6570 \\
\hline 6 & 2.25 & 3.8 & 4 & 4 & 5180 & 6160 \\
\hline 7 & 2.75 & 6 & 6 & 5.9 & 3900 & 5060 \\
\hline 8 & 3 & 7.6 & 8.5 & 7.9 & 3100 & 4030 \\
\hline 9 & 1 & 2.8 & 3.5 & 3.1 & 3590 & 5280 \\
\hline 10 & 3 & 4.2 & 4.5 & 4.1 & 4170 & 5560 \\
\hline 11 & 2.75 & 5.7 & 6.3 & 5.5 & 3300 & 4340 \\
\hline 12 & 3 & 8.3 & 3 & 8.2 & 2410 & 3490 \\
\hline
\end{tabular}


Table 5. Required calculated AVA mixture design input data.

\begin{tabular}{|l|l|l|l|}
\hline Mixture & Mortar Volume,\% & Paste Volume, \% & Design Air Content, \% \\
\hline 1 & 54.5 & 23.6 & 3 \\
\hline 2 & 53.5 & 23.6 & 4 \\
\hline 3 & 51.5 & 23.6 & 6 \\
\hline 4 & 49.5 & 23.6 & 8 \\
\hline 5 & 54.5 & 24.1 & 3 \\
\hline 6 & 53.5 & 24.1 & 4 \\
\hline 7 & 51.5 & 24.1 & 6 \\
\hline 8 & 49.5 & 24.1 & 8 \\
\hline 9 & 54.5 & 24.7 & 3 \\
\hline 10 & 53.5 & 24.7 & 4 \\
\hline 11 & 51.5 & 24.7 & 6 \\
\hline 12 & 49.5 & 24.7 & 8 \\
\hline
\end{tabular}

\section{Specimen preparation}

To characterize the batched mixtures' properties and generate a petrographic specimen of the PCC mixtures, typical quality control specimens were made and tested for each batched mixture. Individual 1.25- $\mathrm{ft}^{3}$ batches of PCC were made using a 2.5- $\mathrm{ft}^{3}$ capacity drum mixer. Aggregate moisture corrections were made on every production day by ASTM D4959 (2007e) to account for the amount of internal water provided by the aggregates at the time of batching.

Five separate batches of concrete were produced for each mixture tested because of the limitations placed on sample freshness stated in ASTM C172 (2010a). Taking multiple measurements on a single batch would take more than the 15 minutes allowed with the staffing provided. Therefore, to generate the replicate data required for the statistical analysis, multiple batches were required. Every batch was tested to have accurate data because each mixture was slightly different because of inherent minor variations in proportioning and mixing.

Six 4-in. by 8-in. cylinders and one 6-in.-square by 21-in.-long beam were cast following ASTM C192 (2007a) for each mixture batched. Specimens were consolidated by rodding. Fresh PCC property data were also obtained for each mixture using the following ASTM specifications: Slump- C143, 
Total Air Content by Pressure-C231 (Type B meter), Volumetric Total Air Content-C173, Temperature-C1064, and Unit Weight-C138.

Four cylinder specimens were demolded the day after casting and moist cured for either 28 or 90 days in a controlled high humidity room. After curing the specified amount of time, two of each cylinder specimen were tested following ASTM C39 (2005a) using a 440-kip capacity hydraulic load frame. Sulfur mortar caps were cast on the ends of the cylinder specimens before testing following ASTM C617 (2009a) to provide a plane, smooth loading surface. One cylinder specimen was cured for a minimum of 14 days before being sent to a concrete petrographer for determination of the specimen's air void system structure (ASTM 2010c). The final cylinder was intended for computed tomography (CT) scanning work to add to the study; however, this work was not completed because of lack of equipment availability.

The AVA specimens were taken from the cast beam. Initial attempts were made to take specimens from an ASTM C231 sample container; however, these failed because of the close spacing required to take multiple specimens from the container's center. The AVA mortar specimens were taken using the standard equipment provided with the machine. Three specimens were taken across the length of the beam. Specimens were stored in a plastic bag and placed in an ice bath to slow the hydration of the cement to test replicate specimens.

The AVA equipment was set up in a separate isolated room to minimize environmental changes and aerial vibrational disturbances from surrounding equipment and personnel. The equipment was set up on a sturdy, fixed laboratory tabletop. The AVA water column unit was placed on a sheet of 40 durometer neoprene rubber, typically sold for low frequency vibration isolation of sensitive equipment, to further prevent any potential vibrational interference from local air compressor and air handling equipment. The AVA manufacturer's instructions were followed to test the mortar specimens taken. Initially, only two of the specimens taken were tested because of conflicts in timing with mixture batching personnel, unless erroneous results were discovered early in the specimen testing. Over the course of the project, the third specimen was tested occasionally if testing on the previous two specimens failed. 


\section{Statistical analysis}

The final stage of the project involved using the air void structure measurement data to draw conclusions about the accuracy and precision of the AVA compared to current accepted testing methods.

\section{Removal of outlying data}

The air void structure measurements taken on each PCC mixture batched were recorded and entered into a spreadsheet. Before analysis of the data sets was performed, the data were examined for outliers. Outliers are data points that did not correspond to the majority of the data points that were collected. Box and whisker plots and normal probability plots were used to remove outliers and construct a normally distributed data set. As outliers were identified and removed, replicate plots were made to verify that the deletion corrected the data set performance.

\section{Hypothesis testing}

Hypothesis testing was used to compare and standardize conclusions generated from the data. For this report, the majority of the hypotheses related compared the differences in values seen from the different testing methods; however, the same general concept was also applied to other situations as needed. The result of this testing showed there was or was not a statistically significant effect based on the differences in the mean and standard deviation values collected for each mixture by the different testing methods considered. Hypothesis test conclusions were based on a typical significance level $(\alpha)$ of 0.05 for a two-side probability value (comparison of unequal means).

\section{Accuracy and precision analysis}

The accuracy and precision of the AVA were evaluated by comparing the different air void structure measurements taken from the controlled laboratory mixtures. A three-phase approach was used to evaluate the machine. First, a global comparison of the data collected from the different testing methods was conducted to see if the testing methods produced similar results as a process. Second, quantitative values of the error observed for both accuracy and precision were computed. Third, plots comparing the different air void structure measurements were made to determine the accuracy and precision of the machine over the range samples tested. 
Before evaluating the AVA performance, accuracy and precision were defined for consistency and clarity. Definitions used for the assessment of the items follow those given by ASTM E177 (2010b):

- Accuracy: how close a measured value (test result) is from its accepted reference value and

- Precision: how close multiple measurements (test results) are when taken under similar conditions.

Bivariate analysis

Comparing distributions of the air void structure parameters for the differing testing processes used yielded preliminary information into the differences in values obtained by each test method. Hypothesis testing using t-statistics was performed to increase understanding of the data collected globally in terms of the processes used for all mixtures. Comparisons made by comparing one mixture to another were not completed because a specified control mixture was not chosen for this analysis. All testing methods were compared to one another to see if the data collected were similar as a whole.

The t-statistic was generated from the difference in the means and the composite standard deviation for two selected data sets. Since the typical spread in the data is unknown, data sets with unequal variances and different sample sizes were assumed for each air void characteristic value. Determining composite values for standard deviation and degrees of freedom required slightly more calculation effort using generalized equations; however, more accurate inference on the distributions tested was expected.

The hypothesis testing conducted for the bivariate analysis required data from approximately normal distributions with independent variables. The data were checked for normality using the normal probability plots and the box plots to some extent. Independence was maintained in two ways: the analysis was divided into separate design features, and the aggregates used were carefully controlled. This approach forces the testing to yield results for a single design feature by reducing the interaction between features as much as possible. Also, no correlation term was used in the standard deviation calculation, and no correlation means independence among all the features considered. 


\section{Quantitative error calculations}

The error measured in the data was quantified by using the standard percent error calculation and applying the definitions of accuracy and precision to them. Equations 1 and 2 detail the calculations made to every data point collected. Values for each error were determined by each individual mixture design used because the true values and data set means vary for each mix design. The overall calculated error was then averaged across both the amounts of fly ash used to look for trends that its content changed within the mixtures and all the mixtures batched to determine the average by the process used. The true value used for this analysis was the ASTM C457-A values reported for each specimen following previous studies with the AVA. It is believed this procedure was originally selected since chord length measurements are physically taken on the voids traversed and yield the most accurate estimate of the diameter of the voids. Data set means were determined from the measurements collected from each mixture design after outliers were removed.

$$
\begin{aligned}
& e_{A}=\frac{\left|x_{m}-x_{t}\right|}{x_{t}} \\
& e_{P}=\frac{\left|x_{m}-\mu\right|}{\mu}
\end{aligned}
$$

where

$$
\begin{aligned}
e_{A} & =\text { Accuracy error } \\
e_{P} & =\text { Precision error (Deviation) } \\
x_{m} & =\text { Measurement taken } \\
x_{t} & =\text { True value } \\
\mu & =\text { Data set mean }
\end{aligned}
$$

There was some difficultly in calculating and using the accuracy error equation for all air void structure values considered. Using the designer, chosen total air content limits the values that can be calculated. Unlike the total air content, specific surface and spacing factor values were not selected and verified by trial batching for each mixture design. Therefore, there was no true value to use, and the calculation could not be completed. When comparing the accuracy error values, care should be taken not to read into the exact numbers shown. The total air content measurements taken 
showed some batched mixtures were outside the \pm 0.5 percent tolerance applied for each of the twelve mixture designs created during trial batching. Mixtures 2 and 6 fell into this category, since the measured air content values showed very little air entrainment was generated, and the results were similar to those of the mixtures that did not have air entraining admixture added. This was not an issue for the other two phases of the statistical analysis, since grouping measurements to specific air content value was not required and the values could be easily used as determined. Putting heavy emphasis into the value calculated is not appropriate; instead, the value should be used as a general indicator of accuracy for comparison purposes only. These issues were not encountered with the precision error calculations because the data set mean was calculated from the data collected and not from a chosen value.

\section{Quantile-Quantile plots}

Quantile-Quantile (Q-Q) plots are statistical charts used to compare data sets. The chart is constructed by making a scatterplot of the data set values against one another, where each axis of the chart corresponds to one of the data sets. For this project, the accuracy and precision analyses were based on comparisons to similar measurement results taken from the mixtures batched that used the same measurement units. Multiple scatterplots were made to compare the results of the different testing standards considered.

After construction, the various Q-Q plots were analyzed for trends and patterns. All Q-Q plots were examined for form (plotted shape or grouping), strength (spread), and influence of any categorical information. The easiest method to examine these characteristics was by applying a linear regression equation to the plotted data and comparing the equation to the one-to-one line denoting equality. Additional regression lines were plotted to distinguish known differences (categories) in the data sets to track the differences between them.

Analysis of the accuracy and precision of the air void structure testing methods was taken from the Q-Q plots produced. Figure 9 provides example scatter plots used to generalize the analysis and trends expected from the data used. The idealized dartboard figures to the left of the figure visually assist with describing the data. Plotting the data and drawing a linear regression equation showed information into both the accuracy and precision of the methods considered. If the test methods compared produce accurate results, the regression equation drawn will fall on the line of 


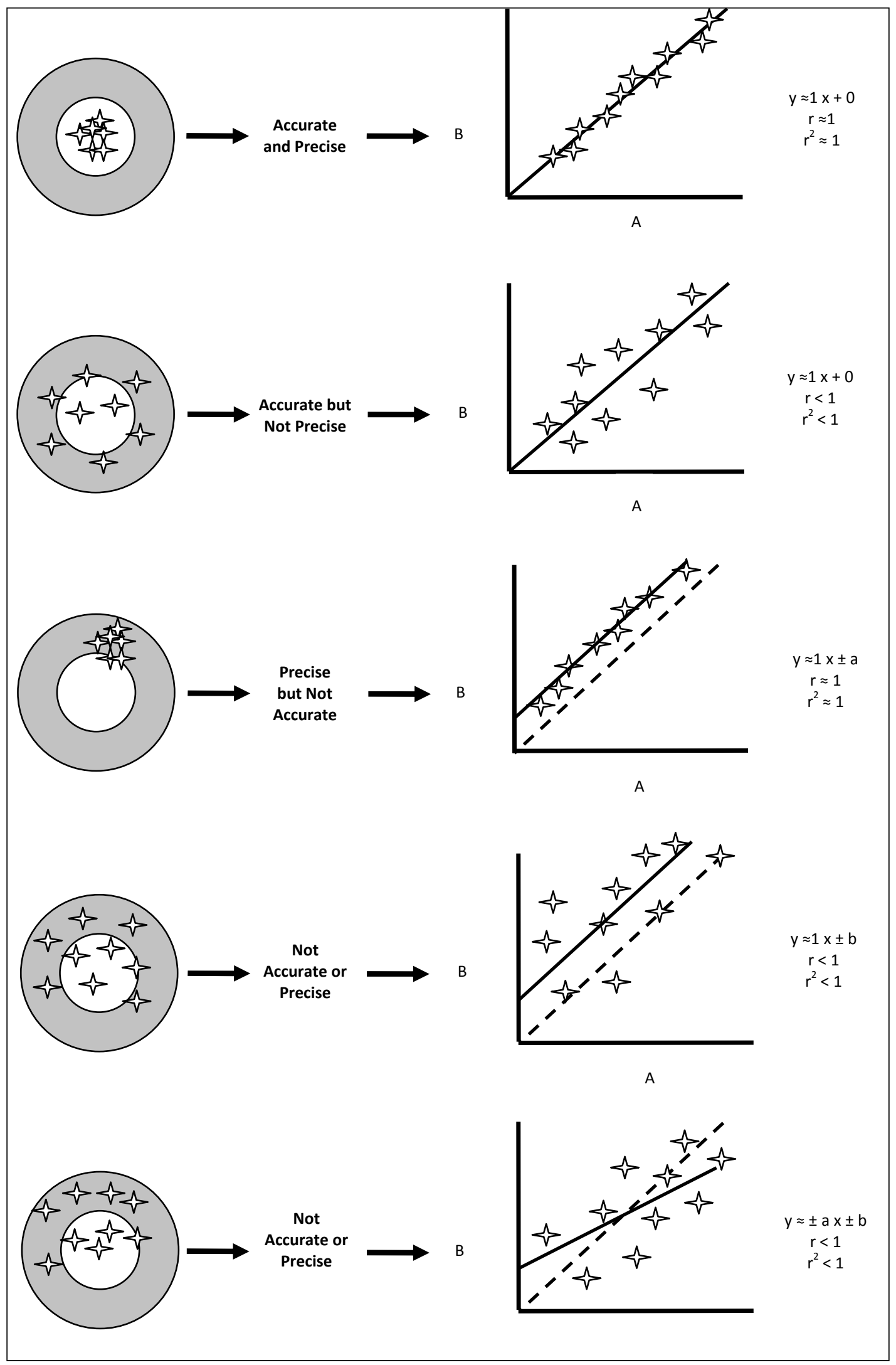

Figure 9. Generalized results for the accuracy and precision analysis. 
equality and have a slope of 1 and an intercept of o. A tight grouping of points along that regression line shows precise results. Data points falling close to the line of equality with very little deviation off the line show the data correlates well (accurate and precise).

Determining the accuracy of the testing method requires a combined approach that evaluates values from the calculated regression lines and compares the number of data points that correlate well. Any deviation of the regression equation from the line of equality measures the sensitivity of the measurements between the values plotted.

Sensitivity can be seen by differences in the slope and the intercept. Differences in the slope alone show the ratio of the observed values over increasing reported values. Differences in the intercept show the measurement does not measure the values outright correctly and some of the measurement is not accounted for. In addition to looking into the regression equation, counting the number of comparable results between the testing methods will also be used to see how the slope and intercept together affect the results. Ultimately, quality control and assurance officers need to minimize the risk of using concrete that is out of project specifications. To ensure this, the number of data points within a specified percentage of the line of equality was counted to determine reliability between methods.

How well the data correlate to a linear trend determines the precision of the testing method used. The regression equation calculations report the coefficient of determination $\left(R^{2}\right)$ for the model, a measure of the linear model's strength when explaining the data set used to develop it. However, to correctly determine statistically speaking the precision of the various test methods in comparison to one another required investigating the (Pearson's) correlation of the data sets. The correlation between two data sets measures the strength of the linear relationship and reports a value ranging from -1 to 1 . The correlation coefficient $(r)$ is taken to be the square root of the $R^{2}$ value determined for the simple linear regression equation used. Values closer to $O$, show a weak linear relationship and produce a large shotgun pattern on the Q-Q plots. Values towards the extremes show a very strong linear relationship and yield a line. The sign of the value gives the direction (slope) of the line drawn between them. For this analysis, the sign should always yield a positive value in a Q-Q plot since the data set values being compared are the same type of measurement. Large deviations 
in the expected linear strength of the datasets show that the measurements taken by at least one of the methods is not consistently the same.

\section{Determination of adequate air void structure}

In addition to determining the accuracy and precision of the AVA compared to the measured values taken by other traditional test methods, the performance of the machine was evaluated to see if poorly performing mixtures could be identified by the machine. One 3-in. by 4-in. by 16-in. rectangular beam was cast from every mixture batched and tested by ASTM C666 (2008c)-Procedure A for freeze-thaw resistance. Dynamic modulus measurements were taken with an ASTM C215 (2008c) sonometer approximately every 30 freeze-thaw cycles to monitor the beams' deterioration until 300 cycles or until the dynamic modulus decreased 40 percent from the initially measured value (relative dynamic modulus). A durability factor value was determined from each sample by comparing the fraction of cycles the sample achieved of 300 in total to the relative dynamic modulus at the time of testing. Mass loss measurements were also taken to monitor physical deterioration. Plots comparing the freeze-thaw resistance to the air void properties were made to show whether the machine can indicate poorly performing mixtures. 


\section{Testing Results and Analysis}

This section documents the evaluation of AVA results collected from each mixture. The evaluation began by grouping the data collected by each test method considered and comparing the results against one another as a whole to detect differences in the measurement techniques used. Next, the errors associated with the accuracy and precision were quantified for each testing method used. The accuracy and precision were also assessed by evaluating how well the results of the different tests correlated to one another with the Q-Q plots. Finally, freeze-thaw testing was used to validate the durability performance of the mixtures in relation to the values produced by the AVA.

\section{Original data}

Sixty PCC mixtures were batched for this study, and their air void structures were measured by six different standardized testing procedures. Measured properties of the plastic and hardened mixtures are presented in Appendix A.

\section{Outlying data detection and descriptive statistics}

The data collected from each mixture batched were examined for outlying results and normality. In general, the data were relatively normally distributed, and very few data points were removed for the statistical analysis. The final box and whisker plots for all measurements taken are shown in Figures 10 to 21. The general trend shown in the plots indicates that the addition of the air entraining admixture generates a larger volume of smaller bubbles that are spaced close together. This trend is expected since the purpose of air entraining admixtures is to produce a network of uniformly distributed microscopic bubbles within concrete. Mixtures 2 and 6 appeared to have lacked the 1 percent entrained air planned for the admixture dosage used.

The final data sets for each mixture were entered into statistical software for analysis. Tables 6 through 8, document the important descriptive statistical values of each testing method used. 


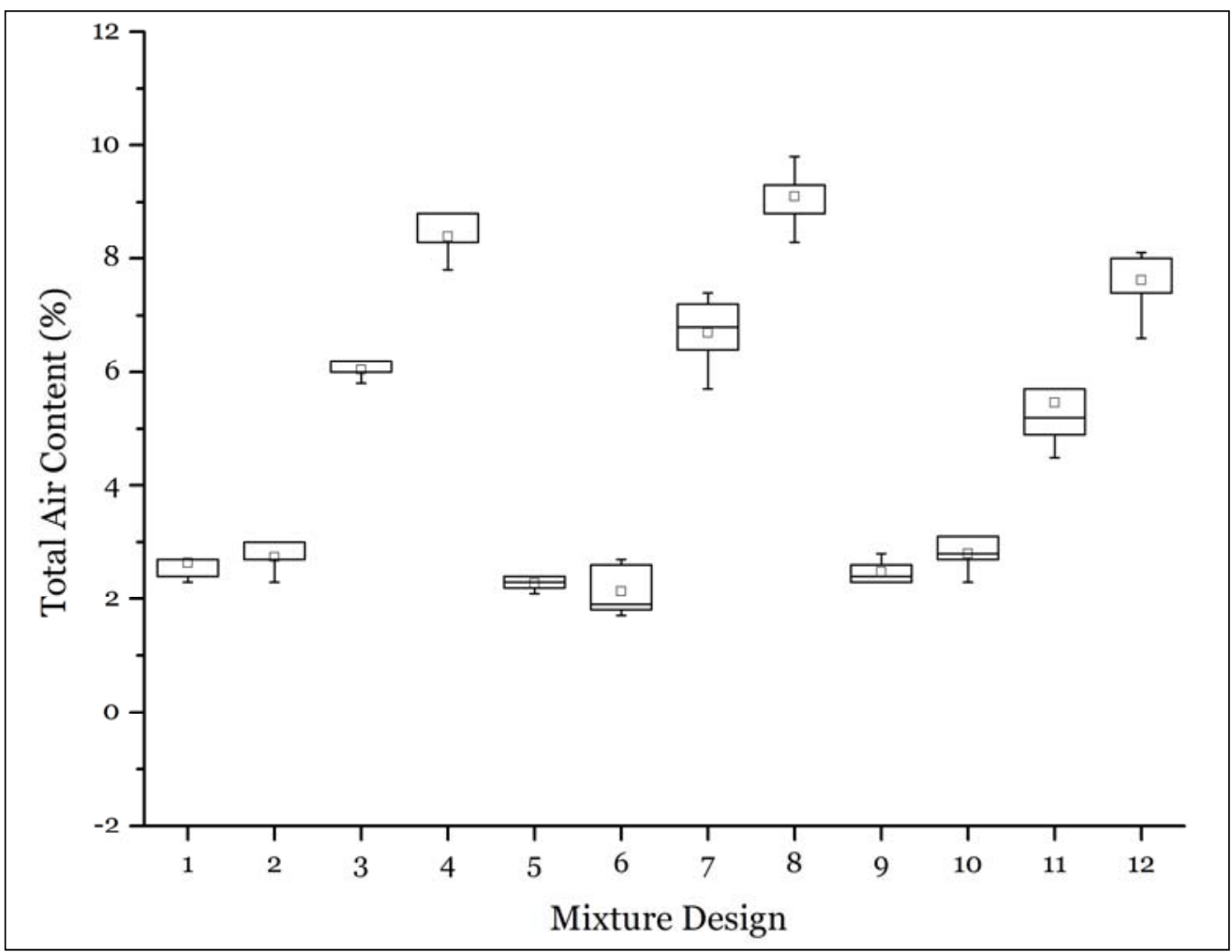

Figure 10. Total air content measured by ASTM C231 for each mixture design.

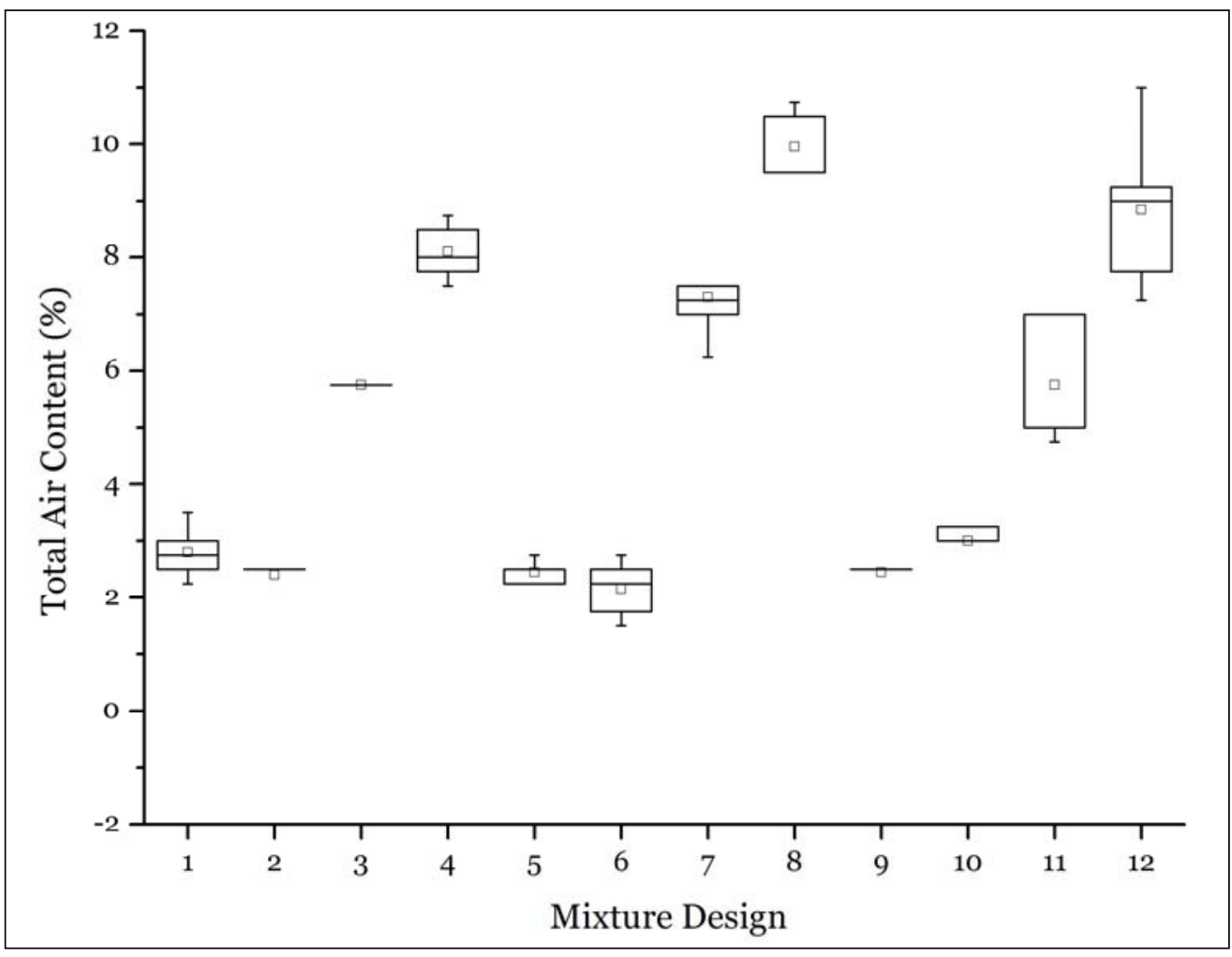

Figure 11. Total air content measured by ASTM C173 for each mixture design. 


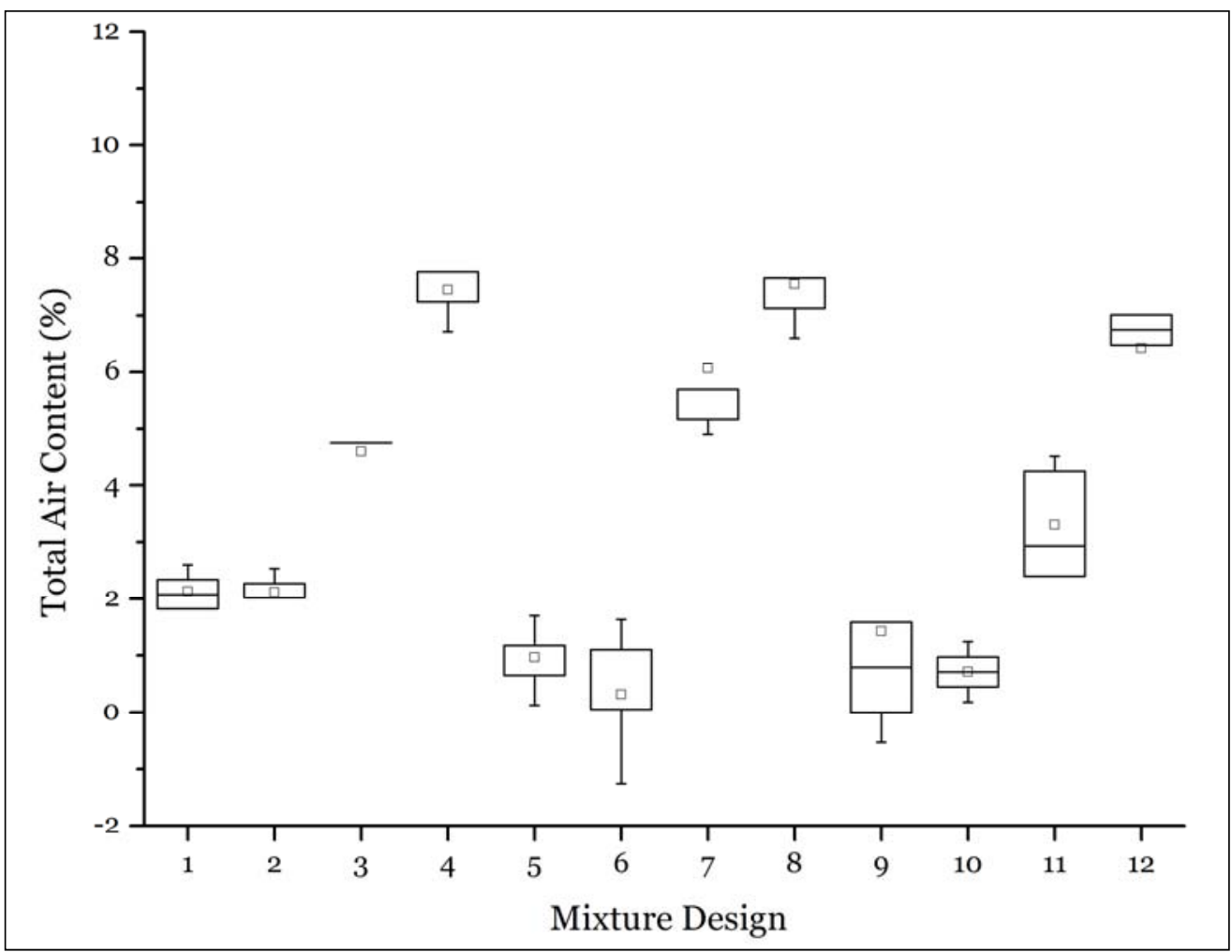

Figure 12. Total air content calculated by ASTM C138 for each mixture design.

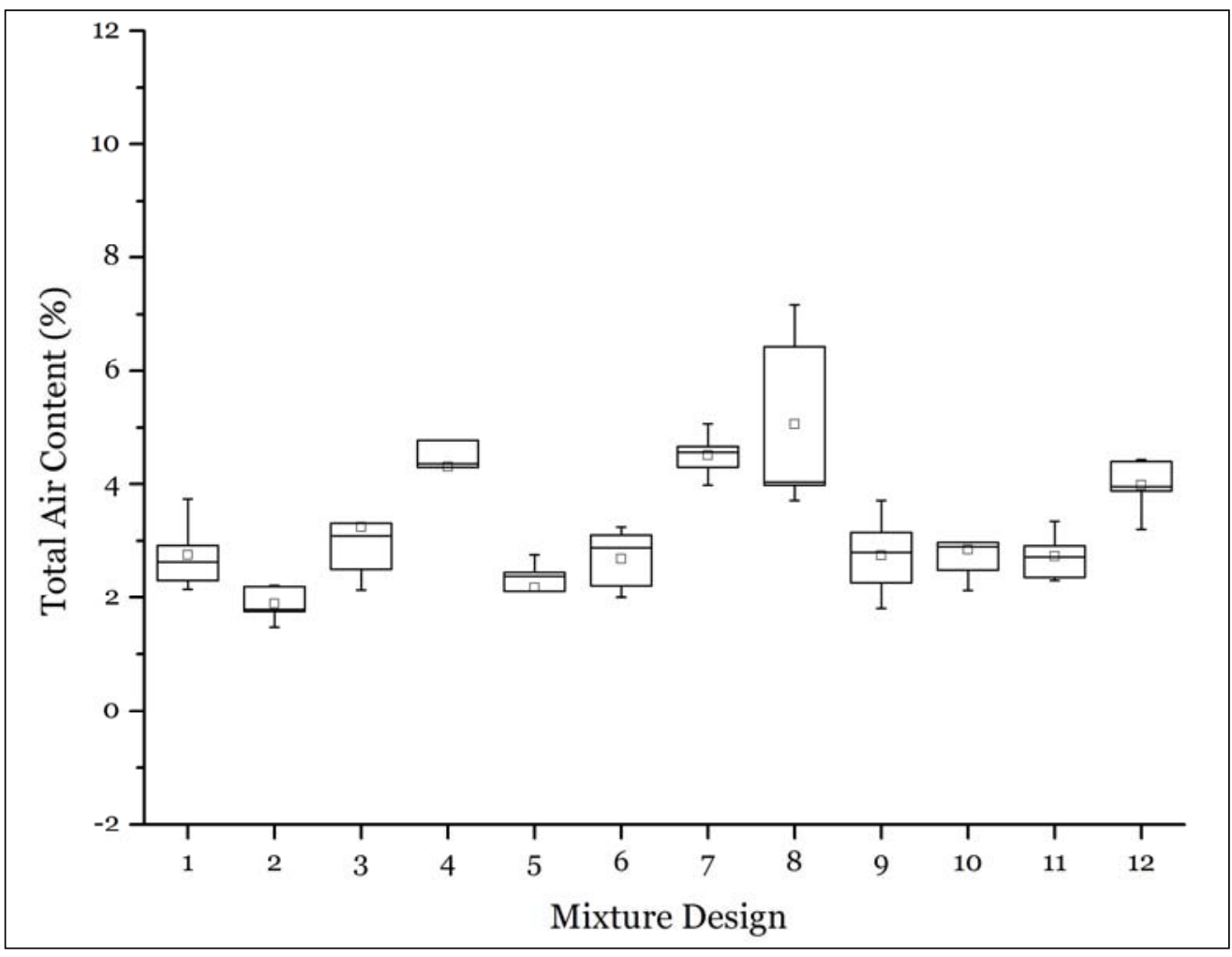

Figure 13. Total air content measured by ASTM C457-A for each mixture design. 


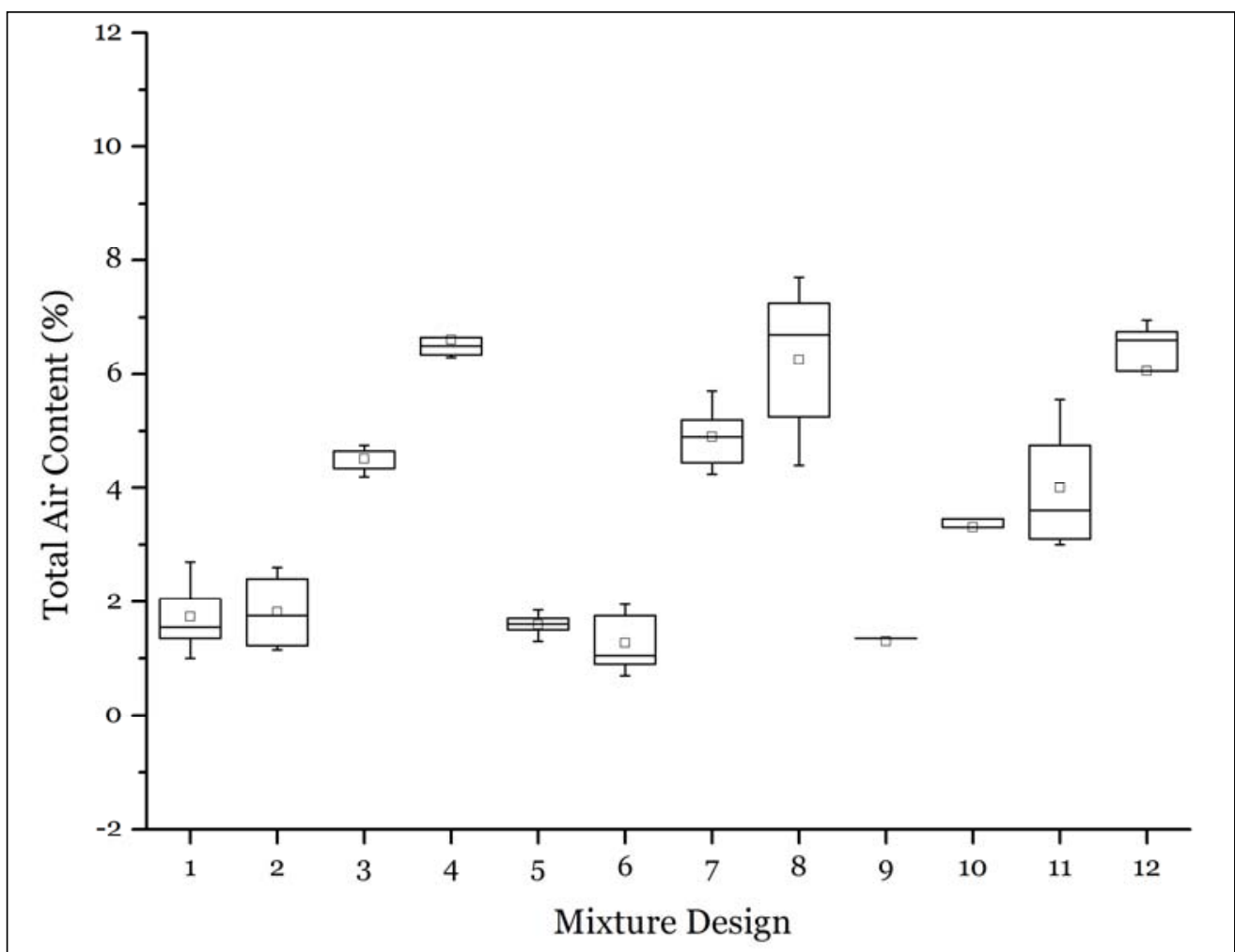

Figure 14. Total air content measured by AVA (less than $2 \mathrm{~mm}$ ) for each mixture design.

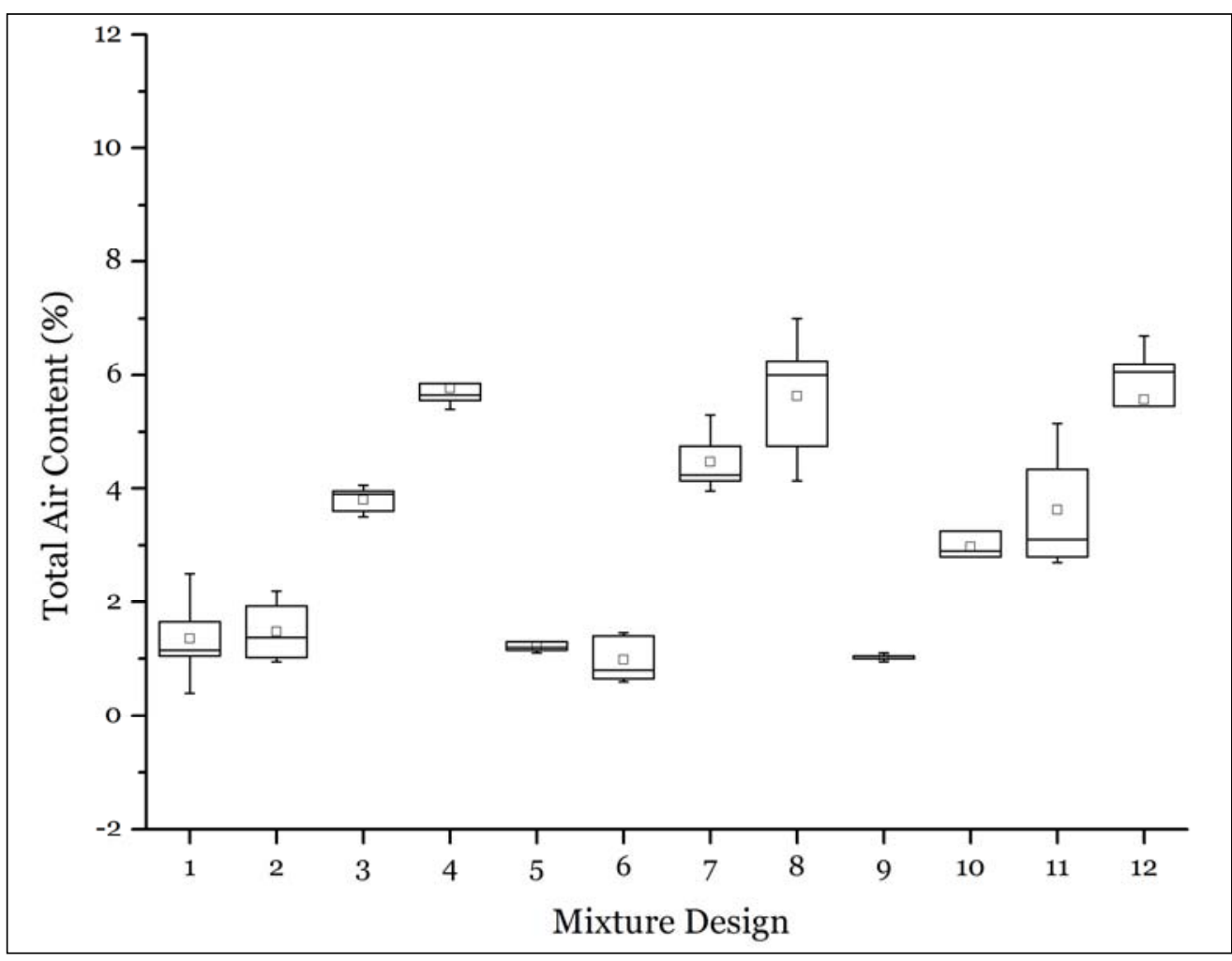

Figure 15. Total air content measured by AVA (less than $1 \mathrm{~mm}$ ) for each mixture design. 


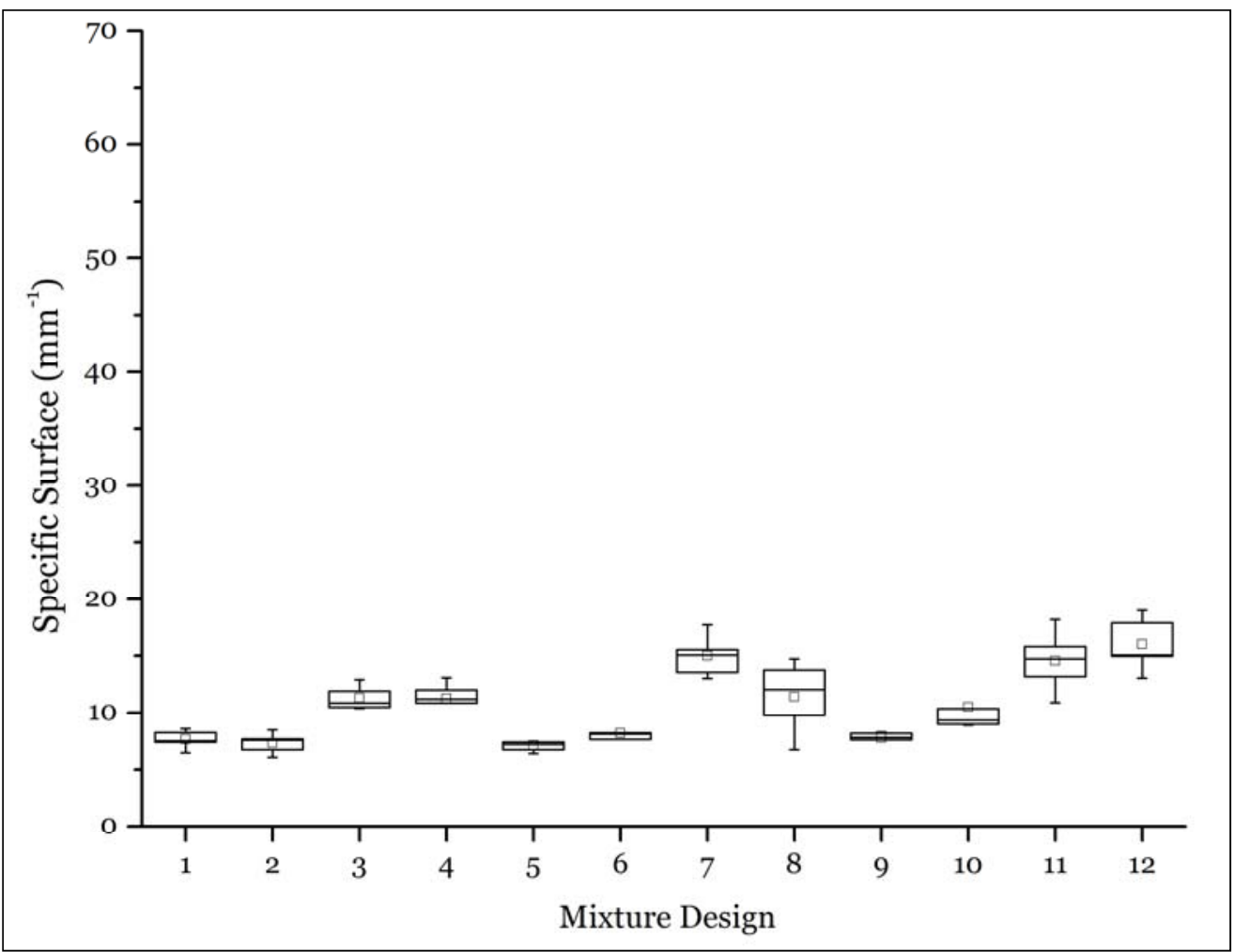

Figure 16. Specific surface measured by ASTM C457-A for each mixture design.

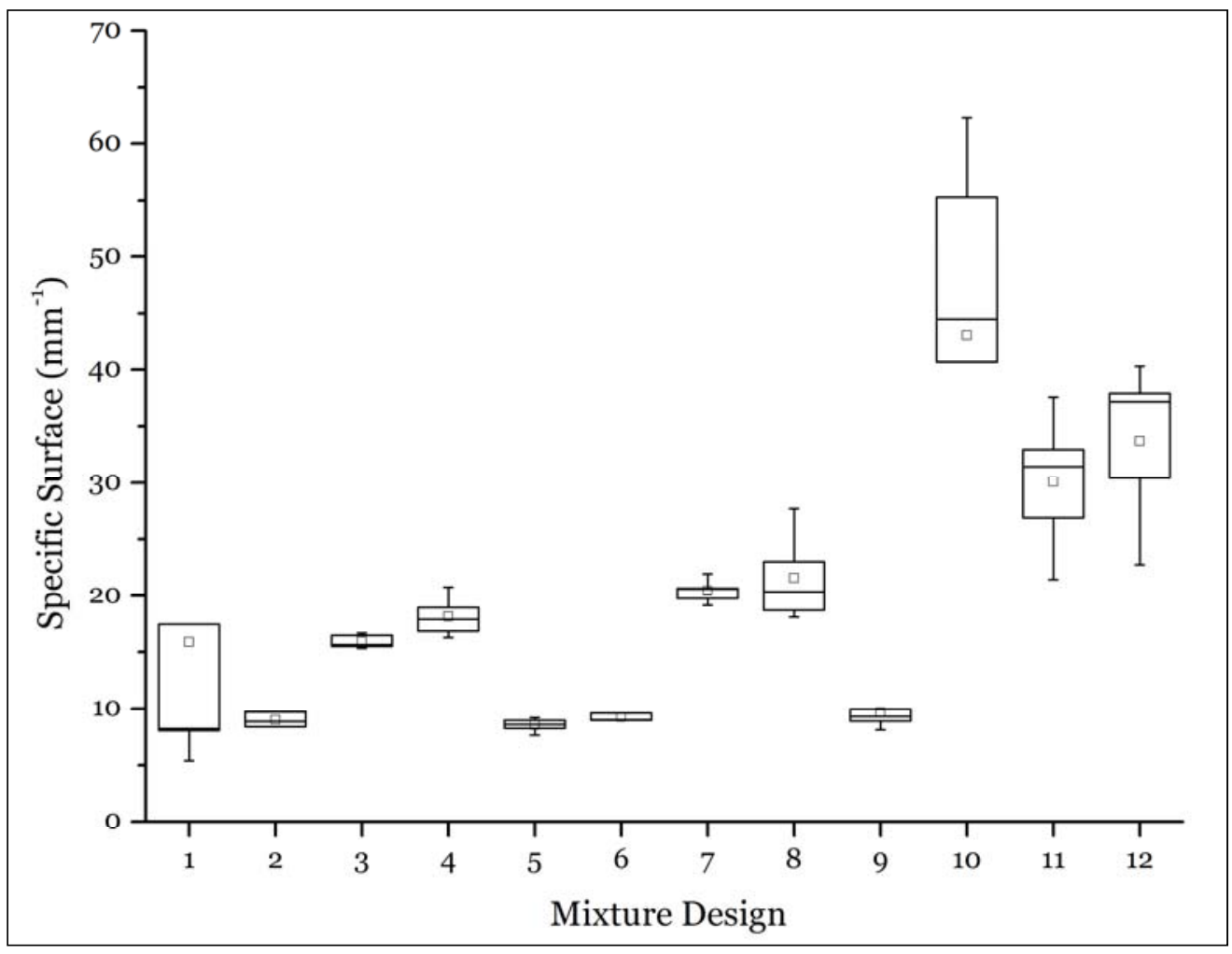

Figure 17. Specific surface measured by AVA (less than $2 \mathrm{~mm}$ ) for each mixture design. 


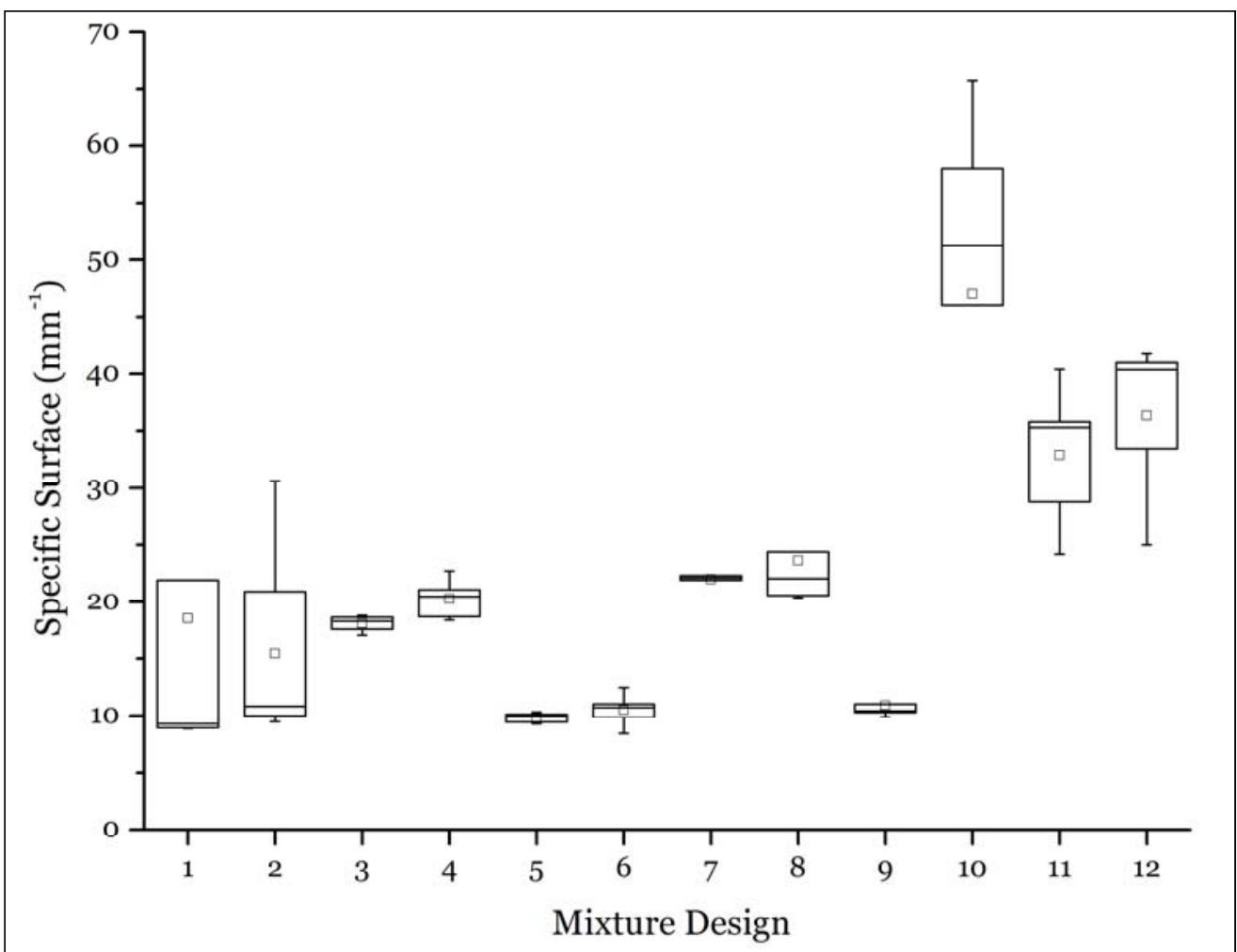

Figure 18. Specific surface measured by AVA (less than $1 \mathrm{~mm}$ ) for each mixture design.

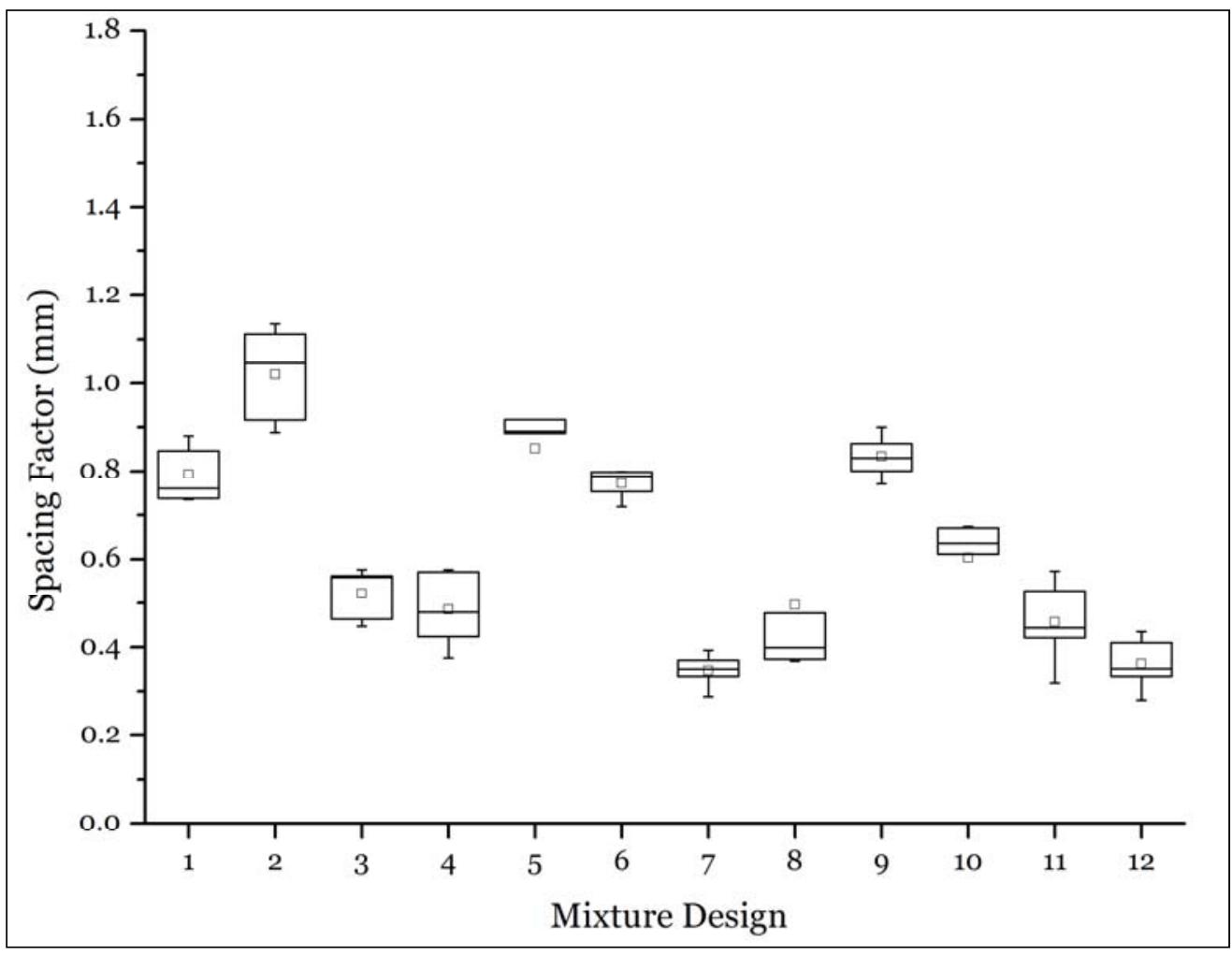

Figure 19. Spacing factor measured by ASTM C457-A for each mixture design. 


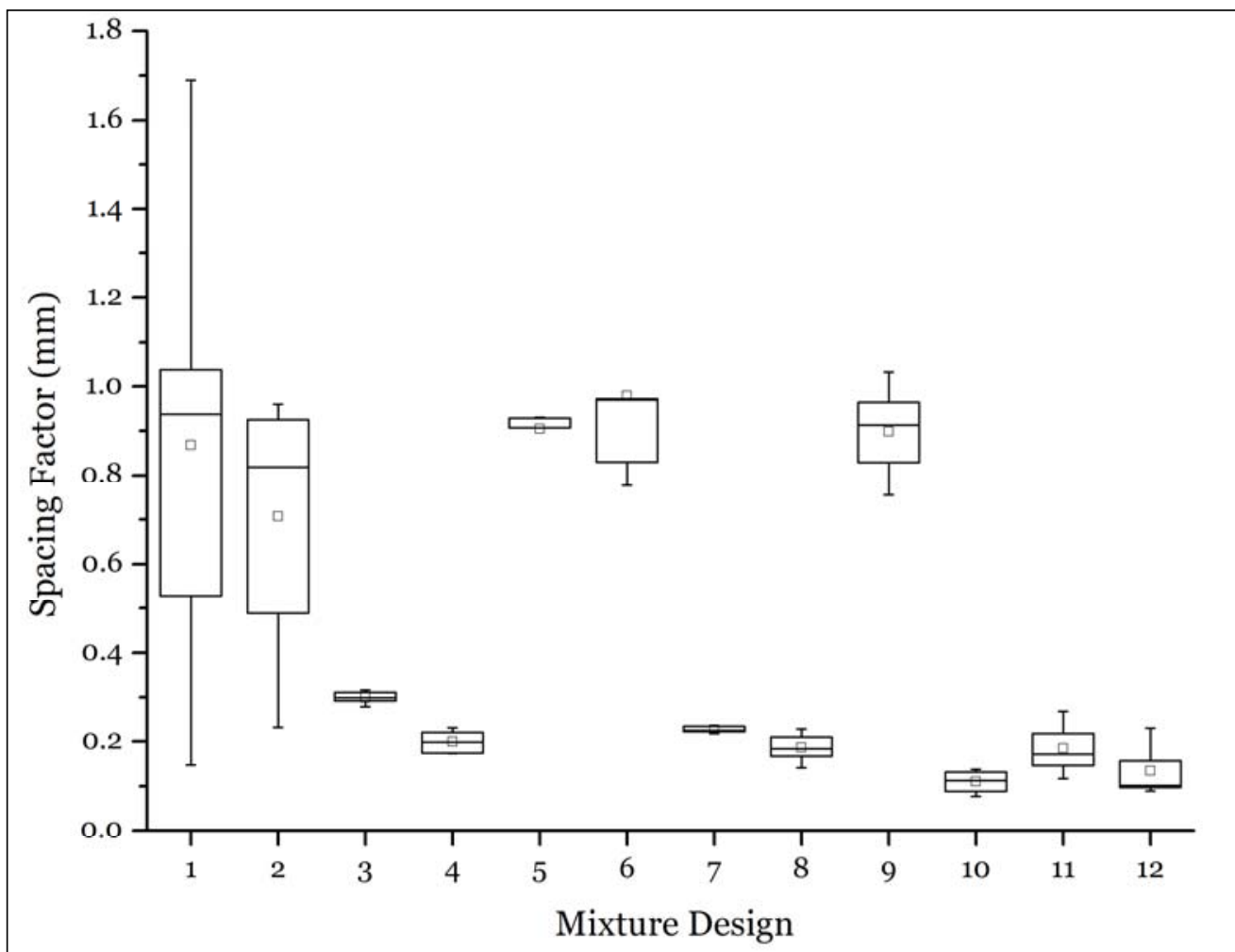

Figure 20. Spacing factor measured by AVA (less than $2 \mathrm{~mm}$ ) for each mixture design.

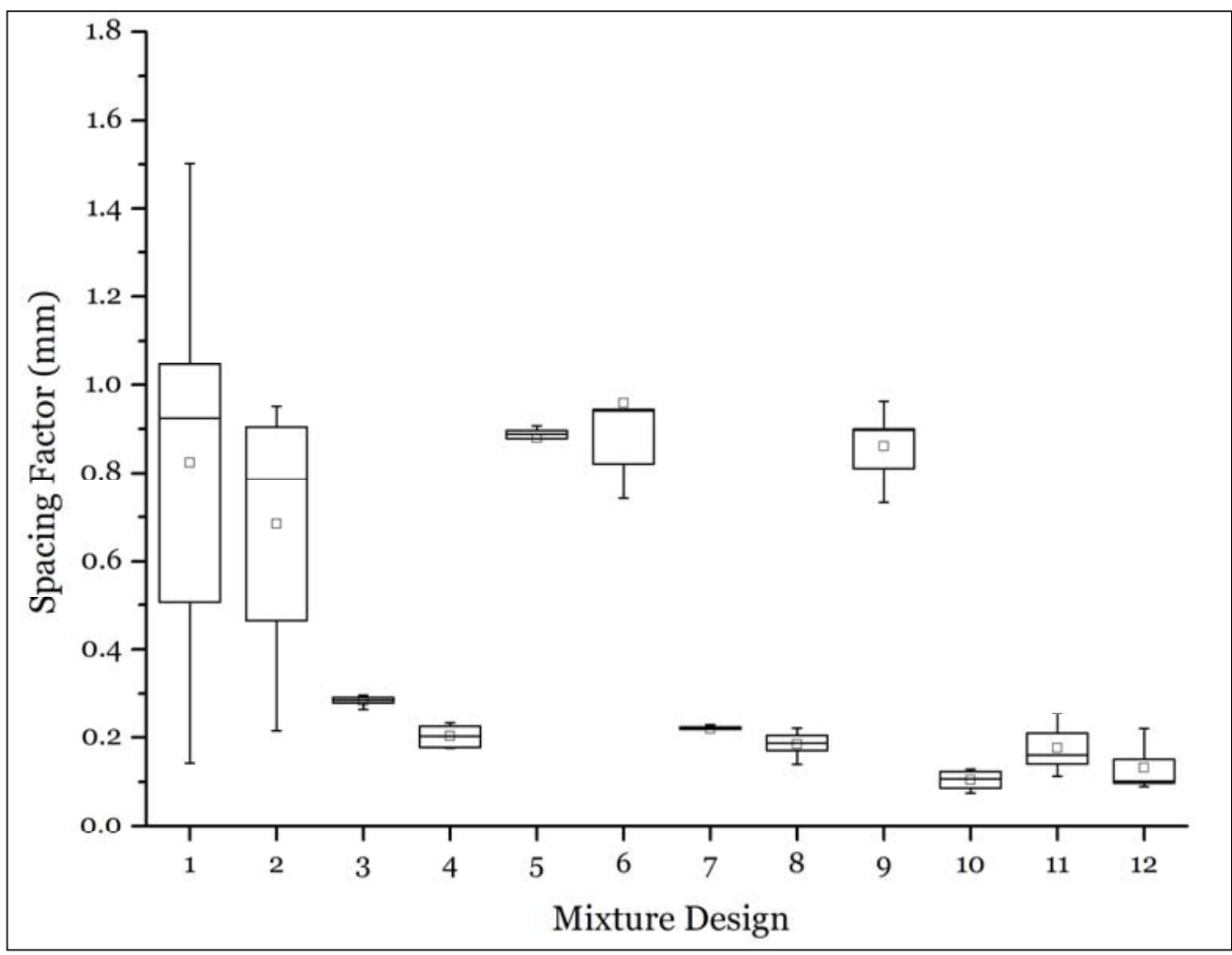

Figure 21. Spacing factor measured by AVA (less than $1 \mathrm{~mm}$ ) for each mixture design. 
Table 6. Descriptive statistics for air content by testing method.

\begin{tabular}{|c|c|c|c|c|c|c|c|c|c|}
\hline Mix & $\begin{array}{l}\text { Sample } \\
\text { Size }\end{array}$ & $\begin{array}{l}\text { Mean, } \\
\%\end{array}$ & \begin{tabular}{|l} 
Standard \\
Deviation, \%
\end{tabular} & $\begin{array}{l}\text { Minimum } \\
\text { Value, \% }\end{array}$ & $\begin{array}{l}\text { First } \\
\text { Quartile, \% }\end{array}$ & Median, \% & \begin{tabular}{|l} 
Third \\
Quartile, \%
\end{tabular} & $\begin{array}{l}\text { Maximum } \\
\text { Value, \% }\end{array}$ & Skew \\
\hline \multicolumn{10}{|c|}{ ASTM C138 } \\
\hline 1 & 5 & 2.1 & 0.3 & 1.8 & 1.8 & 2.1 & 2.5 & 2.6 & 0.36 \\
\hline 2 & 5 & 2.1 & 0.4 & 1.5 & 1.8 & 2.3 & 2.4 & 2.5 & -0.76 \\
\hline 3 & 5 & 4.6 & 0.7 & 3.5 & 4.1 & 4.8 & 5.0 & 5.3 & -1.06 \\
\hline 4 & 5 & 7.5 & 0.5 & 6.7 & 7.0 & 7.8 & 7.8 & 7.8 & -0.84 \\
\hline 5 & 5 & 1.0 & 0.6 & 0.1 & 0.4 & 1.2 & 1.4 & 1.7 & -0.27 \\
\hline 6 & 5 & 0.3 & 1.1 & -1.3 & -0.6 & 0.1 & 1.4 & 1.6 & -0.24 \\
\hline 7 & 5 & 6.1 & 1.6 & 4.9 & 5.0 & 5.7 & 7.3 & 8.9 & 1.33 \\
\hline 8 & 5 & 7.6 & 0.8 & 6.6 & 6.9 & 7.7 & 8.2 & 8.7 & 0.36 \\
\hline 9 & 5 & 1.4 & 2.3 & -0.5 & -0.3 & 0.8 & 3.4 & 5.3 & 1.07 \\
\hline 10 & 5 & 0.7 & 0.4 & 0.2 & 0.3 & 0.7 & 1.1 & 1.2 & -0.01 \\
\hline 11 & 5 & 3.3 & 1.0 & 2.4 & 2.4 & 2.9 & 4.4 & 4.5 & 0.31 \\
\hline 12 & 5 & 6.4 & 0.9 & 4.9 & 5.7 & 6.8 & 7.0 & 7.0 & -1.28 \\
\hline \multicolumn{10}{|c|}{ ASTM C173 } \\
\hline 1 & 5 & 2.8 & 0.5 & 2.3 & 2.4 & 2.8 & 3.3 & 3.5 & 0.40 \\
\hline 2 & 5 & 2.4 & 0.2 & 2.0 & 2.3 & 2.5 & 2.5 & 2.5 & -1.50 \\
\hline 3 & 5 & 5.8 & 0.2 & 5.5 & 5.6 & 5.8 & 5.9 & 6.0 & 0.00 \\
\hline 4 & 5 & 8.1 & 0.5 & 7.5 & 7.6 & 8.0 & 8.6 & 8.8 & 0.16 \\
\hline 5 & 5 & 2.5 & 0.2 & 2.3 & 2.3 & 2.5 & 2.6 & 2.8 & 0.34 \\
\hline 6 & 5 & 2.2 & 0.5 & 1.5 & 1.6 & 2.3 & 2.6 & 2.8 & 0.16 \\
\hline 7 & 5 & 7.3 & 0.8 & 6.3 & 6.6 & 7.3 & 8.0 & 8.5 & 0.28 \\
\hline 8 & 5 & 10.0 & 0.6 & 9.5 & 9.5 & 9.5 & 10.6 & 10.8 & 0.47 \\
\hline 9 & 5 & 2.5 & 0.1 & 2.3 & 2.4 & 2.5 & 2.5 & 2.5 & -1.50 \\
\hline 10 & 5 & 3.0 & 0.3 & 2.5 & 2.8 & 3.0 & 3.3 & 3.3 & -0.91 \\
\hline 11 & 5 & 5.8 & 1.1 & 4.8 & 4.9 & 5.0 & 7.0 & 7.0 & 0.38 \\
\hline 12 & 5 & 8.9 & 1.5 & 7.3 & 7.5 & 9.0 & 10.1 & 11.0 & 0.41 \\
\hline \multicolumn{10}{|c|}{ ASTM C231 - Type B } \\
\hline 1 & 5 & 2.6 & 0.5 & 2.3 & 2.4 & 2.4 & 3.1 & 3.4 & 1.14 \\
\hline 2 & 5 & 2.7 & 0.3 & 2.3 & 2.5 & 2.7 & 3.0 & 3.0 & -0.59 \\
\hline 3 & 5 & 6.0 & 0.2 & 5.8 & 5.9 & 6.0 & 6.2 & 6.2 & -0.34 \\
\hline 4 & 5 & 8.4 & 0.4 & 7.8 & 8.1 & 8.3 & 8.8 & 8.8 & -0.34 \\
\hline 5 & 5 & 2.3 & 0.1 & 2.1 & 2.2 & 2.3 & 2.4 & 2.4 & -0.36 \\
\hline 6 & 5 & 2.1 & 0.5 & 1.7 & 1.8 & 1.9 & 2.7 & 2.7 & 0.36 \\
\hline 7 & 5 & 6.7 & 0.7 & 5.7 & 6.1 & 6.8 & 7.3 & 7.4 & -0.50 \\
\hline 8 & 5 & 9.1 & 0.6 & 8.3 & 8.6 & 9.3 & 9.6 & 9.8 & -0.27 \\
\hline
\end{tabular}




\begin{tabular}{|c|c|c|c|c|c|c|c|c|c|}
\hline Mix & \begin{tabular}{|l} 
Sample \\
Size
\end{tabular} & $\begin{array}{l}\text { Mean, } \\
\%\end{array}$ & \begin{tabular}{|l|} 
Standard \\
Deviation, \%
\end{tabular} & \begin{tabular}{|l|} 
Minimum \\
Value, \%
\end{tabular} & $\begin{array}{l}\text { First } \\
\text { Quartile, \% }\end{array}$ & Median, \% & $\begin{array}{l}\text { Third } \\
\text { Quartile, \% }\end{array}$ & \begin{tabular}{|l|} 
Maximum \\
Value, \%
\end{tabular} & Skew \\
\hline 9 & 5 & 2.5 & 0.2 & 2.3 & 2.3 & 2.4 & 2.7 & 2.8 & 0.61 \\
\hline 10 & 5 & 2.8 & 0.3 & 2.3 & 2.5 & 2.8 & 3.1 & 3.1 & -0.55 \\
\hline 11 & 5 & 5.5 & 1.0 & 4.5 & 4.7 & 5.2 & 6.4 & 7.0 & 0.80 \\
\hline 12 & 5 & 7.6 & 0.6 & 6.6 & 7.0 & 8.0 & 8.1 & 8.1 & -0.93 \\
\hline \multicolumn{10}{|c|}{ ASTM C457 - Procedure A } \\
\hline 1 & 5 & 2.8 & 0.6 & 2.2 & 2.2 & 2.6 & 3.3 & 3.7 & 0.76 \\
\hline 2 & 5 & 1.9 & 0.3 & 1.5 & 1.6 & 1.8 & 2.2 & 2.2 & -0.04 \\
\hline 3 & 5 & 3.2 & 1.2 & 2.1 & 2.3 & 3.1 & 4.2 & 5.2 & 0.93 \\
\hline 4 & 5 & 4.3 & 1.2 & 2.4 & 3.4 & 4.4 & 5.2 & 5.7 & -0.68 \\
\hline 5 & 5 & 2.2 & 0.6 & 1.2 & 1.7 & 2.4 & 2.6 & 2.8 & -0.97 \\
\hline 6 & 5 & 2.7 & 0.6 & 2.0 & 2.1 & 2.9 & 3.2 & 3.2 & -0.31 \\
\hline 7 & 5 & 4.5 & 0.4 & 4.0 & 4.1 & 4.6 & 4.9 & 5.1 & 0.01 \\
\hline 8 & 5 & 5.1 & 1.6 & 3.7 & 3.8 & 4.0 & 6.8 & 7.2 & 0.47 \\
\hline 9 & 5 & 2.7 & 0.7 & 1.8 & 2.0 & 2.8 & 3.4 & 3.7 & 0.00 \\
\hline 10 & 5 & 2.8 & 0.6 & 2.1 & 2.3 & 2.9 & 3.4 & 3.7 & 0.37 \\
\hline 11 & 5 & 2.7 & 0.4 & 2.3 & 2.3 & 2.7 & 3.1 & 3.3 & 0.41 \\
\hline 12 & 5 & 4.0 & 0.5 & 3.2 & 3.5 & 4.0 & 4.4 & 4.4 & -0.63 \\
\hline \multicolumn{10}{|c|}{ AVA $-<2 m m$} \\
\hline 1 & 5 & 1.7 & 0.7 & 1.0 & 1.2 & 1.6 & 2.4 & 2.7 & 0.48 \\
\hline 2 & 4 & 1.8 & 0.7 & 1.2 & 1.2 & 1.8 & 2.5 & 2.6 & 0.14 \\
\hline 3 & 5 & 4.5 & 0.2 & 4.2 & 4.3 & 4.7 & 4.7 & 4.8 & -0.46 \\
\hline 4 & 5 & 6.6 & 0.4 & 6.3 & 6.3 & 6.5 & 7.0 & 7.3 & 1.06 \\
\hline 5 & 5 & 1.6 & 0.2 & 1.3 & 1.4 & 1.6 & 1.8 & 1.9 & -0.19 \\
\hline 6 & 5 & 1.3 & 0.5 & 0.7 & 0.8 & 1.1 & 1.9 & 2.0 & 0.30 \\
\hline 7 & 5 & 4.9 & 0.6 & 4.3 & 4.4 & 4.9 & 5.5 & 5.7 & 0.25 \\
\hline 8 & 5 & 6.3 & 1.4 & 4.4 & 4.8 & 6.7 & 7.5 & 7.7 & -0.36 \\
\hline 9 & 5 & 1.3 & 0.1 & 1.1 & 1.2 & \begin{tabular}{|l|}
1.4 \\
\end{tabular} & 1.4 & \begin{tabular}{|l|}
1.4 \\
\end{tabular} & -1.50 \\
\hline 10 & 5 & 3.3 & 1.0 & 1.9 & 2.6 & 3.3 & 4.0 & 4.6 & -0.25 \\
\hline 11 & 5 & 4.0 & 1.1 & 3.0 & 3.1 & 3.6 & 5.2 & 5.6 & 0.48 \\
\hline 12 & 5 & 6.1 & 1.2 & 3.9 & 5.0 & 6.6 & 6.9 & 7.0 & -1.25 \\
\hline \multicolumn{10}{|c|}{ AVA $-<1 \mathrm{~mm}$} \\
\hline 1 & 5 & 1.4 & 0.8 & 0.4 & 0.7 & 1.2 & 2.1 & 2.5 & 0.38 \\
\hline 2 & 4 & 1.5 & 0.6 & 1.0 & 1.0 & 1.4 & 2.1 & 2.2 & 0.39 \\
\hline 3 & 5 & 3.8 & 0.2 & 3.5 & 3.6 & 3.9 & 4.0 & 4.1 & -0.31 \\
\hline 4 & 5 & 5.8 & 0.4 & 5.4 & 5.5 & 5.7 & 6.1 & 6.4 & 0.83 \\
\hline 5 & 5 & 1.2 & 0.1 & 1.1 & 1.1 & 1.2 & 1.3 & 1.3 & -0.04 \\
\hline
\end{tabular}




\begin{tabular}{|l|l|l|l|l|l|l|l|l|l|}
\hline Mix & $\begin{array}{l}\text { Sample } \\
\text { Size }\end{array}$ & $\begin{array}{l}\text { Mean, } \\
\%\end{array}$ & $\begin{array}{l}\text { Standard } \\
\text { Deviation, \% }\end{array}$ & $\begin{array}{l}\text { Minimum } \\
\text { Value, \% }\end{array}$ & $\begin{array}{l}\text { First } \\
\text { Quartile, \% }\end{array}$ & Median, \% & $\begin{array}{l}\text { Third } \\
\text { Quartile, \% }\end{array}$ & $\begin{array}{l}\text { Maximum } \\
\text { Value, \% }\end{array}$ & Skew \\
\hline 6 & 5 & 1.0 & 0.4 & 0.6 & 0.6 & 0.8 & 1.4 & 1.5 & 0.32 \\
\hline 7 & 5 & 4.5 & 0.5 & 4.0 & 4.1 & 4.3 & 5.0 & 5.3 & 0.65 \\
\hline 8 & 5 & 5.6 & 1.2 & 4.2 & 4.5 & 6.0 & 6.6 & 7.0 & -0.19 \\
\hline 9 & 5 & 1.0 & 0.1 & 1.0 & 1.0 & 1.0 & 1.1 & 1.1 & 0.27 \\
\hline 10 & 5 & 3.0 & 1.0 & 1.6 & 2.2 & 2.9 & 3.8 & 4.4 & -0.06 \\
\hline 11 & 5 & 3.6 & 1.1 & 2.7 & 2.8 & 3.1 & 4.8 & 5.2 & 0.56 \\
\hline 12 & 5 & 5.6 & 1.3 & 3.5 & 4.5 & 6.1 & 6.5 & 6.7 & -1.06 \\
\hline
\end{tabular}

Table 7. Descriptive statistics for specific surface by testing method.

\begin{tabular}{|c|c|c|c|c|c|c|c|c|c|}
\hline Mix & $\begin{array}{l}\text { Sample } \\
\text { Size }\end{array}$ & $\begin{array}{l}\text { Mean, } \\
\text { psi }\end{array}$ & \begin{tabular}{|l|} 
Standard \\
Deviation, psi
\end{tabular} & $\begin{array}{l}\text { Minimum } \\
\text { Value, psi }\end{array}$ & $\begin{array}{l}\text { First } \\
\text { Quartile, psi }\end{array}$ & \begin{tabular}{|l} 
Median, \\
psi
\end{tabular} & $\begin{array}{l}\text { Third } \\
\text { Quartile, psi }\end{array}$ & $\begin{array}{l}\text { Maximum, } \\
\text { psi }\end{array}$ & Skew \\
\hline \multicolumn{10}{|c|}{ ASTM C457 - Procedure A } \\
\hline 1 & 5 & 7.6 & 0.8 & 6.5 & 6.9 & 7.5 & 8.4 & 8.6 & -0.30 \\
\hline 2 & 5 & 7.3 & 0.9 & 6.1 & 6.4 & 7.6 & 8.1 & 8.5 & -0.14 \\
\hline 3 & 5 & 11.3 & 1.1 & 10.4 & 10.5 & 10.9 & 12.4 & 12.9 & 0.66 \\
\hline 4 & 5 & 11.3 & 1.5 & 9.1 & 10.0 & 11.2 & 12.5 & 13.1 & -0.31 \\
\hline 5 & 4 & 7.1 & 0.5 & 6.4 & 6.6 & 7.2 & 7.5 & 7.5 & -0.80 \\
\hline 6 & 5 & 8.2 & 0.7 & 7.6 & 7.7 & 8.1 & 8.8 & 9.3 & 0.94 \\
\hline 7 & 5 & 15.0 & 1.9 & 13.0 & 13.3 & 15.1 & 16.7 & 17.7 & 0.46 \\
\hline 8 & 5 & 11.4 & 3.2 & 6.7 & 8.3 & 12.0 & 14.3 & 14.8 & -0.46 \\
\hline 9 & 5 & 7.7 & 0.6 & 6.7 & 7.2 & 7.8 & 8.2 & 8.3 & -0.87 \\
\hline 10 & 5 & 10.5 & 2.5 & 8.9 & 9.0 & 9.3 & 12.6 & 14.8 & 1.32 \\
\hline 11 & 5 & 14.6 & 2.7 & 10.9 & 12.1 & 14.7 & 17.0 & 18.2 & -0.03 \\
\hline 12 & 5 & 16.0 & 2.4 & 13.1 & 14.0 & 15.1 & 18.5 & 19.0 & 0.13 \\
\hline \multicolumn{10}{|c|}{ AVA $-<2 m m$} \\
\hline 1 & 5 & 15.9 & 14.4 & 5.4 & 6.7 & 8.2 & 28.9 & 40.4 & 1.17 \\
\hline 2 & 3 & 9.0 & 0.7 & 8.4 & 8.4 & 8.9 & 9.7 & 9.7 & 0.36 \\
\hline 3 & 5 & 15.9 & 0.6 & 15.4 & 15.4 & 15.7 & 16.6 & 16.7 & 0.36 \\
\hline 4 & 5 & 18.2 & 1.8 & 16.3 & 16.6 & 17.9 & 19.9 & 20.8 & 0.48 \\
\hline 5 & 5 & 8.5 & 0.6 & 7.7 & 8.0 & 8.6 & 9.1 & 9.2 & -0.41 \\
\hline 6 & 5 & 9.2 & 1.4 & 7.4 & 8.2 & 9.0 & 10.4 & 11.3 & 0.16 \\
\hline 7 & 5 & 20.4 & 1.1 & 19.2 & 19.5 & 20.6 & 21.3 & 22.0 & 0.29 \\
\hline 8 & 5 & 21.6 & 3.9 & 18.1 & 18.4 & 20.4 & 25.4 & 27.7 & 0.77 \\
\hline 9 & 5 & 9.7 & 1.5 & 8.1 & 8.5 & 9.3 & 11.0 & 12.0 & 0.77 \\
\hline 10 & 5 & 43.1 & 19.1 & 12.6 & 26.6 & 44.5 & 58.8 & 62.4 & -0.78 \\
\hline 11 & 5 & 30.1 & 6.1 & 21.5 & 24.2 & 31.5 & 35.3 & 37.6 & 0.27 \\
\hline
\end{tabular}




\begin{tabular}{|l|l|l|l|l|l|l|l|l|l|l|}
\hline Mix & $\begin{array}{l}\text { Sample } \\
\text { Size }\end{array}$ & $\begin{array}{l}\text { Mean, } \\
\text { psi }\end{array}$ & $\begin{array}{l}\text { Standard } \\
\text { Deviation, psi }\end{array}$ & $\begin{array}{l}\text { Minimum } \\
\text { Value, psi }\end{array}$ & $\begin{array}{l}\text { First } \\
\text { Quartile, psi }\end{array}$ & $\begin{array}{l}\text { Median, } \\
\text { psi }\end{array}$ & $\begin{array}{l}\text { Third } \\
\text { Quartile, psi }\end{array}$ & $\begin{array}{l}\text { Maximum, } \\
\text { psi }\end{array}$ & Skew \\
\hline 12 & 5 & 33.7 & 7.1 & 22.8 & 26.6 & 37.2 & 39.1 & 40.3 & -0.73 \\
\hline \multicolumn{7}{|c|}{ AVA - <1mm } \\
\hline 1 & 5 & 18.6 & 15.1 & 8.9 & 8.9 & 9.3 & 32.8 & 43.7 & 1.08 \\
\hline 2 & 4 & 15.5 & 10.1 & 9.5 & 9.8 & 10.9 & 25.8 & 30.6 & 1.14 \\
\hline 3 & 5 & 18.1 & 0.7 & 17.1 & 17.3 & 18.3 & 18.7 & 18.8 & -0.44 \\
\hline 4 & 5 & 20.3 & 1.8 & 18.4 & 18.6 & 20.5 & 21.9 & 22.7 & 0.24 \\
\hline 5 & 5 & 9.8 & 0.5 & 9.3 & 9.4 & 10.0 & 10.3 & 10.4 & -0.16 \\
\hline 6 & 5 & 10.5 & 1.5 & 8.5 & 9.2 & 10.8 & 11.8 & 12.5 & -0.10 \\
\hline 7 & 5 & 22.0 & 1.1 & 20.4 & 21.1 & 22.1 & 22.8 & 23.3 & -0.50 \\
\hline 8 & 5 & 23.6 & 4.3 & 20.4 & 20.5 & 22.1 & 27.6 & 30.8 & 1.04 \\
\hline 9 & 5 & 10.9 & 1.2 & 9.9 & 10.1 & 10.5 & 12.0 & 12.9 & 1.08 \\
\hline 10 & 5 & 47.0 & 19.9 & 14.1 & 30.1 & 51.3 & 61.9 & 65.8 & -1.00 \\
\hline 11 & 5 & 32.9 & 6.4 & 24.2 & 26.5 & 35.3 & 38.1 & 40.4 & -0.29 \\
\hline 12 & 5 & 36.3 & 7.2 & 25.0 & 29.2 & 40.4 & 41.5 & 41.9 & -0.87 \\
\hline
\end{tabular}

Table 8. Descriptive statistics for spacing factor by testing method.

\begin{tabular}{|l|l|l|l|l|l|l|l|l|l|l|l|}
\hline Mix & $\begin{array}{l}\text { Sample } \\
\text { Size }\end{array}$ & $\begin{array}{l}\text { Mean, } \\
\text { psi }\end{array}$ & $\begin{array}{l}\text { Standard } \\
\text { Deviation, psi }\end{array}$ & $\begin{array}{l}\text { Minimum } \\
\text { Value, psi }\end{array}$ & $\begin{array}{l}\text { First } \\
\text { Quartile, psi }\end{array}$ & $\begin{array}{l}\text { Median, } \\
\text { psi }\end{array}$ & $\begin{array}{l}\text { Third } \\
\text { Quartile, psi }\end{array}$ & $\begin{array}{l}\text { Maximum, } \\
\text { psi }\end{array}$ & Skew \\
\hline \multicolumn{7}{|c|}{ ASTM C457- Procedure A } \\
\hline 1 & 5 & 0.79 & 0.07 & 0.74 & 0.74 & 0.76 & 0.86 & 0.88 & 0.45 \\
\hline 2 & 5 & 1.02 & 0.11 & 0.89 & 0.90 & 1.05 & 1.12 & 1.14 & -0.20 \\
\hline 3 & 5 & 0.52 & 0.06 & 0.45 & 0.46 & 0.56 & 0.57 & 0.58 & -0.40 \\
\hline 4 & 5 & 0.49 & 0.09 & 0.38 & 0.40 & 0.48 & 0.57 & 0.58 & -0.07 \\
\hline 5 & 5 & 0.85 & 0.19 & 0.53 & 0.71 & 0.89 & 0.98 & 1.04 & -1.10 \\
\hline 6 & 5 & 0.77 & 0.03 & 0.72 & 0.74 & 0.79 & 0.80 & 0.80 & -0.72 \\
\hline 7 & 5 & 0.35 & 0.04 & 0.29 & 0.31 & 0.35 & 0.38 & 0.39 & -0.44 \\
\hline 8 & 5 & 0.50 & 0.21 & 0.37 & 0.37 & 0.40 & 0.67 & 0.86 & 1.35 \\
\hline 9 & 5 & 0.83 & 0.05 & 0.77 & 0.79 & 0.83 & 0.88 & 0.90 & 0.11 \\
\hline 10 & 5 & 0.60 & 0.10 & 0.42 & 0.52 & 0.64 & 0.67 & 0.67 & -1.28 \\
\hline 11 & 5 & 0.46 & 0.10 & 0.32 & 0.37 & 0.44 & 0.55 & 0.57 & -0.22 \\
\hline 12 & 5 & 0.36 & 0.06 & 0.28 & 0.31 & 0.35 & 0.42 & 0.44 & -0.08 \\
\hline &
\end{tabular}




\begin{tabular}{|l|l|l|l|l|l|l|l|l|l|}
\hline Mix & $\begin{array}{l}\text { Sample } \\
\text { Size }\end{array}$ & $\begin{array}{l}\text { Mean, } \\
\text { psi }\end{array}$ & $\begin{array}{l}\text { Standard } \\
\text { Deviation, psi }\end{array}$ & $\begin{array}{l}\text { Minimum } \\
\text { Value, psi }\end{array}$ & $\begin{array}{l}\text { First } \\
\text { Quartile, psi }\end{array}$ & $\begin{array}{l}\text { Median, } \\
\text { psi }\end{array}$ & $\begin{array}{l}\text { Third } \\
\text { Quartile, psi }\end{array}$ & $\begin{array}{l}\text { Maximum, } \\
\text { psi }\end{array}$ & Skew \\
\hline 5 & 5 & 0.90 & 0.03 & 0.85 & 0.88 & 0.91 & 0.93 & 0.93 & -1.10 \\
\hline 6 & 5 & 0.98 & 0.22 & 0.78 & 0.80 & 0.97 & 1.16 & 1.34 & 0.96 \\
\hline 7 & 5 & 0.23 & 0.01 & 0.22 & 0.22 & 0.22 & 0.23 & 0.24 & 0.08 \\
\hline 8 & 5 & 0.19 & 0.03 & 0.14 & 0.15 & 0.18 & 0.22 & 0.23 & -0.07 \\
\hline 9 & 5 & 0.90 & 0.11 & 0.76 & 0.79 & 0.91 & 1.00 & 1.03 & -0.14 \\
\hline 10 & 4 & 0.11 & 0.03 & 0.08 & 0.08 & 0.11 & 0.13 & 0.14 & -0.23 \\
\hline 11 & 5 & 0.18 & 0.06 & 0.12 & 0.13 & 0.17 & 0.24 & 0.27 & 0.38 \\
\hline 12 & 5 & 0.13 & 0.06 & 0.09 & 0.09 & 0.10 & 0.19 & 0.23 & 0.91 \\
\hline & & & & \multicolumn{1}{|l|}{ AVA - <1mm } & & & & \\
\hline 1 & 5 & 0.82 & 0.52 & 0.14 & 0.32 & 0.92 & 1.27 & 1.50 & -0.05 \\
\hline 2 & 4 & 0.68 & 0.33 & 0.22 & 0.34 & 0.79 & 0.93 & 0.95 & -0.87 \\
\hline 3 & 5 & 0.28 & 0.01 & 0.26 & 0.27 & 0.29 & 0.29 & 0.30 & -0.62 \\
\hline 4 & 5 & 0.20 & 0.03 & 0.18 & 0.18 & 0.20 & 0.23 & 0.23 & 0.04 \\
\hline 5 & 5 & 0.88 & 0.03 & 0.83 & 0.85 & 0.89 & 0.90 & 0.91 & -1.10 \\
\hline 6 & 5 & 0.96 & 0.23 & 0.74 & 0.78 & 0.94 & 1.14 & 1.34 & 1.00 \\
\hline 7 & 5 & 0.22 & 0.01 & 0.21 & 0.21 & 0.22 & 0.23 & 0.23 & -0.42 \\
\hline 8 & 5 & 0.18 & 0.03 & 0.14 & 0.16 & 0.19 & 0.21 & 0.22 & -0.34 \\
\hline 9 & 5 & 0.86 & 0.09 & 0.73 & 0.77 & 0.90 & 0.93 & 0.96 & -0.41 \\
\hline 10 & 4 & 0.10 & 0.02 & 0.07 & 0.08 & 0.11 & 0.13 & 0.13 & -0.30 \\
\hline 11 & 5 & 0.18 & 0.06 & 0.11 & 0.13 & 0.16 & 0.23 & 0.25 & 0.36 \\
\hline 12 & 5 & 0.13 & 0.05 & 0.09 & 0.09 & 0.10 & 0.19 & 0.22 & 0.93 \\
\hline
\end{tabular}

Bivariate analysis on testing methods

The first analysis phase compared the testing procedures used against one another as a whole. The origins of this analysis came from questioning the ASTM C457-A data received from the concrete petrographer. The box plots and Q-Q plots constructed showed the ASTM C457-A testing did not produce similar total air content values as those measured by ASTM C173 and ASTM C231, as expected (Figure 22). The ASTM C457-A results were consistently lower than those for either ASTM C231 or C173 in terms of total air content, and the disagreement between test methods increased as the amount of air entrainment increased.

Table 9 details the descriptive statistics using all the mixtures batched and sampled. Only total air content was considered for this phase of the analysis since this air void structure parameter could be determined by all test 

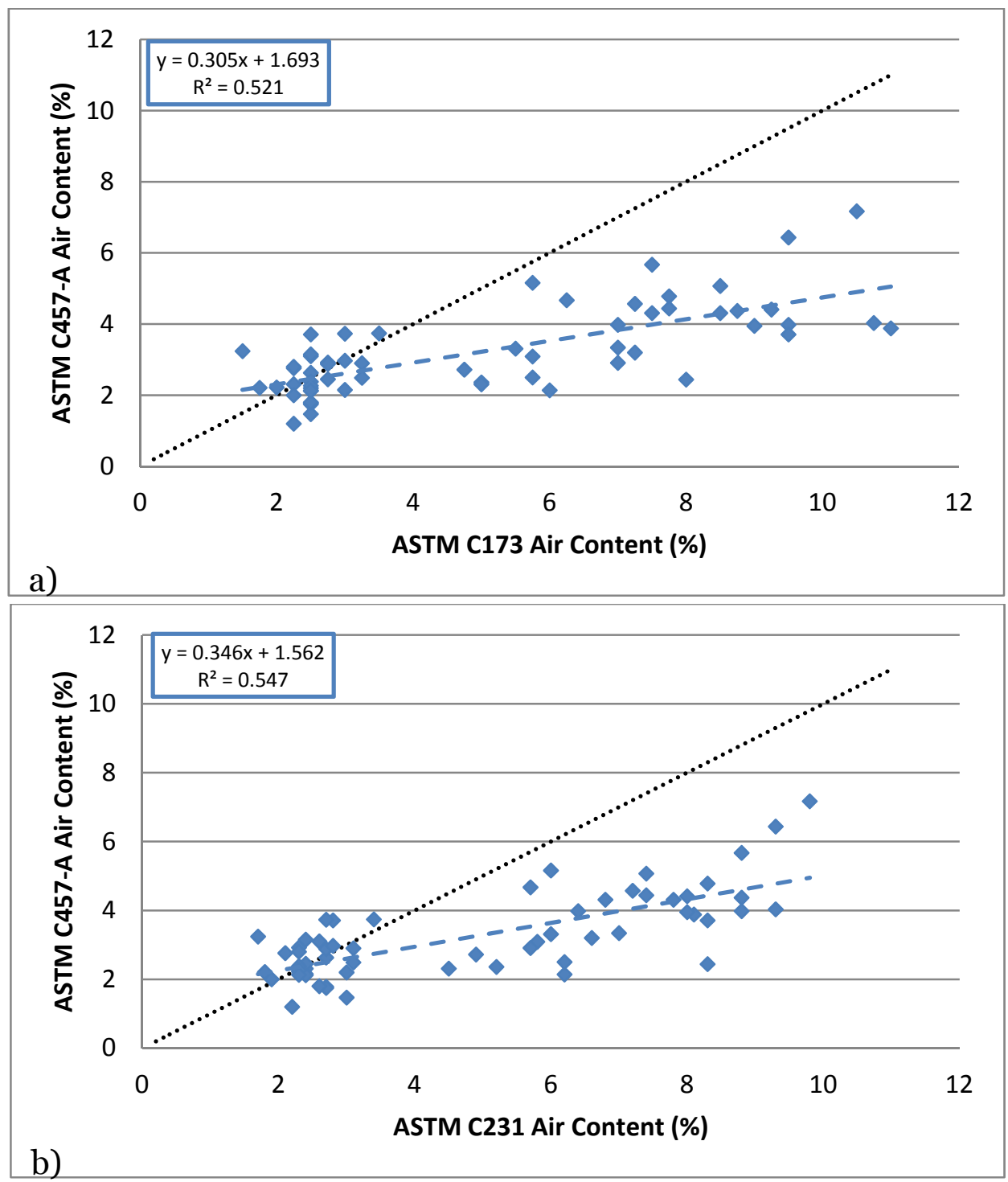

Figure 22. Q-Q plots comparing ASTM C457-A to other fresh property measurements.

Table 9. Total air content descriptive statistics by testing procedure.

\begin{tabular}{|l|l|l|l|l|l|l|l|}
\hline Test Method & ASTM C231 & ASTM C173 & ASTM C138 & ASTM C457-A & ASTM C457-B & AVA < 2mm & AVA <1mm \\
\hline Sample Size & 60 & 60 & 60 & 60 & 20 & 59 & 59 \\
\hline Mean & 4.87 & 5.08 & 3.60 & 3.24 & 5.35 & 3.64 & 3.18 \\
\hline $\begin{array}{l}\text { Standard } \\
\text { Deviation }\end{array}$ & 2.59 & 2.86 & 2.78 & 1.21 & 2.06 & 2.11 & 1.97 \\
\hline Minimum & 1.7 & 1.5 & -1.30 & 1.2 & 2.45 & 0.7 & 0.4 \\
\hline 1 $^{\text {st }}$ Quartile & 2.4 & 2.5 & 1.20 & 2.31 & 3.62 & 1.55 & 1.15 \\
\hline Median & 3.95 & 4.13 & 2.55 & 2.95 & 5.00 & 3.45 & 3.1 \\
\hline $3^{\text {rd }}$ Quartile & 7.35 & 7.5 & 6.30 & 3.98 & 6.84 & 5.25 & 4.75 \\
\hline Maximum & 9.8 & 11 & 8.90 & 7.17 & 9.47 & 7.7 & 7.0 \\
\hline Skewness & 0.37 & 0.50 & 0.26 & 0.94 & 0.43 & 0.28 & 0.26 \\
\hline
\end{tabular}


methods considered. Quantitative evidence of this underestimation is shown in the descriptive statistics. The mean and maximum values for the ASTM C457-A testing are considerably lower than the collected standard field tests ASTM C231 and $\mathrm{C}_{173}$ when considering the testing process alone. All the ASTM field test methods considered, show approximately the same amount of spread (standard deviation) within the data collected but are more variable than ASTM C457-A data. The skewness coefficient shows a considerable right tail in the ASTM C457-A data compared to all tests conducted, indicating there are few higher measurements collected. Some of the data skew reported to the right can be attributed to the poor results observed with the 1 percent entrained air mixture designs (Mixtures 2, 6, and 10). Design air contents for these designs were lower than expected and showed little entrained air was added to mixture designs with entrapped air only (Mixtures 1, 5, and 9). This concentrated data in the lower air contents and drew the results to the right. The results between tests can still be used for comparison against each other, since each mixture batched was measured by each method.

ASTM C457 notes that the total air content of this test "usually agrees closely with the value determined in the fresh concrete in accordance with Test Methods C138, C173 or C231." Circumstances under which these test results may deviate from one another are (1) when samples are consolidated differently from one another and (2) when ASTM C231 values at higher air contents (+7.5 percent) produce lower air contents (at least 1 percent) than ASTM C457. Since the majority (78 percent) of the mixtures measured less than 7.5 percent air by ASTM C231, little deviation between the different test procedures was expected with respect to the ASTM C231 measurement. The remaining mixtures with air contents larger than 7.5 percent show the opposite trend described in the ASTM standard, and all the ASTM C231 measurements are larger than their corresponding ASTM C457-A values.

The consolidation effort used to construct the test specimens can influence the air voids within the concrete, since this process is used to remove large entrapped air voids after placement and over-consolidation can remove entrained air voids. Table 10 describes the average consolidation effort used on each sample constructed, minus the tapping with the rubber mallet used to close the rodding voids on stiffer mixtures. The effort put into consolidating each required layer was fairly different for the specimens constructed and averaged about 0.25 rods/in. 3 of sample volume. The difference in effort used to construct each specimen can help explain some of the 
variability in the air measured for each test, but there appears to be little trend between the data from the following observations:

- ASTM C231 specimens received about 50 percent more consolidation effort, but produced slightly lower air contents than the $\mathrm{C} 173$ specimens on average.

- $\quad$ The ASTM C138 and C231 specimens utilized the same tested sample, and significantly more air (+2 percent) was measured for the C231 testing. Since ASTM C138 is a heavily calculation-based measurement, the calculations were verified to ensure correct results with the numbers on hand.

- Slightly more consolidation effort was used to cast the cylinder used for ASTM C457 testing than that used for C231, but the C231 sample was between the values determined for both $\mathrm{C} 457$ test procedures used.

- The ASTM C457 samples tested by both procedures were the same and yielded different values for the different procedures used.

- The beam cast was consolidated the least, but the AVA sampling does not account for the total vibration induced on the sample when extracted from the beam. This drill vibration is a more significant source of consolidation effort than rodding, especially when the impact hammer mode is used.

Table 10. Consolidation effort used for sample construction.

\begin{tabular}{|c|c|c|c|c|c|c|}
\hline \multirow[b]{2}{*}{$\begin{array}{l}\text { Specimen } \\
\text { Geometry }\end{array}$} & \multirow{2}{*}{$\begin{array}{l}\text { ASTM } \\
\text { Construction } \\
\text { Specification }\end{array}$} & \multirow{2}{*}{$\begin{array}{l}\text { Rods } \\
\text { per } \\
\text { Layer }\end{array}$} & \multirow[b]{2}{*}{ Layers } & \multirow[b]{2}{*}{ Vessel Dimensions } & \multicolumn{2}{|c|}{$\begin{array}{l}\text { Average Consolidation Effort } \\
\text { per Sample Layer }\end{array}$} \\
\hline & & & & & $\begin{array}{l}\text { Surface Area, } \\
\text { rod/in. }{ }^{2}\end{array}$ & $\begin{array}{l}\text { Volume, } \\
\text { rod/in. }{ }^{3}\end{array}$ \\
\hline Cylinder & C1921 & 25 & 2 & $\begin{array}{l}4 \text { in. diameter } \\
8 \mathrm{in.} \mathrm{height} \\
0.06 \mathrm{ft}^{3} \text { volume }\end{array}$ & 1.99 & 0.50 \\
\hline Cylinder & C231 & 25 & 3 & $\begin{array}{l}8 \text { in. diameter } \\
8.5 \mathrm{in} \text {. height } \\
0.25 \mathrm{ft}^{3} \text { volume }\end{array}$ & 0.50 & 0.57 \\
\hline Cylinder & C173 & 25 & 2 & $\begin{array}{l}5.9 \mathrm{in} \text {. diameter } \\
4.75 \mathrm{in} \text {. height } \\
0.075 \mathrm{ft}^{3} \text { volume }\end{array}$ & 0.91 & 0.39 \\
\hline Beam & C192 & 63 & 2 & $\begin{array}{l}6 \text { in. width } \\
6 \text { in. depth } \\
21 \text { in. length } \\
0.44 \mathrm{ft}^{3} \text { volume }\end{array}$ & 2.00 & 0.33 \\
\hline
\end{tabular}

${ }^{1}$ C192 can be found in the references as ASTM 2007a and will be cited throughout the report as C192. 
The deviation seen in the ASTM C138 test is somewhat concerning since mixtures made in the laboratory were under much stricter control than any concrete batched in the field would be. Since this test method is much more mathematical, any inaccuracies in measured aggregate properties (gradation and bulk specific gravity) and water content (total batched into mixer and moisture corrections) can lead to greater than 1 percent differences in the calculated air contents compared to the other field tests (Lamond and Pielert 2006). Typically this value is only used for a quick check of other collected values. These issues would be minimized since aggregates were stored indoors before use to stabilize moisture contents, no additional mixing water was added after batching the concrete, and all materials used for this study were purchased and sampled at the beginning of the investigation, as they were for this study.

Previous research using the ASTM C457 analysis shows the greatest sources of procedural error encountered were with preparing the surface and reporting air voids. Specimen surface preparation can greatly affect the observer's visual assessment of the points under the microscope and yield results that can over- or undervalue the amount of total air (Ozyildirim 1991; Cahill et al. 1994; Lamond and Pielert 2006, ASTM 2010b). Overestimation of air voids is more common and results from two major sources. One source results from taking measurements around the vicinity of air voids where the paste surrounding the perimeter of the voids is damaged during grinding (Figure 23). This yields larger chord lengths or more air points counted in the procedure, A and B, respectively. This is common in specimens with high air contents where the paste is weakened from the high air void density and sharp, defined edges on the void perimeter cannot be produced. The second source of overestimating error is related to grinding around the aggregates. Sand can be dislodged and scratch the prepared surface, leaving unintended voids from particle removal and the scratching. Undercutting and removal of paste from around higher quality (harder) aggregates is also possible (Lamond and Pielert 2006). A simple study by Roberts and Gaynor (1991) showed that specimen preparation alone can change the results by more than 3 percent from inaccurately measuring chord lengths and misinterpretating the texture of ground specimens (Ozyildirium 1991). In situations like these, ASTM C457 recommends melting carnauba wax onto the surface before grinding to fill and reinforce the air voids at the prepared surface. This wax is removed by reheating and draining at the end of the grinding process (ASTM 2010b). 


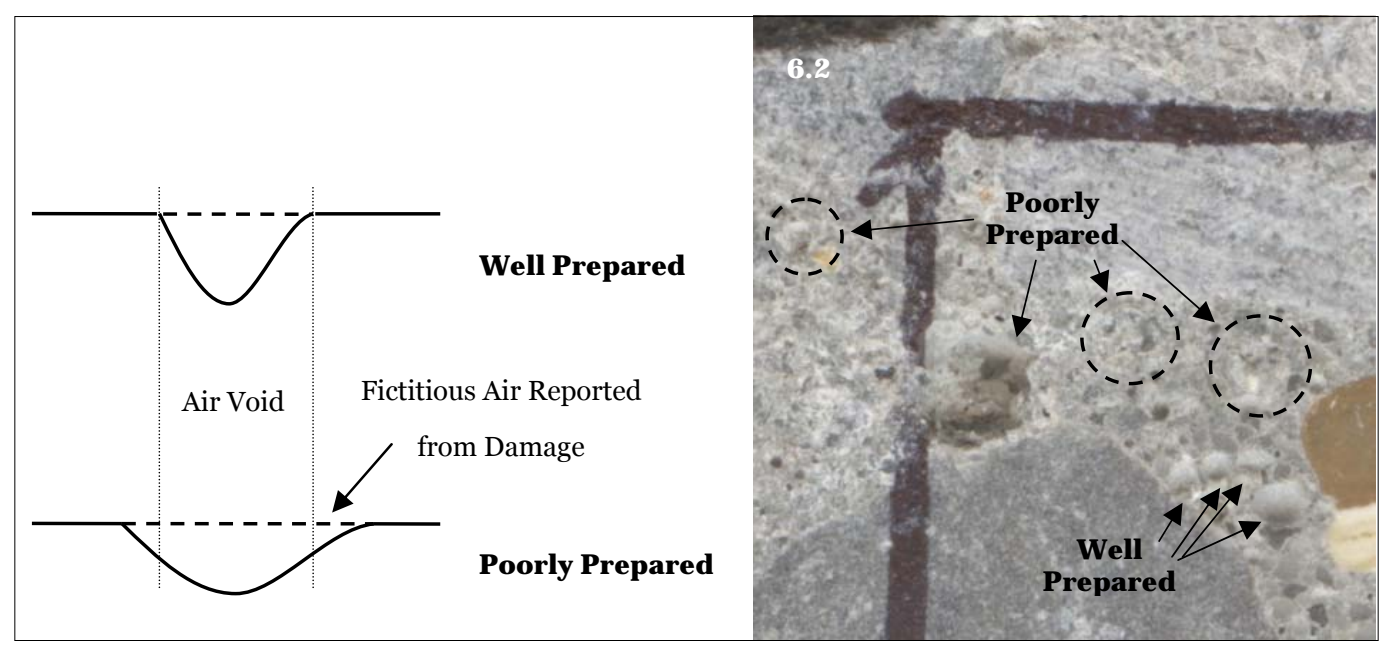

Figure 23. Comparison of air void perimeter damage on measurement.

Underestimation of air voids results from the observer's inability to count the air within the sample, either from not being able to see smaller diameter voids or from the voids' not being clearly defined under the microscope. This type of error is less common (Ozyildirim 1991), but not counting all the air voids will affect the measured air void structure properties, especially the smaller diameter voids. The circled air voids in Figure 23 show how difficult it is to see voids on surfaces that still require grinding. The easiest way to ensure smaller voids are counted is to increase the magnification of the microscope used. The ASTM $\mathrm{C} 457$ requires that the microscope to be used is able to magnify the sample from 50 to $125 \times$ (ASTM 2010b); however, previous studies recommend samples under magnifications greater than $100 \times$ must be more "optically flat" and ground to a higher standard to ensure any surface irregularities not removed are not perceived as air voids. Not counting smaller voids does not significantly affect the total air content calculation since the smaller voids take up less surface area on the specimen surface. There is greater concern over the specific surface and spacing factor values, since smaller voids impact these values much more. Smaller voids have larger surface areas per unit volumes and can be dispersed between larger observed voids. Not factoring these voids into the calculations can lead to lower specific surface and higher void spacing that are not representative of the samples measured (Lamond and Pielert 2006).

Using the recommended abrasive grit sizes of \#100 $(140 \mu \mathrm{m})$, \#220 $(68 \mu \mathrm{m})$, \#320 $(36 \mu \mathrm{m})$, \#600 $(16 \mu \mathrm{m})$, \#800 (12.5 $\mu \mathrm{m})$, and \#2500 $(5 \mu \mathrm{m})$, if necessary with the processing techniques given in ASTM C457, is reported to produce well-defined air voids with sharp perimeters and no erosion or crumbling. The surface should be fairly shiny without waxing the surface 
when viewed under a distant low angle light source and have a texture similar to glass when complete. The ASTM C457 reports that this preparation method should make voids as small as $4 \cdot 10^{-4}$ in. $(10 \mu \mathrm{m})$ "clearly distinguishable" (ASTM 2010b), well within the $1 \cdot 10^{-3}$ in. (30 $\left.\mu \mathrm{m}\right)$ range a typical observer can see (Ramezanianpour and Hooten 2010).

A review of the prepared and analyzed specimens returned from the petrographer showed the quality of the surface grinding on the samples was not sufficient. The petrographer reported that the provided concrete cylinders were cut into four pieces with a wet cut diamond tipped saw, where the two ends were trimmed horizontally and the remaining 4-in.-tall central cylinder was cut in half vertically. One of the central cylinder pieces was selected and ground for analysis at the petrographer's choosing. Grinding of the interior saw cut surface was completed by rubbing by hand the saw cut surface of the sample on a sheet of glass with successively finer silicon carbide abrasives. The petrographer used abrasive grit sizes of \#80 $(190 \mu \mathrm{m})$, \#120 (115 $\mu \mathrm{m}), \# 220$, \#320, and \#600 when preparing the samples. This series of abrasives deviated from the recommended list; however, the use of the grit sizes described is not required since the standard gives subjective directions on the grinding process. The use of the\# 80 grit is not expected to cause any issues with the results and will only assist in the preparation process by removing the coarser irregularities more efficiently. The lack of finer grinding compared to the standard's recommended list does raise concerns on the quality of the finished surfaces since the ASTM C457-A air content results are significantly lower than the standard field tests. Not being able to identify all the voids, like those circled in Figure 23, will explain the difference between the petrographer's results and the standard field test results.

A gross assessment of the samples' finished surface showed some of the samples were not ground completely flat. Examples of surfaces are shown in Figure 24. The condition of the surface was easily distinguishable by look and feel when comparing poorly to well ground samples within those returned. The samples also showed minor fresh scratches because of the poor shipping practices the petrographer used when returning the samples to the ERDC. Closer evaluation of the amount of unprepared surface area showed the majority of the samples ( 51 of 60 ) were ground fairly flat and had a smooth surface, where the positioning of the 3-in.-square box provided a surface that was at least 95 percent ground. It is concerning that the nine samples which the boxed analysis area utilized were not 
ground flat. This was fairly obvious to the untrained eye, and their condition was not corrected before analysis by the petrographer. Additional grinding with the coarser abrasives should have been completed on all samples to ensure the surfaces were leveled.
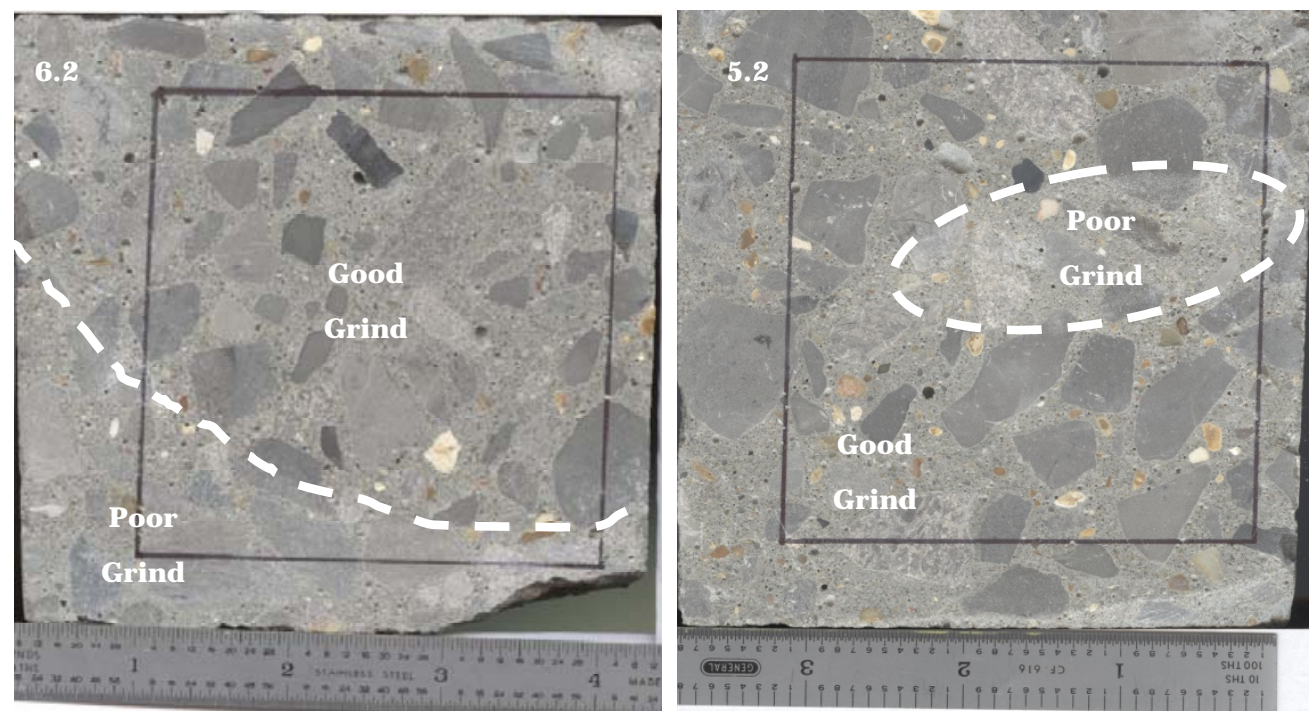

Figure 24. Examples of samples that were not ground flat.

Having confidence in the ASTM C457-A results is critical, since this test yields all air void structure properties for comparison and has been the accepted reference value for previous studies. An attempt to verify the ASTM C457-A measurements was made by retesting twenty semi-randomly selected samples by the same petrographer using the B procedure given in ASTM C457. From discussions with the petrographer, this petrographer's laboratory was more familiar with the B procedure since this test was performed frequently for other clients. The B procedure was used more frequently because less analysis time is required to achieve the same answers, resulting in a price difference of about $\$ 50$ per sample to clients. Retesting was considered semi-random, since at least one sample, but not more than two, from each of the twelve mixture designs was selected. This was done to consider a variety of air contents across the samples provided and minimize skew in the retested data.

The difference between the two procedures given under ASTM C457 is the way the air within the concrete is observed. The observation methodology for both procedures is shown in Figure 25. Procedure A, the linear traverse method, counts the depressions across a series of parallel rows. When a series of depressions (air voids) is encountered along a row, the individual chord lengths of the air voids found along the line are measured by tracking 


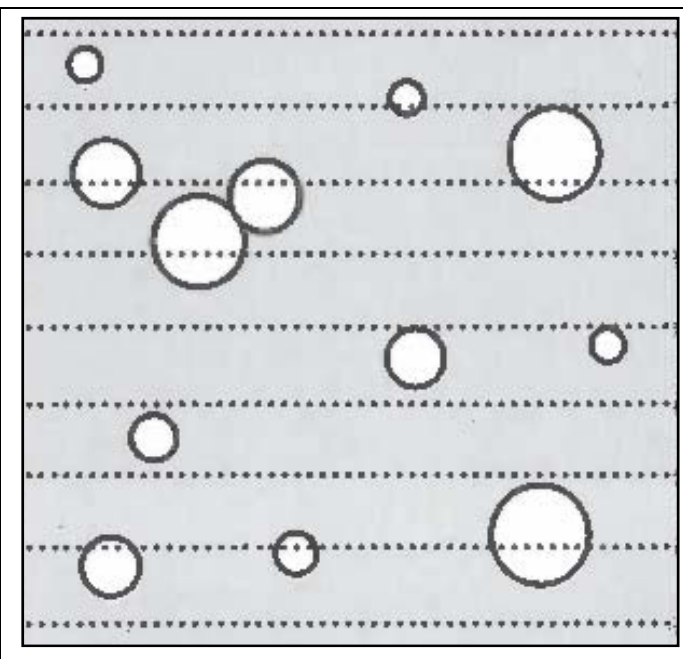

a) Procedure A - Linear Traverse

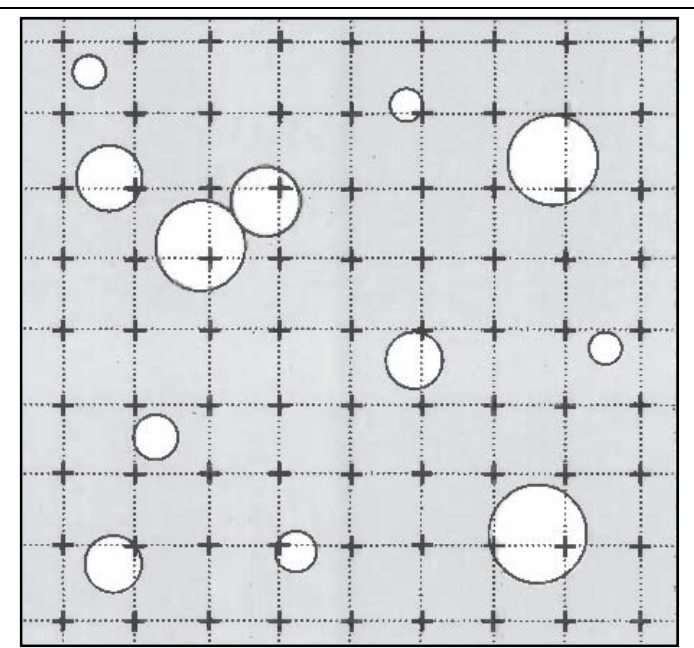

b) Procedure B- Modified Point Count

Figure 25. Comparison of ASTM C457 Procedures (Lamond and Pielert 2006).

the length of the series of depressions. The voids are assumed to be spherical for both entrained and entrapped air. These measured chord length values are manipulated in additional calculations and used in determining the other air void structure parameters. The total length of the rows traversed depends on the maximum aggregate size used for the concrete. Procedure B, the modified point-count method, uses a superimposed grid and tallies the batched component items seen at the grid intersections (air void, aggregate, paste). Typical grid spacing of 0.025 to 0.2 inches are used where the number of points counted depends on the maximum aggregate size of the sample. This method shortcuts some of the work completed in Procedure A because the chord lengths of the voids are not tracked: only the number of depression points per parallel row traversed is calculated. The values calculated by each method are "theoretically equivalent" to one another at this point and further calculations on the air void structure properties are similar (St. John, Poole, and Sims 1998; Lamond and Pielert 2006).

Table 9 detailed the descriptive statistics for the twenty samples retested by ASTM C457-B. The observed surfaces of the samples were not reground before observation and were assumed to be equivalent to the surface used for Procedure A since measurements were made within the boxed areas from the earlier testing. The measurements taken by the Procedure B method show that additional air was counted compared to the Procedure A method. About 2 percent more air on average was observed with Procedure $\mathrm{B}$ and the minimum and maximum values were greater than those 
measured with Procedure A. The skewness coefficient shows the Procedure B data are much more centered about the mean than the Procedure A results and are within range of the other ASTM field testing methods considered. The Procedure B results were also twice as variable as the Procedure A results.

Table 11 shows the results of the bivariate analysis on the data collected for total air content by each testing method utilized in this study. The statistical testing completed to compare the results of two tests was a hypothesis testing using student-t test. The student-t distribution was selected over a normal $(Z)$ distribution because of the ASTM C457-B small sample size. The majority of the data collected used at least 59 samples, whereas the ASTM C457-B test had only 20 samples. Typically when 30 to 40 samples are used in a statistical analysis like this, the data are believed to be large enough to be normally distributed by the law of large numbers. Large sample sizes show similar results when calculating the student-t and normal statistic. However when the ASTM C457-B data are considered, the pooled degrees of freedom (based on the number of samples from each group) is significantly reduced to the point where the calculated student- $t$ and normal statistic will be different. Using the student-t distribution was the most appropriate method to ensure accuracy with all the results.

Table 11. Statistical testing by testing method.

\begin{tabular}{|c|c|c|c|c|c|c|c|}
\hline \multicolumn{2}{|c|}{ Comparison by Testing Method } & \multirow{2}{*}{$\begin{array}{l}\text { Difference } \\
\text { in Means }\end{array}$} & \multirow{2}{*}{$\begin{array}{l}\text { Pooled } \\
\text { Standard } \\
\text { Deviation }\end{array}$} & \multicolumn{3}{|c|}{ Statistical Testing } & \multirow{2}{*}{$\begin{array}{l}\text { Significantly } \\
\text { Different } \\
\text { Results } \\
\text { Obtained? }\end{array}$} \\
\hline Group 1 & Group 2 & & & t-value & $d_{f}$ & P-value & \\
\hline ASTM C173 & ASTM C231 & 0.21 & 2.73 & 0.43 & 116.9 & 0.670 & No \\
\hline ASTM C173 & ASTM C138 & 1.48 & 2.82 & 2.88 & 117.9 & $4.7 \cdot 10^{-3}$ & Yes \\
\hline ASTM C173 & ASTM C457-A & 1.84 & 2.20 & 4.58 & 79.5 & 0.000 & Yes \\
\hline ASTM C173 & ASTM C457-B & -0.27 & 2.69 & -0.46 & 45.3 & 0.648 & No \\
\hline ASTM C173 & $\begin{array}{l}\text { AVA, less than } \\
2 \mathrm{~mm}\end{array}$ & 1.44 & 2.52 & 3.12 & 108.6 & $2.3 \cdot 10^{-3}$ & Yes \\
\hline ASTM C173 & $\begin{array}{l}\text { AVA, less than } \\
1 \mathrm{~mm}\end{array}$ & 1.90 & 2.46 & 4.22 & 104.9 & $0.1 \cdot 10^{-3}$ & Yes \\
\hline ASTM C231 & ASTM C138 & 1.27 & 2.69 & 2.59 & 117.4 & 0.011 & Yes \\
\hline ASTM C231 & ASTM C457-A & 1.62 & 2.02 & 4.40 & 83.6 & 0.000 & Yes \\
\hline ASTM C231 & ASTM C457-B & -0.48 & 2.47 & -0.85 & 40.7 & 0.400 & No \\
\hline ASTM C231 & $\begin{array}{l}\text { AVA, less than } \\
2 \mathrm{~mm}\end{array}$ & 1.22 & 2.36 & 2.83 & 113.1 & $5.5 \cdot 10^{-3}$ & Yes \\
\hline
\end{tabular}




\begin{tabular}{|c|c|c|c|c|c|c|c|}
\hline \multicolumn{2}{|c|}{ Comparison by Testing Method } & \multirow[b]{2}{*}{$\begin{array}{l}\text { Difference } \\
\text { in Means }\end{array}$} & \multirow{2}{*}{$\begin{array}{l}\text { Pooled } \\
\text { Standard } \\
\text { Deviation }\end{array}$} & \multicolumn{3}{|c|}{ Statistical Testing } & \multirow{2}{*}{$\begin{array}{l}\text { Significantly } \\
\text { Different } \\
\text { Results } \\
\text { Obtained? }\end{array}$} \\
\hline Group 1 & Group 2 & & & t-value & $d_{f}$ & P-value & \\
\hline ASTM C231 & $\begin{array}{l}\text { AVA, less than } \\
1 \mathrm{~mm}\end{array}$ & 1.68 & 2.30 & 3.99 & 110.1 & $0.1 \cdot 10^{-3}$ & Yes \\
\hline ASTM C138 & ASTM C457-A & 0.35 & 2.15 & 0.89 & 80.5 & 0.374 & No \\
\hline ASTM C138 & ASTM C457-B & -1.76 & 2.63 & -3.01 & 44.0 & $4.4 \cdot 10^{-3}$ & Yes \\
\hline ASTM C138 & $\begin{array}{l}\text { AVA, less than } \\
2 \mathrm{~mm}\end{array}$ & -0.05 & 2.47 & -0.10 & 109.9 & 0.917 & No \\
\hline ASTM C138 & $\begin{array}{l}\text { AVA, less than } \\
1 \mathrm{~mm}\end{array}$ & 0.41 & 2.42 & 0.93 & 106.4 & 0.354 & No \\
\hline ASTM C457-A & ASTM C457-B & -2.11 & 1.46 & -4.33 & 23.5 & $0.2 \cdot 10^{-3}$ & Yes \\
\hline ASTM C457-A & $\begin{array}{l}\text { AVA, less than } \\
2 \mathrm{~mm}\end{array}$ & -0.40 & 1.72 & -1.26 & 92.1 & 0.211 & No \\
\hline ASTM C457-A & $\begin{array}{l}\text { AVA, less than } \\
1 \mathrm{~mm}\end{array}$ & 0.06 & 1.63 & 0.20 & 96.0 & 0.840 & No \\
\hline ASTM C457-B & $\begin{array}{l}\text { AVA, less than } \\
2 \mathrm{~mm}\end{array}$ & 1.71 & 2.10 & 3.19 & 33.5 & $3.1 \cdot 10^{-3}$ & Yes \\
\hline ASTM C457-B & $\begin{array}{l}\text { AVA, less than } \\
1 \mathrm{~mm}\end{array}$ & 2.17 & 1.99 & 4.11 & 31.6 & $0.3 \cdot 10^{-3}$ & Yes \\
\hline $\begin{array}{l}\text { AVA, less than } \\
2 \mathrm{~mm}\end{array}$ & $\begin{array}{l}\text { AVA, less than } \\
1 \mathrm{~mm}\end{array}$ & 0.46 & 2.04 & 115.5 & 1.22 & 0.225 & No \\
\hline
\end{tabular}

The results of the bivariate analysis confirm that the ASTM C457-A results are not similar to those collected by the ASTM C231 and C173. Comparison of ASTM C457-A results against the ASTM C138 results shows both of these tests yielded lower air contents than the other ASTM fresh property tests measured and show no significant difference between one another; however, these results can be deceiving. The Q-Q plot constructed shows no real trend in the data (Figure 26) where lower values from the ASTM $\mathrm{C} 138$ testing correspond to higher ASTM C457-A values and vice versa. Care should also be taken when comparing data against the ASTM C138 data, since the value reported is calculated mathematically instead of by a direct measurement. The very low and negative total air contents reported for ASTM C138 are obviously unrealistic. They are the result of measuring a lower unit weight from a sample taken or calculating a higher unit weight using the weight of each material batched and calculated air-free volume using the measured bulk specific gravities. 


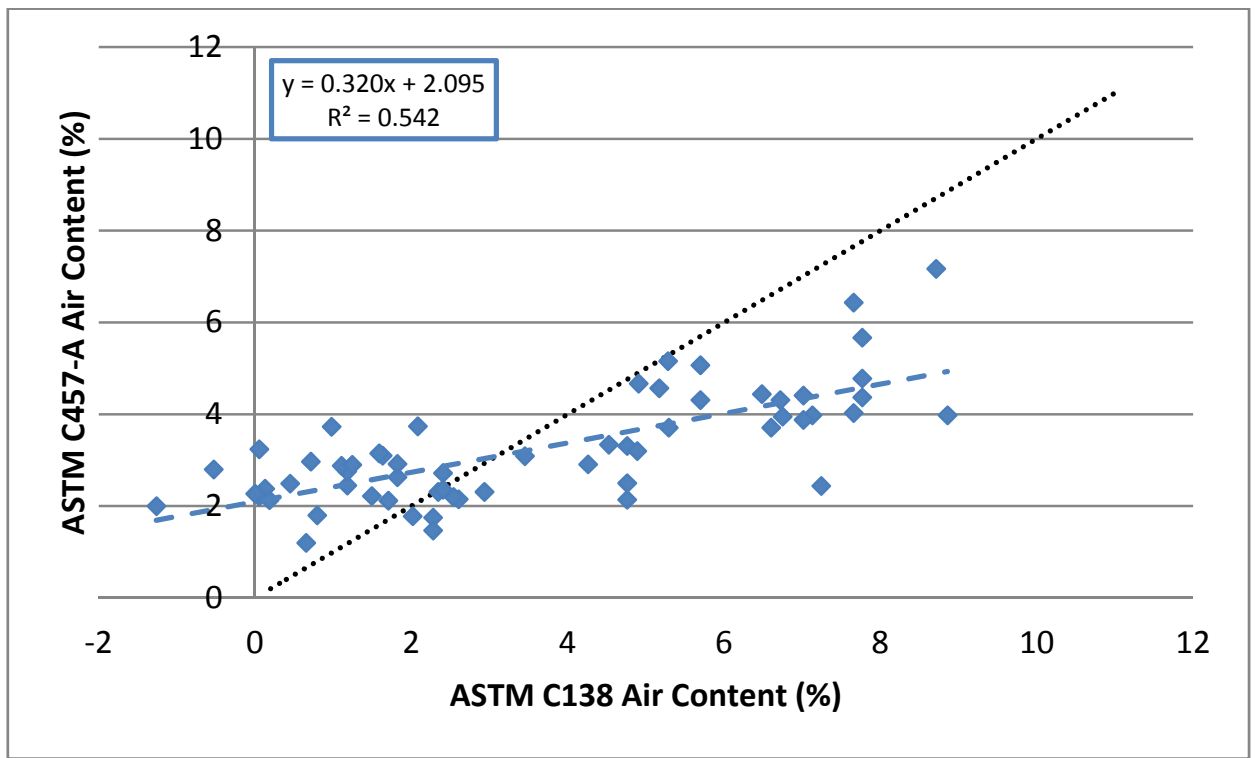

Figure 26. Q-Q plot comparing ASTM C457-A and ASTM C138 results.

Most surprising was the stark difference between the ASTM C457-A and B procedure results. The results show 19 of the 20 samples had larger procedure B measurements than procedure A, yielding a 2 percent difference in the mean air content overall (Figure 27a). Additional statistical testing completed on the specific surface and spacing factor data also showed the reported results are significantly different between the two procedures. Figures $27 \mathrm{~b}$ and $27 \mathrm{c}$ suggest that smaller voids were counted in the procedure $B$ testing than the procedure A since these values are most affected by smaller voids; however, this cannot be verified since procedure B counts only the observations under the microscope at grid line intersections and does not make any measurement on the voids encountered as procedure $\mathrm{A}$ does. The B procedure results better resemble the ASTM C173 and C231 results (Figure 28) collected in this study and shown by Ozyildirim (1991). Further collection of the B procedure results from the samples constructed for this study is expected to show better correlation with the fresh sampling tests compared to the A procedure results.

Further review of the petrographer's ASTM C457 test results showed the microscope magnification used to view the sample was different when completing each test. The petrographer used $80 \times$ when completing the A procedure results and used $70 \times$ for the $B$ procedure results. Both magnification levels are within the allowable $50 \times$ to $125 \times$ range given in ASTM C457, but working at higher magnifications requires considerable care in surface preparation. Hover summarizes multiple studies where the level of magnification influenced the results obtained (Lamond and Pielert 2006). Higher 

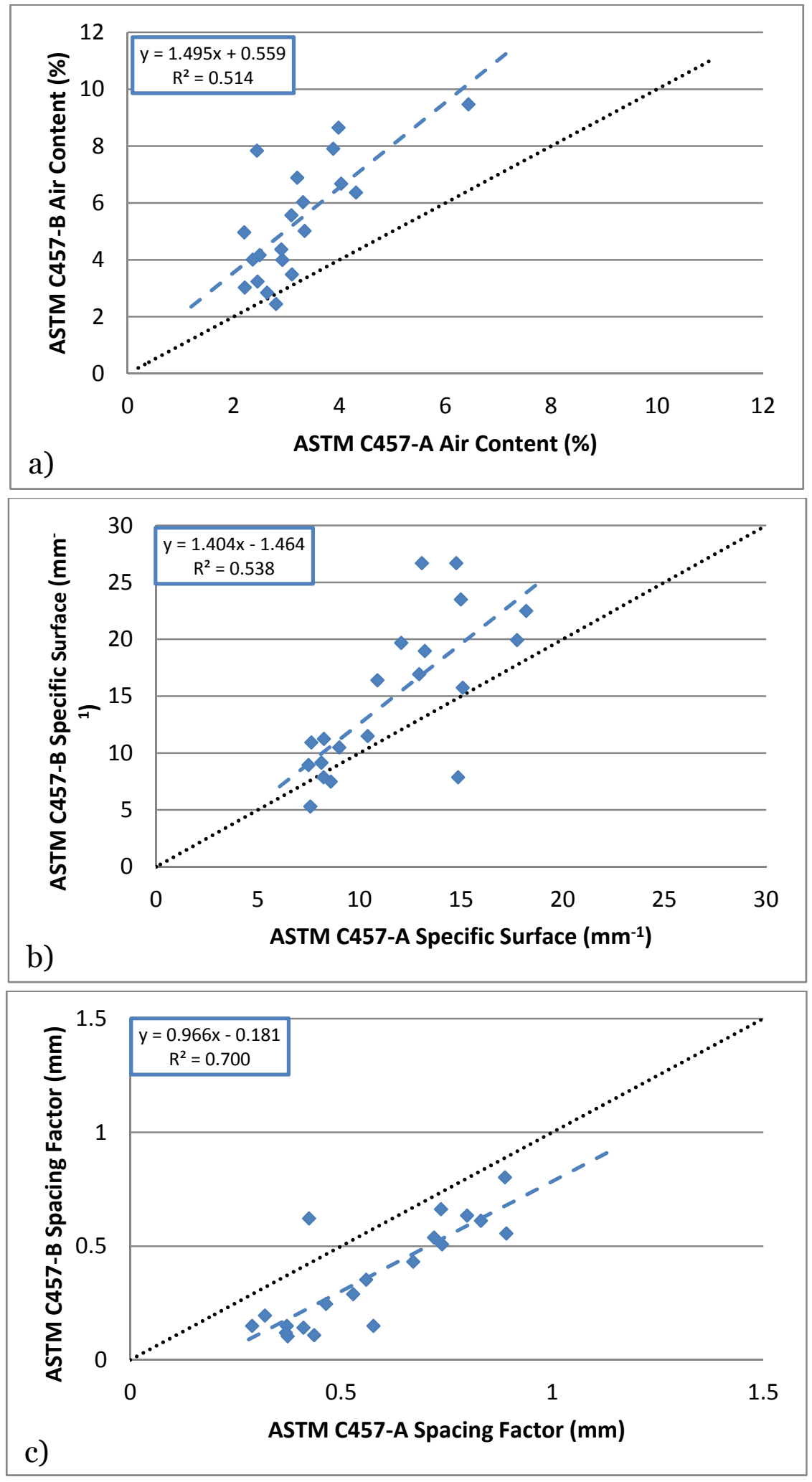

Figure 27. Q-Q plot comparing ASTM C457 Procedure A and B air void structure results. 


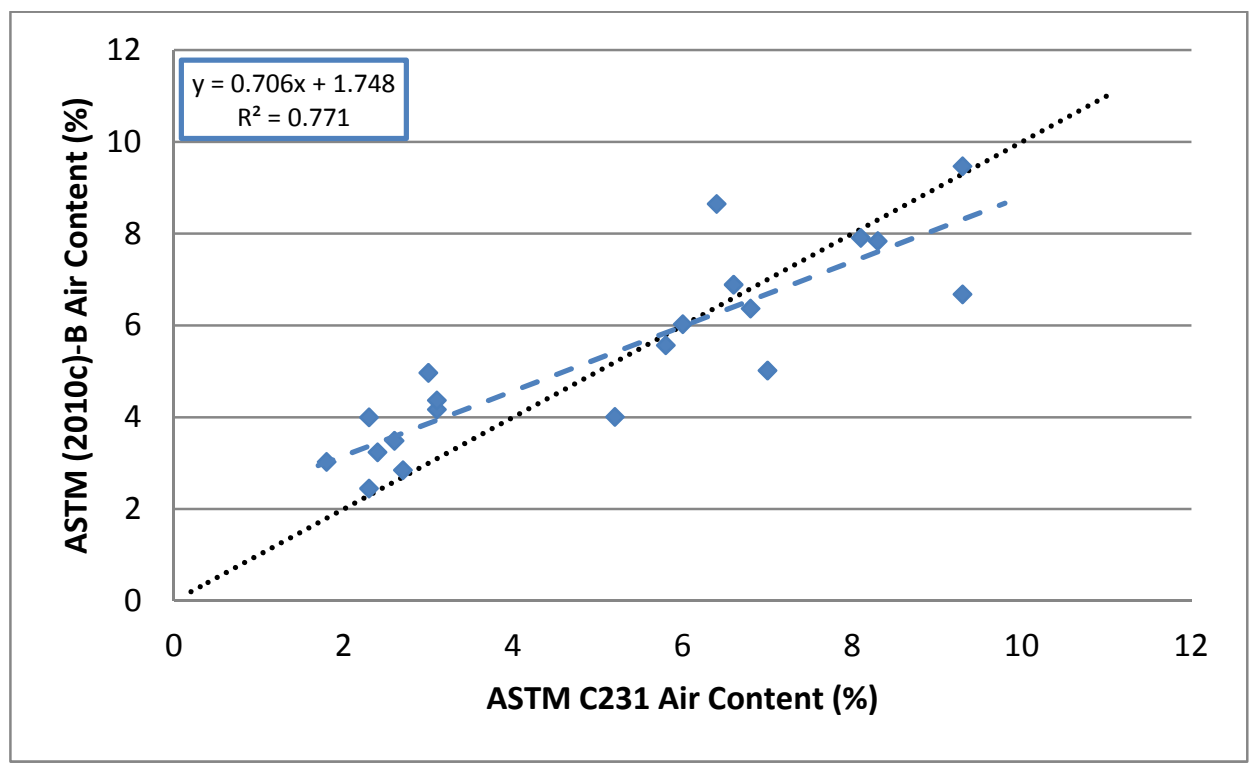

Figure 28. Q-Q plot comparing ASTM C457-B and C231 results.

magnifications are desirable because smaller air voids can be seen, and the results become more accurate with respect to specific surface and spacing factor values. However, samples must be ground smoother to ensure the finished surface texture of a sample is not misinterpreted and leads the observer to count fictitious voids. Even though Hover's summary details much more drastic differences in magnification power than seen in this study, 80 $\times$ compared to $10 \times$ (Lamond and Pielert 2006), the fact that significantly more air was counted at lower magnification suggests the sample was not completely prepared for analysis and more grinding was needed for examination at the slightly higher magnification.

\section{Quantitative error calculations}

The second phase of the analysis placed a quantitative value on the accuracy and precision of the different testing methods. Percent error calculations were completed on the measurements taken for comparison to one another. Tables 12 and 13 detail the error calculation values for each mixture produced. The accepted reference value used for the accuracy error calculations was the reported ASTM C457-A values. The calculated error was averaged from the individual values collected for each sample tested. Values for the ASTM C457-B testing were not completed because of the limited amount of data available for all mixture designs considered, even though the data appear to be more representative of the concrete. 
Table 12. Accuracy error calculations made.

\begin{tabular}{|c|c|c|c|c|c|c|c|c|c|c|c|c|c|c|c|c|c|}
\hline \multirow{2}{*}{\multicolumn{2}{|c|}{$\begin{array}{l}\text { Results } \\
\text { Mixture }\end{array}$}} & \multicolumn{12}{|c|}{ By Mixture Design Used } & \multicolumn{3}{|c|}{$\begin{array}{l}\text { Use of Fly Ash, } \\
\text { by Weight Replacement }\end{array}$} & \multirow[b]{3}{*}{ All (\%) } \\
\hline & & 1 & 2 & 3 & 4 & 5 & 6 & 7 & 8 & 9 & 10 & 11 & 12 & \multirow[b]{2}{*}{$0 \%$} & \multirow[b]{2}{*}{$10 \%$} & \multirow[b]{2}{*}{$20 \%$} & \\
\hline Design & otal Air Content (\%) & 3 & 4 & 6 & 8 & 3 & 4 & 6 & 8 & 3 & 4 & 6 & 8 & & & & \\
\hline \multicolumn{18}{|c|}{ With ASTM C457-A as reference value } \\
\hline \multicolumn{2}{|c|}{ ASTM C173 Total Air (\%) } & 11.9 & 35.4 & 94.8 & 103.9 & 28.2 & 22.2 & 62.0 & 111.1 & 24.4 & 16.1 & 110.6 & 124.4 & 61.5 & 55.9 & 68.9 & 62.1 \\
\hline \multicolumn{2}{|c|}{ ASTM C231 Total Air (\%) } & 9.7 & 50.0 & 104.6 & 110.3 & 25.2 & 18.7 & 48.8 & 91.4 & 22.4 & 14.5 & 100.1 & 93.1 & 68.6 & 46.0 & 57.6 & 57.4 \\
\hline \multicolumn{2}{|c|}{ ASTM C138 Total Air (\%) } & 27.1 & 29.3 & 54.1 & 86.0 & 53.8 & 93.6 & 37.0 & 57.5 & 73.4 & 76.1 & 24.5 & 61.9 & 49.1 & 60.5 & 59.0 & 56.2 \\
\hline \multirow{3}{*}{$\begin{array}{l}\text { AVA - } \\
<2 \mathrm{~mm}\end{array}$} & Total Air (\%) & 34.2 & 45.6 & 59.7 & 65.7 & 26.3 & 53.6 & 13.6 & 27.4 & 49.4 & 31.6 & 44.6 & 51.5 & 51.3 & 30.2 & 44.3 & 41.9 \\
\hline & Specific Surface $\left(\mathrm{mm}^{-1}\right)$ & 115.0 & 115.7 & 41.6 & 63.0 & 18.2 & 17.0 & 37.9 & 103.6 & 25.9 & 357.5 & 111.5 & 113.8 & 83.8 & 44.2 & 152.2 & 93.4 \\
\hline & Spacing Factor (mm) & 57.8 & 45.5 & 41.8 & 58.0 & 18.5 & 26.4 & 34.2 & 59.2 & 11.4 & 83.0 & 59.4 & 62.8 & 50.8 & 34.6 & 54.1 & 46.5 \\
\hline \multirow{3}{*}{$\begin{array}{l}\text { AVA - } \\
<1 \mathrm{~mm}\end{array}$} & Total Air (\%) & 48.9 & 39.4 & 42.3 & 43.8 & 40.5 & 64.1 & 9.2 & 17.1 & 60.7 & 26.9 & 30.6 & 39.4 & 43.6 & 32.7 & 39.4 & 38.6 \\
\hline & Specific Surface $\left(\mathrm{mm}^{-1}\right)$ & 135.1 & 123.5 & 60.7 & 81.9 & 38.8 & 28.6 & 48.3 & 121.8 & 42.2 & 394.1 & 132.1 & 130.0 & 100.3 & 59.4 & 174.6 & 111.4 \\
\hline & Spacing Factor (mm) & 53.3 & 47.3 & 45.0 & 57.3 & 19.1 & 23.7 & 36.3 & 59.5 & 8.1 & 83.9 & 61.3 & 63.7 & 50.7 & 34.6 & 54.2 & 46.5 \\
\hline
\end{tabular}


Table 13. Precision error calculations made.

\begin{tabular}{|c|c|c|c|c|c|c|c|c|c|c|c|c|c|c|c|c|c|}
\hline \multirow{2}{*}{\multicolumn{2}{|c|}{\begin{tabular}{|l|} 
Results \\
Mixture
\end{tabular}}} & \multicolumn{12}{|c|}{ By Mixture Design } & \multicolumn{3}{|c|}{$\begin{array}{l}\text { Use of Fly Ash, } \\
\text { by Weight Replacement }\end{array}$} & \multirow[b]{3}{*}{ All, $\%$} \\
\hline & & 1 & 2 & 3 & 4 & 5 & 6 & 7 & 8 & 9 & 10 & 11 & 12 & & & & \\
\hline \multicolumn{2}{|c|}{ Design Total Air Content, \% } & 3 & 4 & 6 & 8 & 3 & 4 & 6 & 8 & 3 & 4 & 6 & 8 & $0 \%$ & $10 \%$ & $20 \%$ & \\
\hline \multicolumn{2}{|c|}{ ASTM C173 Total Air, \% } & 12.9 & 6.7 & 1.7 & 5.2 & 6.5 & 19.5 & 7.7 & 5.4 & 3.3 & 6.7 & 17.4 & 12.2 & 6.6 & 9.8 & 9.9 & 8.8 \\
\hline \multicolumn{2}{|c|}{ ASTM C231 Total Air, \% } & 12.4 & 7.6 & 2.1 & 3.8 & 4.6 & 19.1 & 7.8 & 4.8 & 7.1 & 8.6 & 13.0 & 6.5 & 6.5 & 9.1 & 8.8 & 8.1 \\
\hline \multicolumn{2}{|c|}{ ASTM C138 Total Air, \% } & 12.7 & 13.8 & 10.0 & 5.1 & 47.8 & 265.8 & 18.4 & 7.3 & 112.6 & 44.6 & 26.3 & 9.6 & 10.4 & 84.8 & 48.3 & 47.8 \\
\hline \multirow{3}{*}{$\begin{array}{l}\text { ASTM } \\
\text { C457-A }\end{array}$} & Total Air, \% & 16.9 & 13.8 & 24.6 & 17.4 & 19.1 & 17.3 & 6.6 & 27.4 & 20.7 & 15.0 & 11.6 & 9.0 & 18.2 & 17.6 & 14.1 & 16.6 \\
\hline & Specific Surface, $\mathrm{mm}^{-1}$ & 8.1 & 2.4 & 1.1 & 3.3 & 1.9 & 5.5 & 4.1 & 3.2 & 2.2 & 2.3 & 4.6 & 3.1 & 3.7 & 3.7 & 3.1 & 3.5 \\
\hline & Spacing Factor, mm & 7.2 & 9.2 & 10.2 & 14.6 & 15.2 & 3.6 & 8.3 & 29.6 & 4.6 & 11.9 & 16.4 & 13.3 & 10.3 & 14.2 & 11.6 & 12.0 \\
\hline \multirow{3}{*}{$\begin{array}{l}\text { AVA - } \\
<2 \mathrm{~mm}\end{array}$} & Total Air, \% & 29.8 & 45.9 & 4.3 & 4.1 & 9.6 & 36.5 & 9.0 & 18.3 & 6.2 & 17.6 & 23.0 & 14.2 & 21.1 & 18.4 & 15.2 & 18.2 \\
\hline & Specific Surface, $\mathrm{mm}^{-1}$ & 65.5 & 41.9 & 3.3 & 7.5 & 5.4 & 10.4 & 3.8 & 14.0 & 11.0 & 30.6 & 15.7 & 16.9 & 29.6 & 8.4 & 18.5 & 18.8 \\
\hline & Spacing Factor, mm & 48.9 & 46.9 & 3.8 & 10.5 & 2.5 & 14.9 & 2.8 & 14.0 & 9.5 & 19.8 & 25.6 & 34.6 & 27.5 & 8.6 & 22.4 & 19.5 \\
\hline \multirow{3}{*}{$\begin{array}{l}\text { AVA - } \\
<1 \mathrm{~mm}\end{array}$} & Total Air, \% & 43.0 & 44.4 & 5.3 & 4.7 & 6.0 & 36.3 & 9.7 & 16.8 & 4.3 & 22.4 & 25.0 & 16.1 & 24.3 & 17.2 & 16.9 & 19.5 \\
\hline & Specific Surface, $\mathrm{mm}^{-1}$ & 61.5 & 59.2 & 3.3 & 6.8 & 3.8 & 10.4 & 3.1 & 13.4 & 7.7 & 28.9 & 15.6 & 15.7 & 32.7 & 7.7 & 17.0 & 19.1 \\
\hline & Spacing Factor, mm & 48.5 & 47.4 & 3.3 & 10.3 & 2.5 & 16.0 & 2.2 & 12.7 & 8.2 & 17.7 & 25.6 & 32.5 & 27.4 & 8.3 & 21.0 & 18.9 \\
\hline
\end{tabular}


The accuracy error results show interesting trends. The accuracy error of all the tests compared to the ASTM C457-A results is very poor overall and especially when the amount of fly ash included in the mixture is considered. However, the accuracy error of the individual mixture designs show that the error increases as the entrained air increases in the mixtures for the ASTM $\mathrm{C} 173$ and $\mathrm{C} 231$. This trend supports the observation made in the previous section where the ASTM C457-A tests showed less entrained air overall. The results for the other test methods and measurements vary and show no real pattern. The precision error results are scattered as well, but were lower and more consistent between the different tests than seen with the accuracy error. This indicates the results of the majority of the testing are reproducible between samples taken.

The selection of the accepted reference value in the accuracy error calculations is the largest factor responsible for the poor results and the large error values calculated. Using the ASTM C457-A results for this value in the calculations may not be correct since the validity of these results was previously questioned. However, the ASTM C457 values are the best candidate for this role because all three air void parameters are available. The procedure B measurements taken for this investigation appear to be much more accurate and could be used in place of the procedure A values; however, limited data are available to come to an accurate conclusion.

\section{Quantile-Quantile plots}

Multiple Q-Q plots were made to show the correlation of the various testing results. Because of the number of plots made, the information given in the calculated regression equations is reported in Tables 14 and 15. When comparing two separate test methods, accuracy was judged by having the majority of the values within 15 percent of each other and precision by having regression equations correlate within 85 percent of each other. The value of 15 percent was selected for the accuracy threshold after determining that the first Q-Q plot yielded over 90 percent of its points within the area selected. This value was held constant over all air void parameters for simplicity. Figure 29 details the count process used to generate the numbers in Table 15. Additional threshold values are shown for comparison and justification. A value of 85 percent was chosen somewhat arbitrarily for the precision threshold because literature describes no commonly accepted value to select. A higher value than typically accepted should be chosen, since the smaller scale laboratory mixtures will be more consistent from batch to batch than field produced mixtures will. 
Table 14. Q-Q plot regression equation analysis values.

\begin{tabular}{|c|c|c|c|c|c|c|c|}
\hline \multicolumn{2}{|c|}{ Comparison of Tests } & \multirow[b]{2}{*}{ Slope } & \multirow[b]{2}{*}{ Intercept } & \multirow[b]{2}{*}{$R^{2}$} & \multirow[b]{2}{*}{$R$} & \multirow[b]{2}{*}{ Accurate? } & \multirow[b]{2}{*}{ Precise? } \\
\hline$X$-axis & $Y$-axis & & & & & & \\
\hline \multicolumn{8}{|c|}{ Air Content } \\
\hline C173 & C231 & 0.886 & 0.365 & 0.958 & 0.979 & Y & $Y$ \\
\hline C173 & C138 & 0.886 & -0.908 & 0.830 & 0.911 & $\mathrm{~N}$ & $Y$ \\
\hline C231 & C138 & 1.003 & -1.293 & 0.873 & 0.934 & $\mathrm{~N}$ & $Y$ \\
\hline C173 & C457-A & 0.305 & 1.693 & 0.521 & 0.721 & $\mathrm{~N}$ & $\mathrm{~N}$ \\
\hline C231 & C457-A & 0.346 & 1.562 & 0.547 & 0.740 & $\mathrm{~N}$ & N \\
\hline C138 & C457-A & 0.320 & 2.910 & 0.542 & 0.736 & $\mathrm{~N}$ & N \\
\hline C138 & C457-B & 0.672 & 2.851 & 0.883 & 0.940 & $\mathrm{~N}$ & $Y$ \\
\hline C173 & C457-B & 0.596 & 2.141 & 0.743 & 0.862 & $\mathrm{~N}$ & $Y$ \\
\hline C231 & C457-B & 0.706 & 1.748 & 0.771 & 0.878 & $\mathrm{~N}$ & $Y$ \\
\hline C457-A & C457-B & 1.495 & 0.559 & 0.514 & 0.717 & N & N \\
\hline C138 & $\mathrm{AVA},<2 \mathrm{~mm}$ & 0.663 & 1.249 & 0.775 & 0.880 & $\mathrm{~N}$ & $Y$ \\
\hline C173 & AVA, $<2 \mathrm{~mm}$ & 0.682 & 0.150 & 0.856 & 0.925 & $\mathrm{~N}$ & $Y$ \\
\hline C231 & $\mathrm{AVA},<2 \mathrm{~mm}$ & 0.761 & -0.086 & 0.879 & 0.938 & $\mathrm{~N}$ & $Y$ \\
\hline C457-A & $\mathrm{AVA},<2 \mathrm{~mm}$ & 1.273 & -0.510 & 0.535 & 0.731 & $\mathrm{~N}$ & N \\
\hline C457-B & $\mathrm{AVA},<2 \mathrm{~mm}$ & 0.897 & -0.877 & 0.779 & 0.883 & $\mathrm{~N}$ & Y \\
\hline C138 & $\mathrm{AVA},<1 \mathrm{~mm}$ & 0.611 & 0.979 & 0.754 & 0.868 & $\mathrm{~N}$ & $Y$ \\
\hline C173 & $\mathrm{AVA},<1 \mathrm{~mm}$ & 0.641 & -0.098 & 0.866 & 0.931 & $\mathrm{~N}$ & $Y$ \\
\hline C231 & $\mathrm{AVA},<1 \mathrm{~mm}$ & 0.707 & -0.280 & 0.870 & 0.933 & $\mathrm{~N}$ & $Y$ \\
\hline C457-A & $\mathrm{AVA},<1 \mathrm{~mm}$ & 1.186 & -0.684 & 0.531 & 0.729 & $\mathrm{~N}$ & $N$ \\
\hline C457-B & $\mathrm{AVA},<1 \mathrm{~mm}$ & 0.818 & -0.928 & 0.734 & 0.857 & $\mathrm{~N}$ & $Y$ \\
\hline \multicolumn{8}{|c|}{ Specific Surface } \\
\hline C457-A & C457-B & 1.404 & -1.464 & 0.538 & 0.733 & $\mathrm{~N}$ & N \\
\hline C457-A & $\mathrm{AVA},<2 \mathrm{~mm}$ & 1.381 & 4.806 & 0.148 & 0.385 & $\mathrm{~N}$ & $\mathrm{~N}$ \\
\hline C457-B & $\mathrm{AVA},<2 \mathrm{~mm}$ & 0.669 & 11.952 & 0.091 & 0.302 & $\mathrm{~N}$ & $N$ \\
\hline C457-A & $\mathrm{AVA},<1 \mathrm{~mm}$ & 1.332 & 7.725 & 0.126 & 0.355 & $\mathrm{~N}$ & N \\
\hline C457-B & $\mathrm{AVA},<1 \mathrm{~mm}$ & 0.684 & 13.907 & 0.091 & 0.302 & $\mathrm{~N}$ & N \\
\hline \multicolumn{8}{|c|}{ Spacing Factor } \\
\hline C457-A & C457-B & 0.966 & -0.181 & 0.700 & 0.837 & $\mathrm{~N}$ & N \\
\hline C457-A & $\mathrm{AVA},<2 \mathrm{~mm}$ & 1.152 & -0.246 & 0.459 & 0.677 & $\mathrm{~N}$ & N \\
\hline C457-B & $\mathrm{AVA},<2 \mathrm{~mm}$ & 1.429 & -0.037 & 0.405 & 0.636 & $\mathrm{~N}$ & $N$ \\
\hline C457-A & $\mathrm{AVA},<1 \mathrm{~mm}$ & 1.110 & -0.235 & 0.465 & 0.682 & $\mathrm{~N}$ & N \\
\hline C457-B & $\mathrm{AVA},<1 \mathrm{~mm}$ & 1.362 & -0.034 & 0.423 & 0.650 & $\mathrm{~N}$ & $\mathrm{~N}$ \\
\hline
\end{tabular}


Table 15. Determination of appropriate error.

\begin{tabular}{|c|c|c|c|c|}
\hline \multicolumn{2}{|c|}{ Comparison of Tests } & \multicolumn{3}{|c|}{ Number of Points Within $\pm \_\%$ of Line of Equality, $\%$} \\
\hline $\mathrm{X}$ axis & Y axis & 10 & 15 & 20 \\
\hline \multicolumn{5}{|c|}{ Air Content } \\
\hline C173 & C231 & 76.7 & 90.0 & 98.3 \\
\hline C173 & C138 & 11.7 & 16.7 & 25.0 \\
\hline C231 & C138 & 5.0 & 21.7 & 31.7 \\
\hline C173 & C457-A & 13.3 & 23.3 & 25.0 \\
\hline C231 & C457-A & 20.0 & 23.3 & 30.0 \\
\hline $\mathrm{C} 138$ & C457-A & 8.3 & 16.7 & 21.7 \\
\hline C138 & C457-B & 15.0 & 30.0 & 30.0 \\
\hline C173 & C457-B & 30.0 & 45.0 & 50.0 \\
\hline C231 & C457-B & 45.0 & 45.0 & 45.0 \\
\hline C457-A & C457-B & 5.0 & 15.0 & 15.0 \\
\hline C138 & $\mathrm{AVA},<2 \mathrm{~mm}$ & 25.0 & 33.3 & 41.7 \\
\hline C173 & $\mathrm{AVA},<2 \mathrm{~mm}$ & 5.0 & 8.3 & 15.0 \\
\hline C231 & $\mathrm{AVA},<2 \mathrm{~mm}$ & 0.0 & 3.3 & 20.0 \\
\hline C457-A & AVA, $<2 \mathrm{~mm}$ & 11.7 & 18.6 & 20 \\
\hline C457-B & $\mathrm{AVA},<2 \mathrm{~mm}$ & 15.0 & 20.0 & 25.0 \\
\hline C138 & $\mathrm{AVA},<1 \mathrm{~mm}$ & 13.3 & 21.7 & 36.7 \\
\hline C173 & $\mathrm{AVA},<1 \mathrm{~mm}$ & 8.3 & 8.3 & 10.0 \\
\hline C231 & $\mathrm{AVA},<1 \mathrm{~mm}$ & 5.0 & 6.7 & 10.0 \\
\hline C457-A & AVA, $<1 \mathrm{~mm}$ & 20.0 & 27.1 & 36.7 \\
\hline C457-B & $\mathrm{AVA},<1 \mathrm{~mm}$ & 15.0 & 15.0 & 20.0 \\
\hline \multicolumn{5}{|c|}{ Specific Surface } \\
\hline C457-A & C457-B & 15.0 & 30.0 & 40.0 \\
\hline C457-A & AVA, $<2 \mathrm{~mm}$ & 13.6 & 18.6 & 22.0 \\
\hline C457-B & $\mathrm{AVA},<2 \mathrm{~mm}$ & 52.6 & 50.0 & 50 \\
\hline C457-A & $\mathrm{AVA},<1 \mathrm{~mm}$ & 5.1 & 5.1 & 10.1 \\
\hline C457-B & $\mathrm{AVA},<1 \mathrm{~mm}$ & 36.8 & 40.0 & 50 \\
\hline \multicolumn{5}{|c|}{ Spacing Factor } \\
\hline C457-A & C457-B & 10.0 & 10.0 & 15.0 \\
\hline C457-A & $\mathrm{AVA},<2 \mathrm{~mm}$ & 15.3 & 22.4 & 23.7 \\
\hline C457-B & $\mathrm{AVA},<2 \mathrm{~mm}$ & 5.3 & 15.0 & 20.0 \\
\hline C457-A & $\mathrm{AVA},<1 \mathrm{~mm}$ & 17.0 & 22.4 & 23.7 \\
\hline C457-B & $\mathrm{AVA},<1 \mathrm{~mm}$ & 10.5 & 10.0 & 20.0 \\
\hline
\end{tabular}




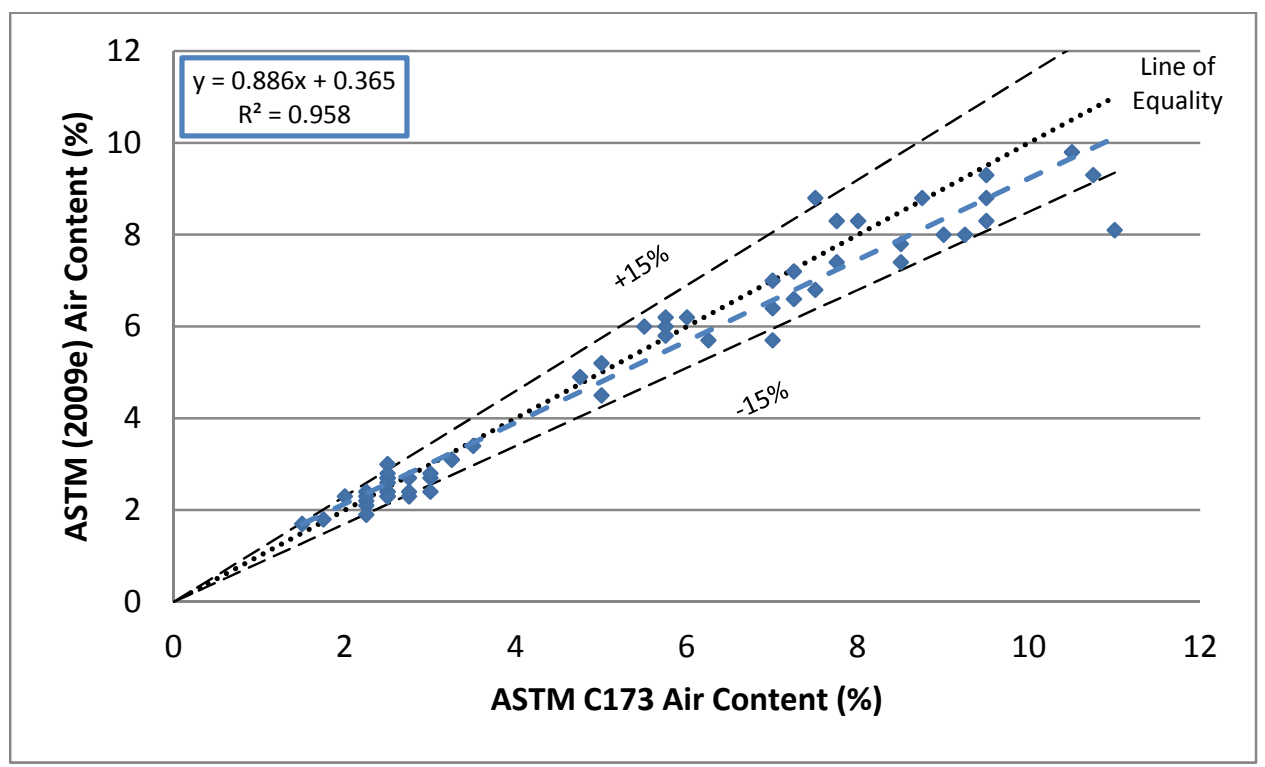

Figure 29. Accuracy point counting process.

Only the ASTM C173 and C231 results were shown to be accurate and precise when compared to one another. No additional testing comparisons showed the results were accurate for all air void parameters collected. The majority of the regression equation slopes were not close to 1 , indicating that equal results between the tests compared were not seen. All air content results except for those collected by ASTM C457-A were considered precise when compared to one another. This indicates a strong linear correlation between the testing values collected. Results that correlate well offer confidence that results of different test methods can be used interchangeably if the data are stable over a variety of mixture designs and material combinations. This needs to be investigated to ensure a consistent and measureable trend can be produced.

\section{AVA specific results}

Much of the information to this point has focused on the poor results obtained for the ASTM C457-A measurements and the data for all test methods conducted. This section details the AVA results specifically to ensure a discussion is provided.

\section{Bivariate analysis on testing methods}

The AVA data showed less total air had been measured than with the standard ASTM field tests. This concurs with previous reports. The lower reported total air content values for the AVA are expected, since the machine is designed to measure entrained air voids smaller than 0.12 in. 
in diameter, whereas the other tests can measure all sizes of air voids. The AVA data showing no significant statistical difference between the ASTM C457-A should not be relied on too heavily following the discussion of the sample preparation and ASTM C457-B results described earlier.

\section{Quantitative error calculations}

The AVA data appear to be fairly accurate for air content at first glance at the values shown in Table 12; however, the results compared to the majority of the other testing conducted have shown the results of the ASTM C457-A testing to be poor. The accuracy of the spacing factor results is on par with that of the air content. Previous reports stated that the spacing factor was the most accurate and the small difference between the AVA and ASTM $\mathrm{C} 457$ results is within the between-lab precision. The specific surface values are the most inaccurate of all the values determined. Not observing the smaller air voids in the ASTM C457-A results is believed to be the cause of this discrepancy as well as that seen in the spacing factor results. Magura (1996) showed the specific surface measurements taken by the AVA were higher than those measured by the ASTM (C457), but the differences were not significant (Crawford et al. 2003). The precision error between measurements taken is consistent with the $\mathrm{C} 457-\mathrm{A}$ results, but less consistent than the ASTM C173 and C231 results.

\section{Quantile-quantile plots}

Figures 30 and 31 show a complete series of Q-Q plots comparing the different ASTM testing and measurements completed. The trends for total air content described by others in previous studies are present in the data collected for this study. All plots made comparing the AVA values to other standard test methods for total air content alone were precise and not accurate, except for the ASTM C457-A comparisons. These results were neither accurate nor precise. Specific surface and spacing factor results for both ASTM C457 comparisons were also neither accurate nor precise. The limited ASTM C457-B data collected appear to best follow the trend described in previous reports compared to the AVA data recorded for total air. The specific surface values of both the ASTM C457 tests conducted are similar, except the regression line drawn is translated above previous reports because of the few larger AVA reported values collected. Further investigation into the larger AVA reported values showed a majority of the values larger than $40 \mathrm{~mm}^{-1}$ by the AVA came from mixture design 10 (Figure 32). The fresh property data collected after batching the concrete 

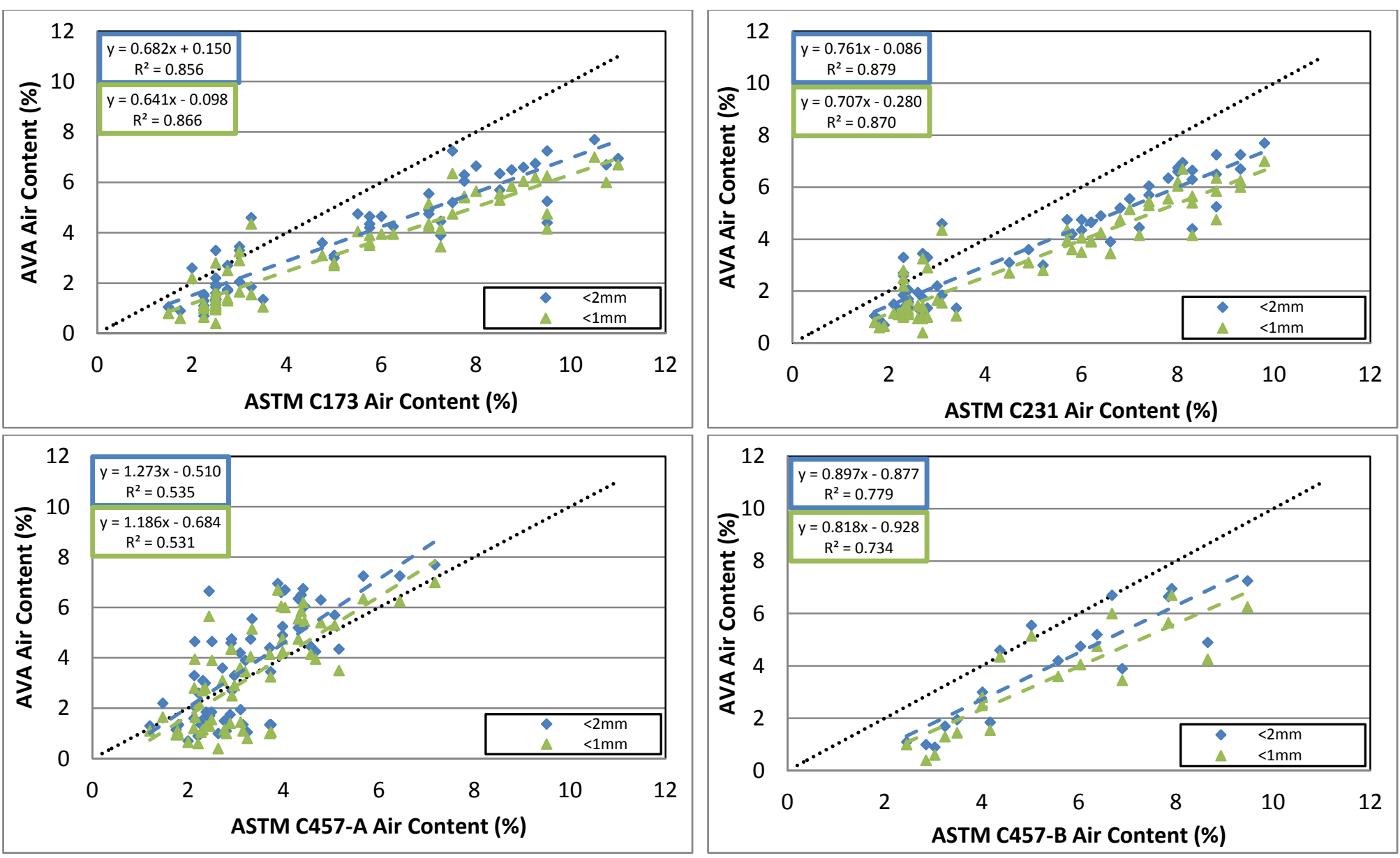

Figure 30. Q-Q plots made for comparison of ASTM air content tests against the AVA. 

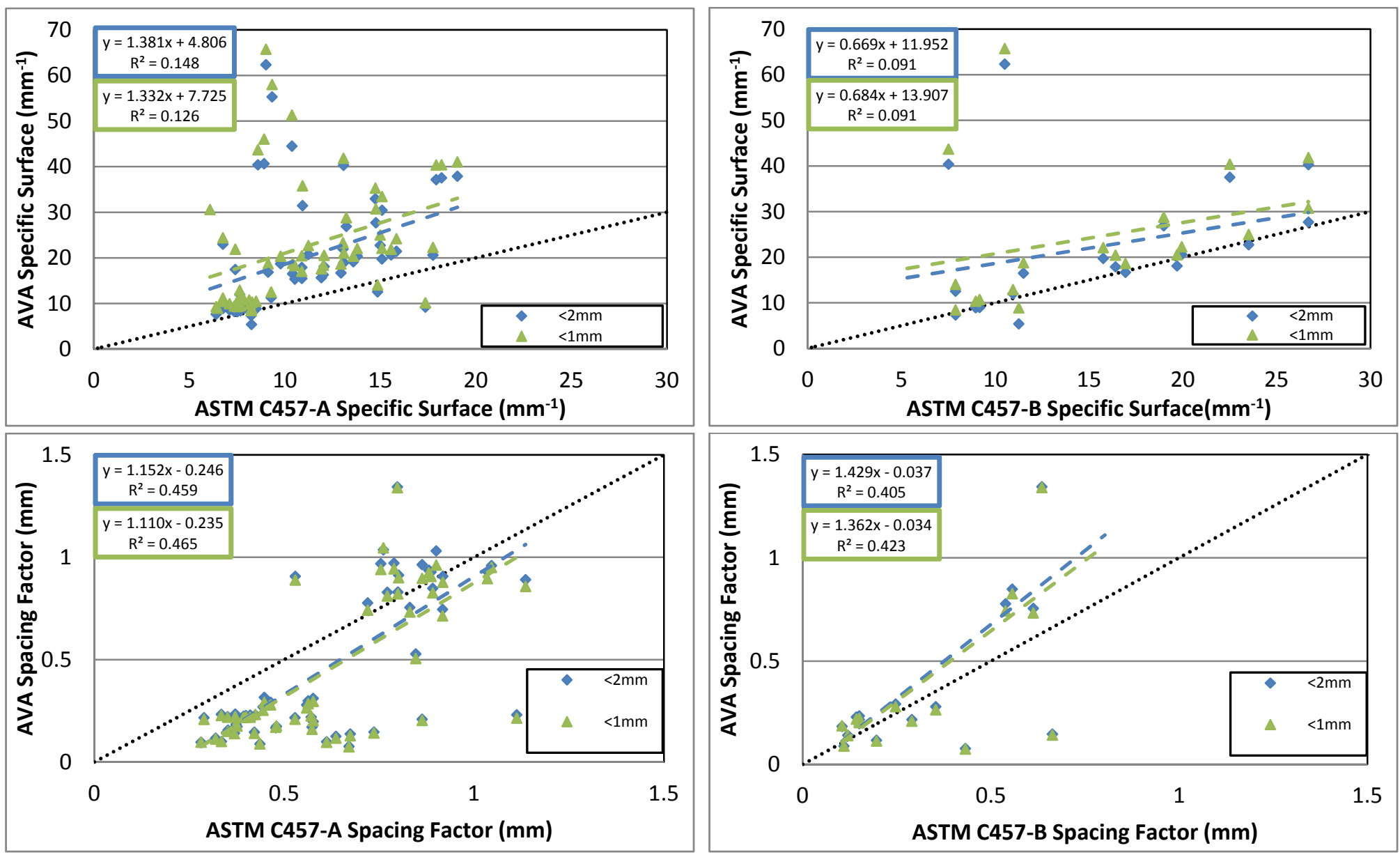

Figure 31. Comparison of additional ASTM C457 air void structure properties compared to AVA results. 


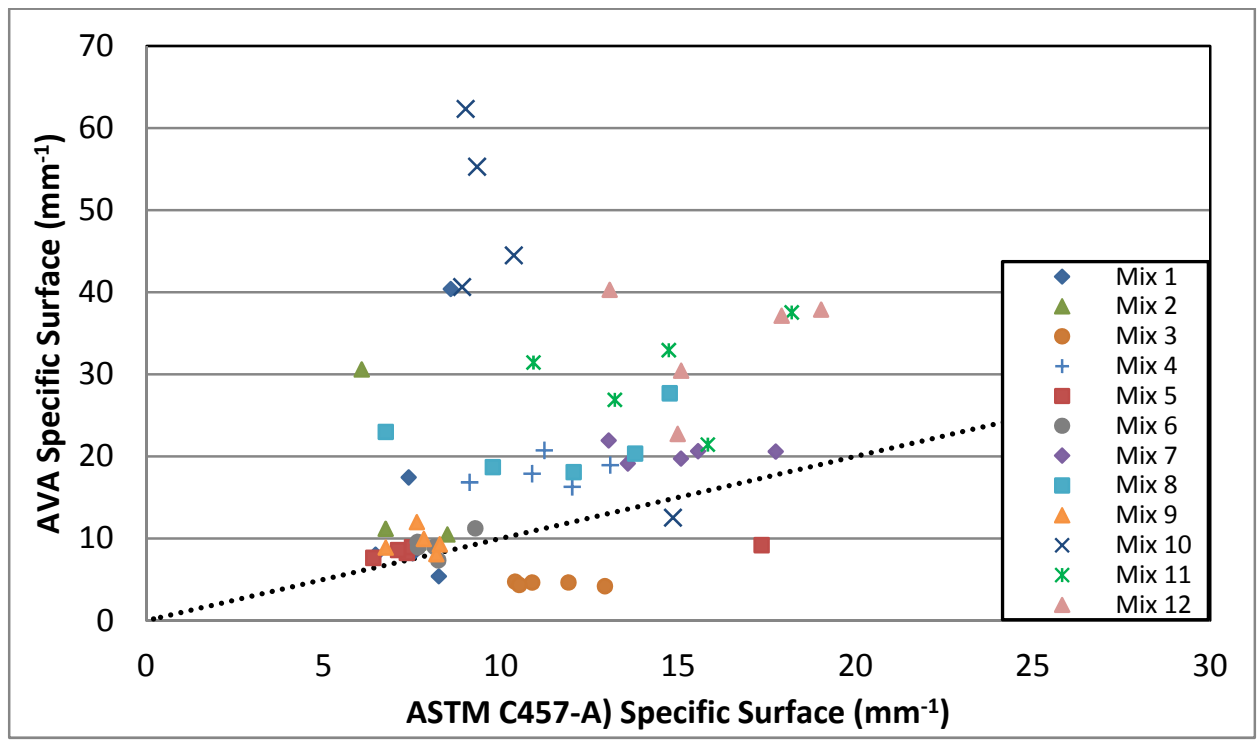

Figure 32. Breakdown of specific surface measurements by mixture design for AVA data of voids less than $2 \mathrm{~mm}$.

for these batches show the properties are consistent with the trial batching measurements. Closer inspection of these data points appears to show the specific surface values to be erroneous based on the lower air content and higher spacing factor values measured with the specific surface values. To achieve these specific surface values, a significant amount of smaller entrained air voids is needed. Since very little air entrainer was added to the mixture, this would not be possible with the materials used, and the material design best reflects the air content and spacing factor measured. Care should be taken when interpreting the spacing factor results based on the previous discussions about the ASTM C457 results; the results may be different if the samples are correctly prepared and viewed.

\section{Poor mixture identification}

The frost performance of all mixtures batched was measured to verify if the air void structure measurements taken from the AVA equipment truly reflect those seen in the concrete mixtures. Table 16 summarizes the ASTM C666-A (2008c) freeze-thaw deterioration testing completed for each mixture design made, and a complete listing of information can be found in Appendix A. The durability factor results presented are a calculated value that compares the change in dynamic modulus of tested specimens from an initial value. Periodic measurements were taken over successive freeze-thaw cycles until a value less than 60 percent of the original was achieved. The relative amount of dynamic modulus and fraction of cycles achieved to the maximum of 300 are used to compute the durability factor. 
Table 16. ASTM C666-A (2008c) testing data.

\begin{tabular}{|l|l|l|l|}
\hline \multirow{2}{*}{$\begin{array}{l}\text { Mixture } \\
\text { Design }\end{array}$} & \multirow{2}{*}{$\begin{array}{l}\text { Design Air } \\
\text { Content (\%) }\end{array}$} & \multicolumn{2}{|c|}{ Durability Factor } \\
\cline { 3 - 4 } & 3 & 2.1 & $\begin{array}{l}\text { Standard } \\
\text { Deviation }\end{array}$ \\
\hline 1 & 3 & 5.5 & 0.9 \\
\hline 2 & 4 & 49.0 & 5.3 \\
\hline 3 & 6 & 51.2 & 19.8 \\
\hline 4 & 8 & 2.3 & 0.5 \\
\hline 5 & 3 & 2.5 & 1.1 \\
\hline 6 & 4 & 29.1 & 24.5 \\
\hline 7 & 6 & 29.9 & 10.0 \\
\hline 8 & 8 & 1.9 & 0.2 \\
\hline 9 & 3 & 6.7 & 3.9 \\
\hline 10 & 4 & 31.1 & 16.3 \\
\hline 11 & 6 & 44.4 & 9.9 \\
\hline 12 & 8 & & \\
\hline
\end{tabular}

Figure 33 shows photos of various specimens after testing, detailing the extent of freeze-thaw damage observed across the levels of air entrainment used. Figures 34 and 35 detail the freeze-thaw resistance of each mixture batched against the air void structure measurements taken for each mixture made for this study. These plots were further broken down by mixture design in Figures 36 and 37. Only the AVA data measurements collected for the voids less than $2 \mathrm{~mm}$ are shown to present a clear, understandable figure. American Concrete Institute (ACI) recommended a maximum spacing factor of $8 \cdot 10^{-3} \mathrm{in}$. and was plotted for reference. The historical approximate curves and rules of thumb from previous studies on the topic were also plotted on the charts for comparison. The general trend of increased air entrainment producing mixtures with greater frost resistance can be seen in the plots made; however, there is significant scatter with mixtures with total air contents greater than 4 percent.

The plots show that, as the air content increases, the majority of the mixtures batched are not similar to historical trends. The poor freeze-thaw performance seen with mixtures with both low air contents and high spacing factors is expected for non-air-entrained concrete. Here there is no internal volume for water to freeze as it expands and changes phase to ice; however, the air-entrained concrete shows scattered results and generally 
less resistance to freezing and thawing. This was unexpected for the amount of entrained air measured. Air entrained concrete should have higher air contents and lower spacing factors, yielding higher durability factors, since more internal volume into which the freezing waters can expand is scattered within the concrete.
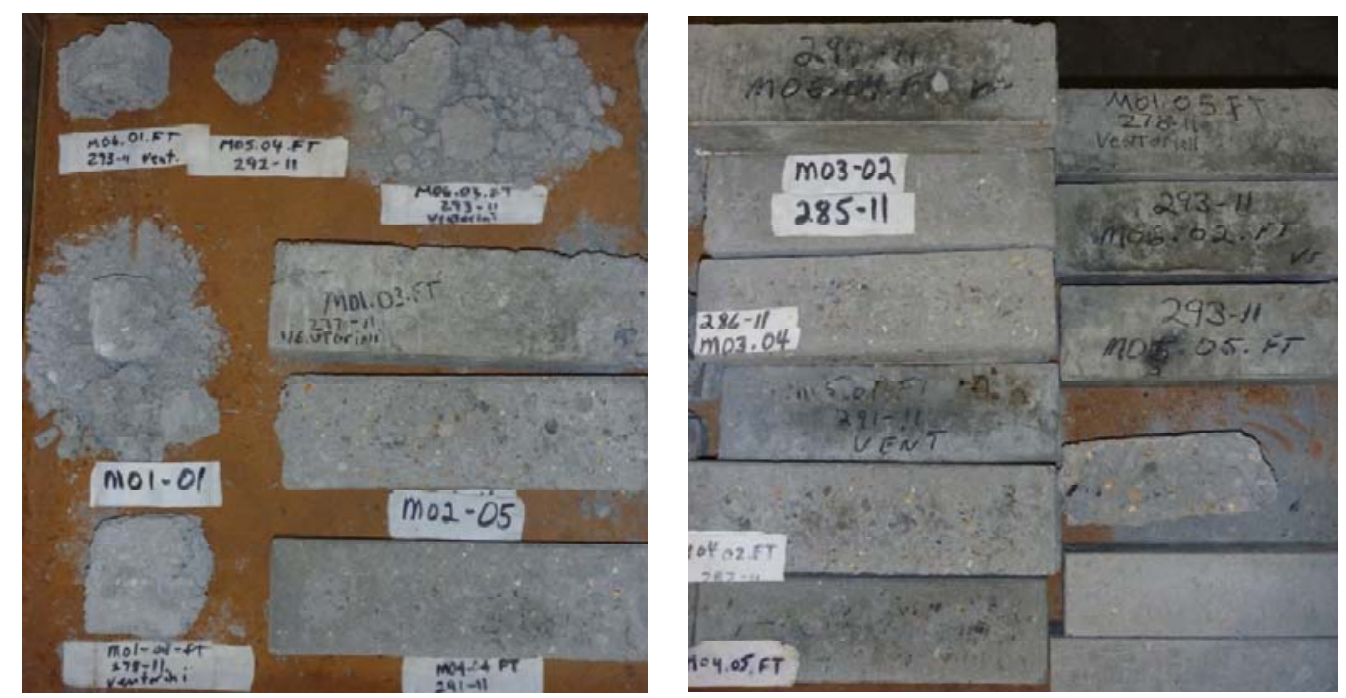

Figure 33. Tested freeze-thaw specimens.

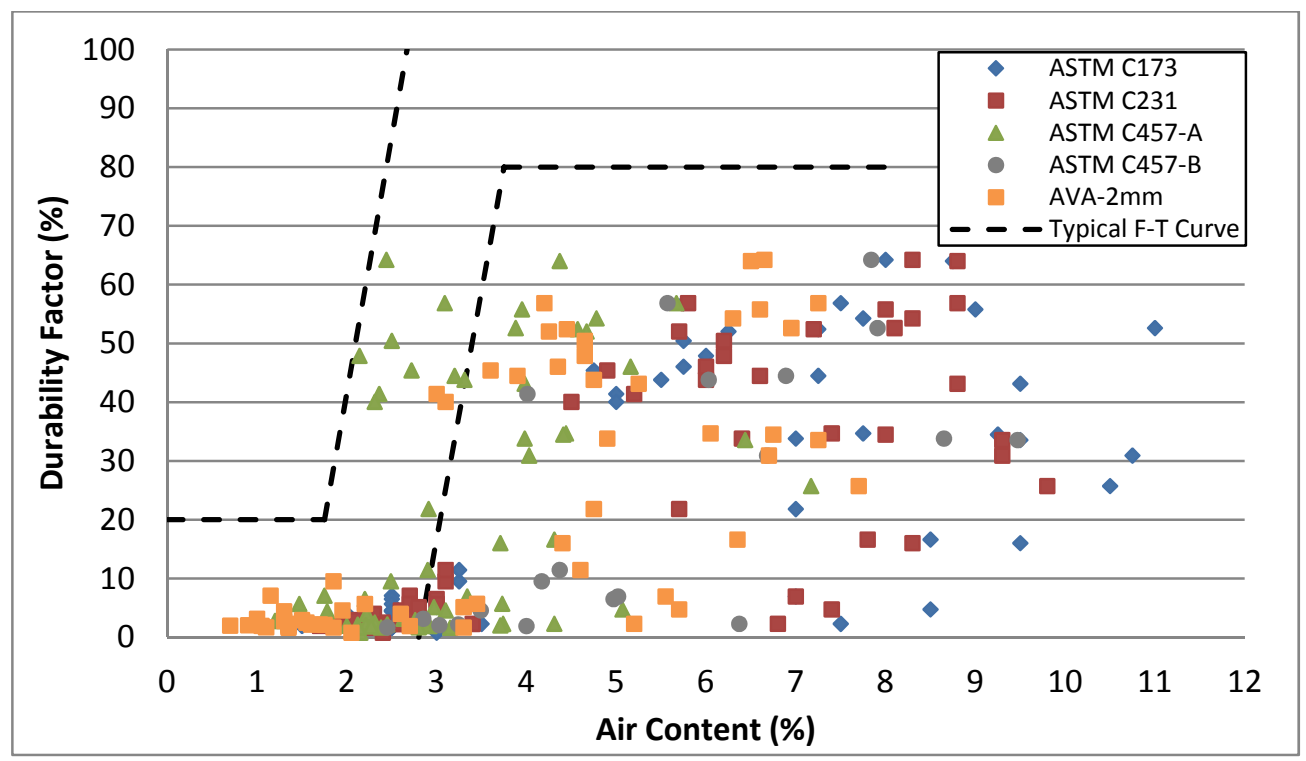

Figure 34. Freeze-thaw durability results by air content for all concrete batched. 


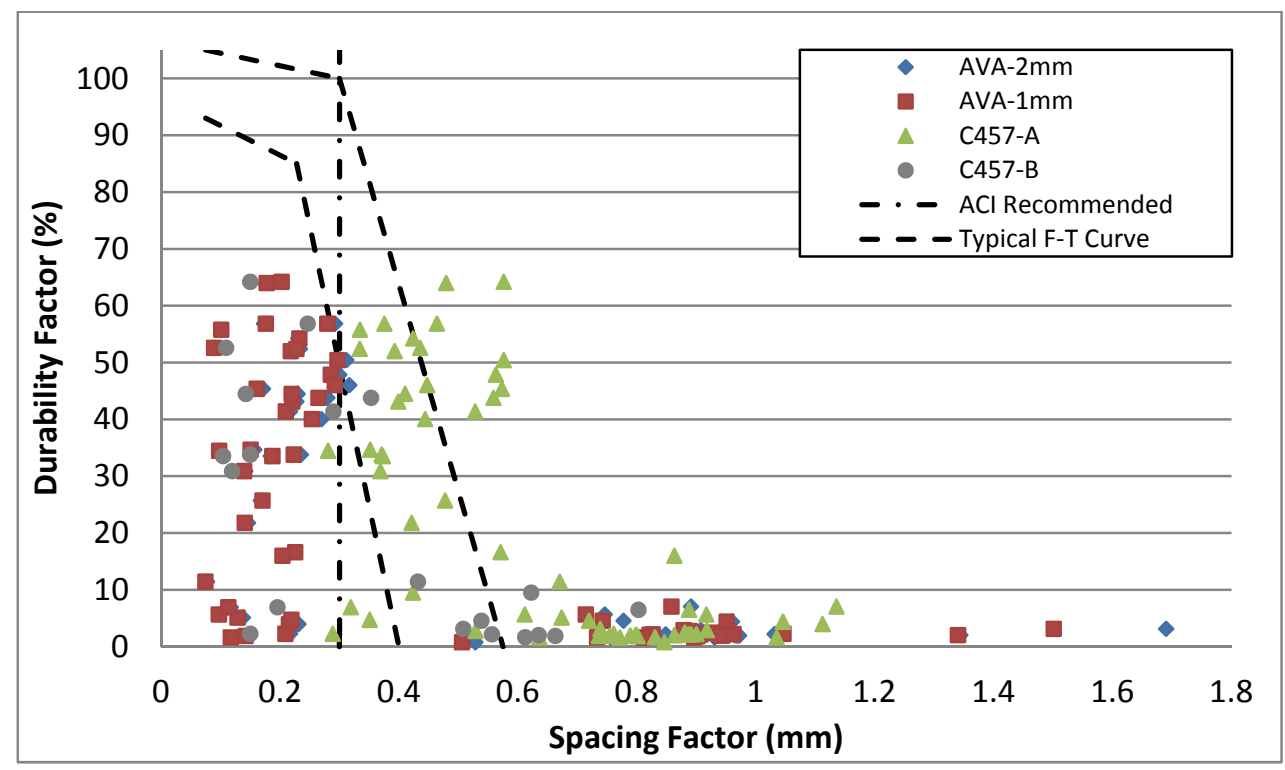

Figure 35. Freeze-thaw durability results by air spacing factor for all concrete batched.

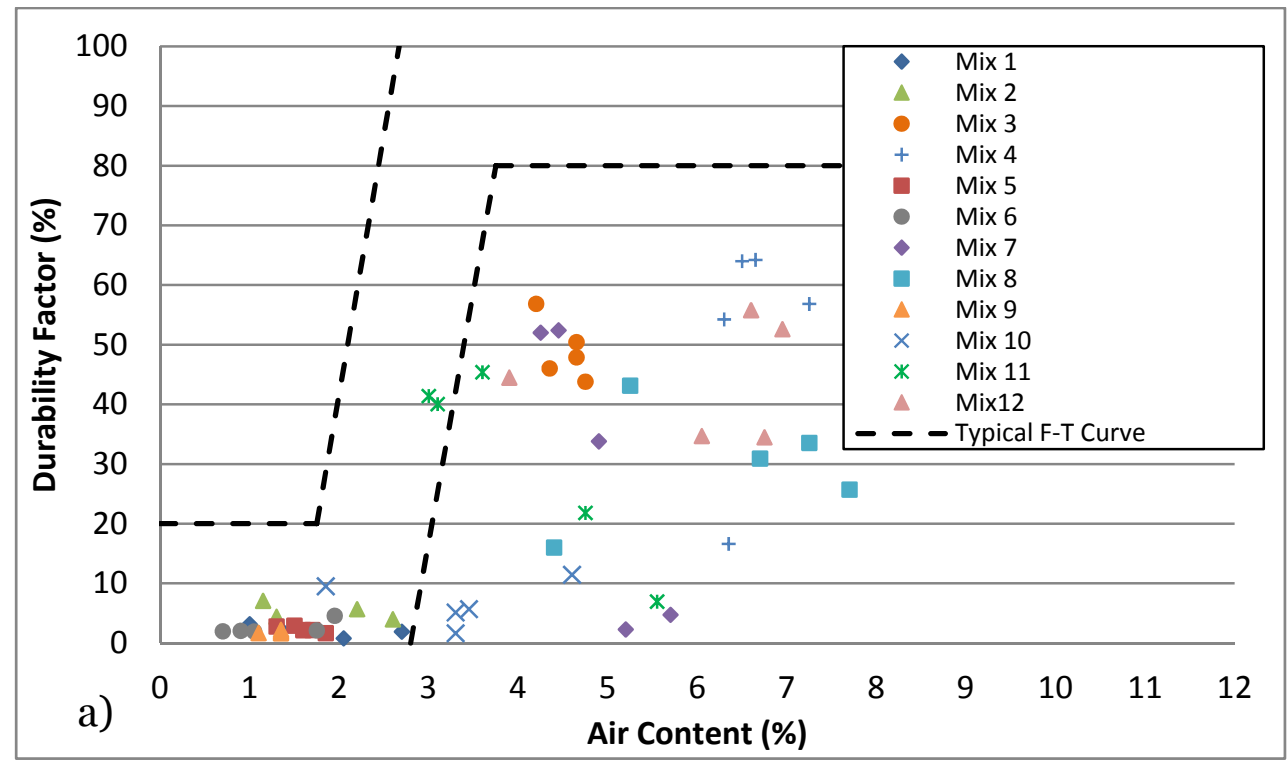

Figure 36. Freeze-thaw durability results against AVA (less than $2 \mathrm{~mm}$ ) air content measurements by mixture design. 


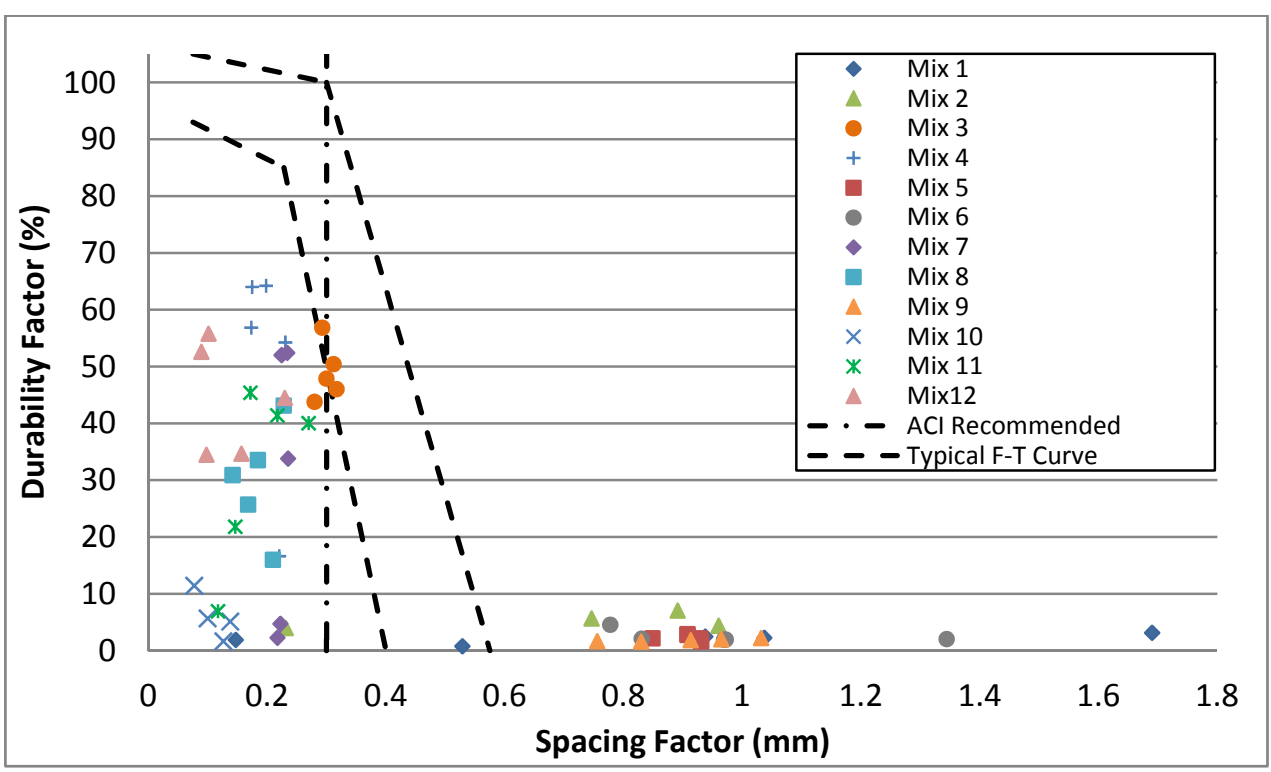

Figure 37. Freeze-thaw durability results against AVA ( $2 \mathrm{~mm}$ and less) spacing factor measurements by mixture design.

Further review into the historical freeze-thaw data suggests that the poorer performing air entrained concrete data shown here may not be caused by a deficient air void system, but rather by the use of frost susceptible aggregates in the concrete (Figure 38 ). Figure $38 \mathrm{~b}$ shows the freeze-thaw resistance results of three different mixtures where identical mixture designs were batched at different laboratories. The group of circled points represents air entrained concrete batched with poor quality coarse aggregate, whereas the other mixtures were batched with good quality aggregates and different amounts of air entrainment.

Aggregate related freeze-thaw resistance problems typically result from the use of poor quality coarse aggregates. Coarse aggregates prone to frost damage are those with high porosity and pore sizes ranging from $4 \cdot 10^{-6}$ to $2 \cdot 10^{-4}$ in. that become easily saturated (Kosmatka and Wilson 2011). Larger voids fail to become saturated, and water in smaller voids may not freeze easily (Cordon 1966; Kosmatka and Wilson 2011). Cherts, shales, claystones, siltstones and some limestones are known to be frost susceptible because they can absorb large quantities of water before saturation (Cordon 1966). Typically, reducing the maximum size of aggregates can reduce the potential for frost damage; however, this maximum size varies by aggregate type (Cordon 1966; Kosmatka, and Wilson 2011). 

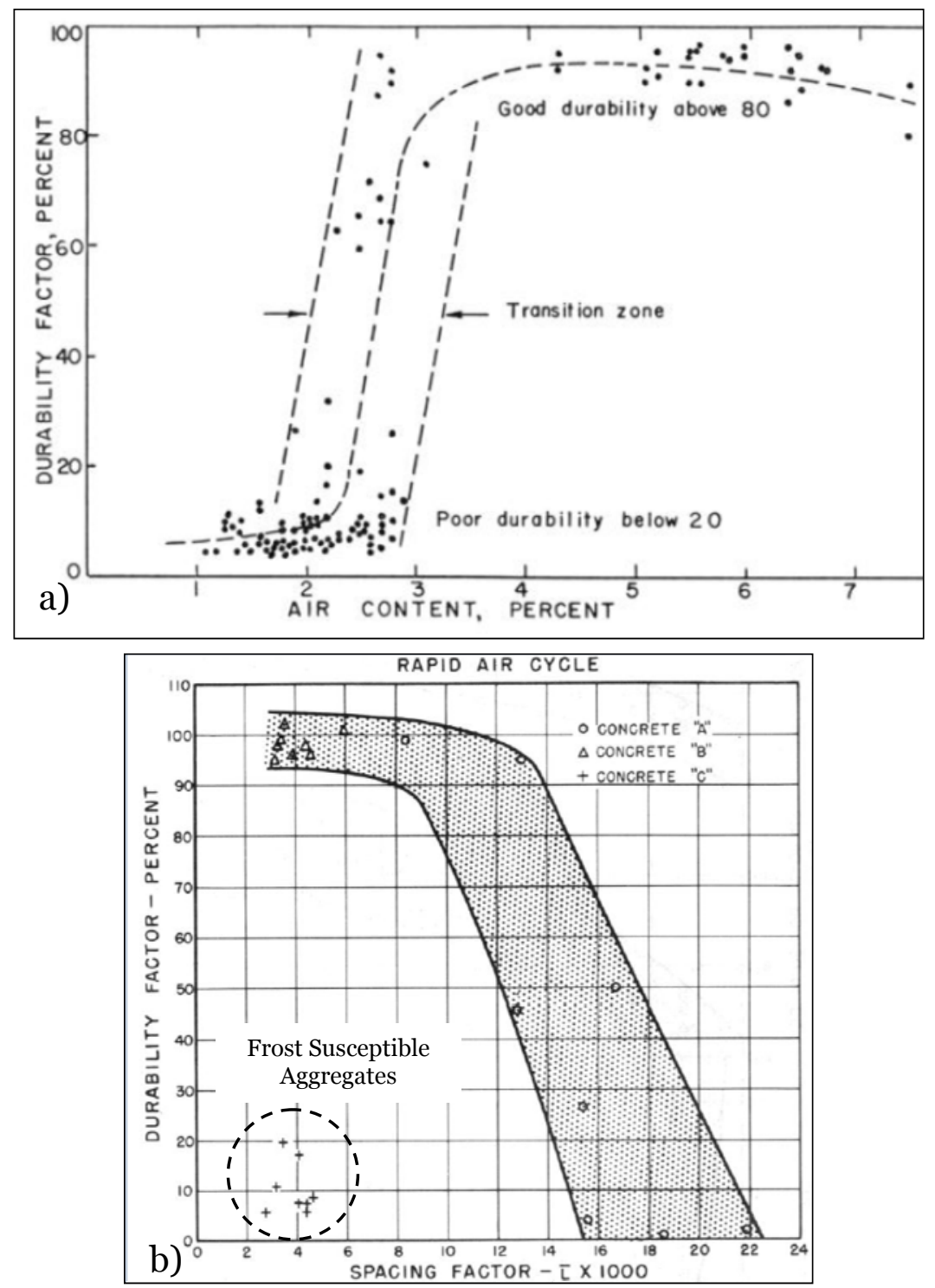

Figure 38. Historical freeze-thaw durability results of different concretes by (a) air content (Cordon 1966) and (b) spacing factor (Backstrom 1956).

The variation seen in the mixtures with poor durability factors, but low spacing factors, is most likely from having different amounts of poor quality coarse aggregate intermixed into the material delivered from the aggregate supplier. There is no pattern to the data presented by mixture design used to suggest any other explanation. Evidence of the poor freeze-thaw performance of the aggregates used in this investigation could not be found after testing was completed, since this was not considered to be an issue in the project planning stages. The few spent samples with higher entrained air contents found after testing were among the ones that made it through the most freeze-thaw cycles. These particular samples showed more surface 
scaling than that depicted for air entrained concrete in Figure 6, but not to the extent of that shown for non-air entrained concrete.

It will be reiterated that care should be taken when observing the ASTM C457-A data shown. The charts show these results best fit the values collected; however, the previous statements about the quality of the data received from the petrographer should not be neglected. Trying to correlate only the data that shows better results would not be correct. The AVA plots are promising since the machine does show that concrete with poor air void systems will perform poorly. A paper by Tanesi and Meininger (2007) mentions that more research is needed in determining a reliable spacing factor criterion for freeze-thaw durability when comparing against AVA collected data. The ACI recommended value of $0.008 \mathrm{in}$. may not be correct since this value was developed using ASTM C457 results. This value may not be "appropriate" since the testing procedures are different, even though the machine is designed to provide values similar to ASTM C457-A. Additional freeze-thaw testing should be completed with good performing aggregate to verify that the limestone aggregate used for this study was frost susceptible. Such testing would provide additional data to the discussion on selecting a proper spacing factor criterion.

Figure 39 has been shown by others in previous work to describe the need for alternative methods for measuring air void structures. It is believed that specifying higher air content instills an air void structure that can better resist frost damage to the paste; however, this may not always be achieved. The results of the ASTM C457-B and AVA testing shown look good overall when compared to the ASTM C231 results. The majority of the air entrained mixtures are within the ACI recommended maximum spacing factor and are considered adequately frost protected. When plotted against the results of a standard field test like ASTM C231, the spacing factor data show that field testing measurement would be a good indicator of a mixture's spacing factor and potential frost performance. However, the data shown would not be typical of field collected samples, and much more scatter is expected because of the control over material batching tolerances, mixing, and consolidation effort of a plant batched and field constructed material. Obtaining a true measure of the air void structure that is more closely related to the freeze-thaw performance of PCC would provide the best information on the material's ability to resist damage. 


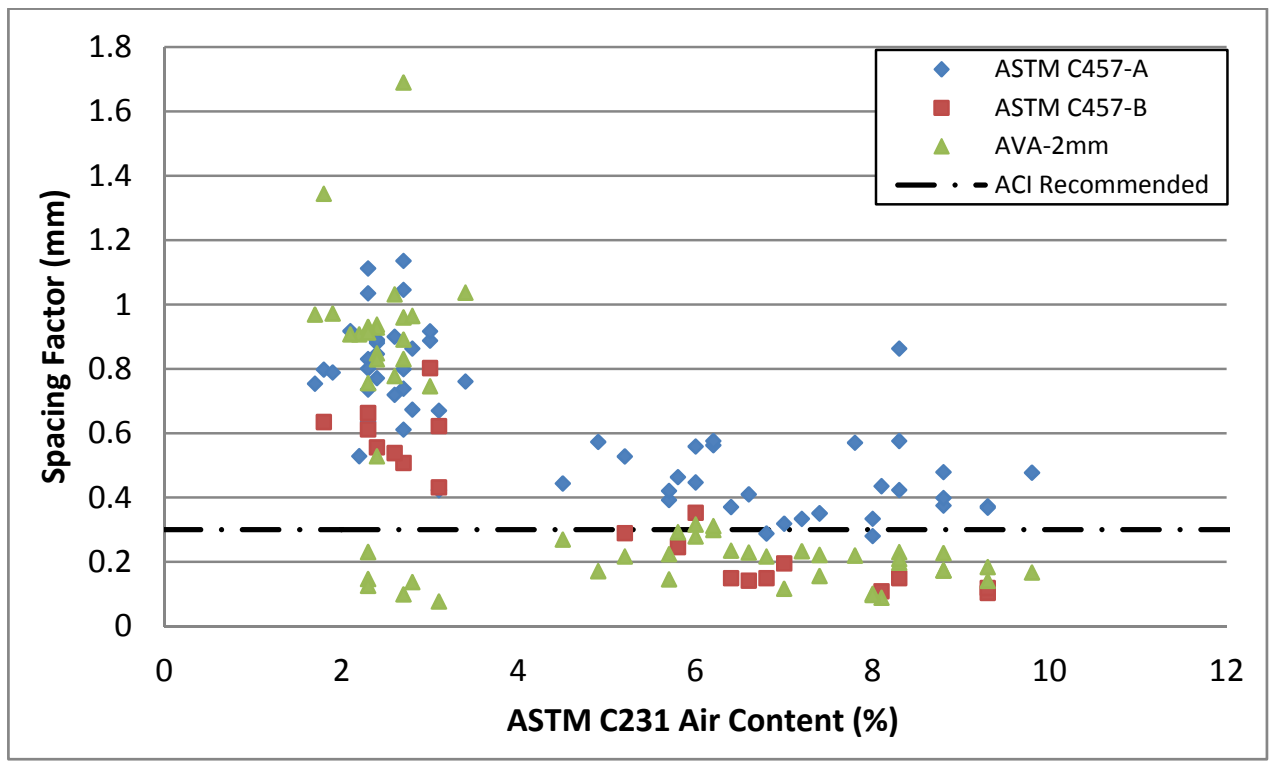

Figure 39. Plot of measured spacing factors against air content. 


\section{Conclusions and Recommendations}

The ERDC evaluated the performance of the AVA in relation to other standard tests that are currently used to monitor the air void system within PCC. Sixty batches of PCC were made, and the air void systems were measured with five ASTM tests conducted on both freshly batched and hardened PCC specimens. A statistical study was completed to evaluate the accuracy and precision of the AVA. The freeze-thaw performance of the mixtures was also evaluated to determine if the AVA could identify poor PCC mixtures in the laboratory. Conclusions from the evaluation and recommendations for future work and guidance on the AVA are summarized below.

\section{Conclusions}

- The ASTM C457-A results do not agree with the ASTM C173, C231, and $\mathrm{C} 457-\mathrm{B}$ results and are the least consistent. The results do not report as much total air within the concrete compared to standard test methods on average. Additionally, the ASTM C457-A results show the air void structure of the concrete batched consists of fewer, larger voids that are further spaced apart compared to the ASTM C457-B results. The ASTM C457-A results should not be relied on heavily when used as the reference test method when comparisons to the other test methods are made.

- The results of the AVA compared to the ASTM C138, C173, C231, and C457-B results presented in this study show a strong linear correlation for total air content. The AVA was precise when compared to these four standardized test methods, but not accurate for collecting total air contents of the laboratory batched concrete mixtures used. Accuracy is lost because the machine can measure voids only within a specific range. The AVA does not measure large entrapped air voids larger than 0.12 in. because they rise out of the water column too fast for measurement. Smaller voids still rise in the column after the 25-min maximum measurement time, but it is believed these smaller voids would also not be counted by ASTM (C457) testing (Magura 1996). The correlation between these results is more complex than the straight 2 percent underestimation by the AVA to ASTM (C231) described by Magura (1996) and with other standard tests. The data suggest that 
there is an increasing amount of underestimation as more air is entrained into the concrete.

- The ASTM C457 samples were not prepared properly. Nine of sixty samples were not ground completely flat over the area observed for analysis. The ASTM recommended abrasive sizes were not followed, and the samples were not ground fine enough, leading to potential errors in counting the air voids.

- With the additional air void structure data available on the ASTM C457 samples, the specific surface and spacing factor measurements were neither accurate nor precise when compared to the AVA data. This is different from previous reports where precision and accuracy were found between the specific surface and spacing factor data values, but not the total air content. This may be a function of improper sample preparation.

- Not enough specimens were analyzed by ASTM C457-B (20 of 60-total) to use this dataset in place of the presumed low and inconsistent ASTM C457-A results as traditionally used with previous AVA testing. A minimum of three specimens per mixture design would be required to complete the calculations (yields 36 of 6o-total) as the reference test method, but more are recommended to account for outliers.

- The AVA is more than capable of determining mixtures with poor air void structures. The machine should not be used to judge the freezethaw resistance of the mixture as a whole. This machine will assist only in evaluating the effectiveness of the paste as advertised and not the aggregates used.

\section{Recommendations}

- The following correlation equations are proposed to predict the total air content of individual standardized test methods from reported AVA results. The equations are given in terms of air content (AC) by test measurement considered. Use of ASTM C173 and C231 methods should be used over ASTM C138 to maximize the precision of the equations. The AVA cannot accurately predict either the specific surface or spacing factor in a similar manner.

o $\quad$ ASTM C138

- $\mathrm{AC}_{\mathrm{C} 138}=1.169 \mathrm{AC}_{\mathrm{AVA}<2 \mathrm{~mm}}-0.648 \quad\left(\mathrm{R}^{2}=0.775\right)$

- $\mathrm{AC}_{\mathrm{C}_{13} 8}=1.233 \mathrm{AC}_{\mathrm{AVA}<1 \mathrm{~mm}}-0.318 \quad\left(\mathrm{R}^{2}=0.754\right)$

o $\quad$ ASTM C173 
- $\mathrm{AC}_{\mathrm{C} 173}=1.255 \mathrm{AC}_{\mathrm{AVA}<2 \mathrm{~mm}}-0.551 \quad\left(\mathrm{R}^{2}=0.856\right)$

- $\mathrm{AC}_{\mathrm{C} 173}=1.351 \mathrm{AC}_{\mathrm{AVA}<1 \mathrm{~mm}}-0.820 \quad\left(\mathrm{R}^{2}=0.866\right)$

o $\quad$ ASTM C231

- $\mathrm{AC}_{\mathrm{C} 231}=1.155 \mathrm{AC}_{\mathrm{AVA}<2 \mathrm{~mm}}-0.691 \quad\left(\mathrm{R}^{2}=0.879\right)$

- $\mathrm{AC}_{\mathrm{C}_{231}}=1.230 \mathrm{AC}_{\mathrm{AVA}<1 \mathrm{~mm}}-0.983 \quad\left(\mathrm{R}^{2}=0.870\right)$

o ASTM C457-B

- $\mathrm{AC}_{\mathrm{C} 457 \mathrm{~B}}=0.869 \mathrm{AC}_{\mathrm{AVA}<2 m m}+1.949 \quad\left(\mathrm{R}^{2}=0.779\right)$

- $\mathrm{AC}_{\mathrm{C} 457 \mathrm{~B}}=0.898 \mathrm{AC}_{\mathrm{AVA}<1 \mathrm{~mm}}+2.261 \quad\left(\mathrm{R}^{2}=0.734\right)$

- To ensure the AVA is given a fair assessment, the ASTM C457 testing should be repeated to provide accurate values for comparison, and the analysis should be repeated with the new values determined.

o All C457 sample surfaces should be prepared again to ensure accurate visual observations are made. The optional requirement for using carnauba wax should be used to ensure crisp, well defined perimeters on the exposed air voids. This did not appear to be a significant issue with the preparation technique used on these samples, but every precaution should be taken to prepare the samples correctly since they must be prepared again. The samples should be reground with coarser abrasives to remove any surface irregularities still present after the initial grinding and to remove any damage from being poorly packaged when returned to the ERDC. The progressive series of finer abrasives used should follow that listed in the standard at a minimum. The samples should be ground for a longer period of time with each abrasive size to ensure the sample is completely leveled; furthermore, at least one abrasive grit finer than the \#800 listed in the standard should be used to ensure the smaller air voids are clearly distinguishable.

o To ensure accuracy in the results, the samples should be viewed at higher magnification than that used to ensure the smaller voids can be seen. The magnification used should allow the average petrographer to observe the smallest voids the AVA can measure for a more equal comparison. Further review of literature may be necessary to determine the minimum size of air voids that mitigate frost damage and assist with drawing an acceptable lower measurement boundary for the AVA.

o Even though ASTM C457 states that no distinction between entrapped and entrained air voids should be made, these values 
should be counted as separate items to monitor the amount of entrained air counted by the petrographer when retested.

- Additional batches of concrete should be made with good quality aggregate with the air entrained mixture design used to verify the limestone aggregates used in this study were frost susceptible. A good quality limestone of similar properties is preferred; however, any other type of good quality rock will work.

- Participation in any future multi-laboratory studies should be taken to collect additional data for analysis of the AVA for further development of measurement error statements and official testing standards. Obtaining replicate data information is not possible based on the ASTM requirements of sampling fresh concrete, and purchasing multiple machines is not economical. The Department of Transportation began work on a federal level standard (AASHTO 2008), and the DoD should take part in its development if it chooses to use the AVA in future contract requirements.

- Current UFGS PCC construction specification requirements for monitoring total air content could use the prediction equations given for ASTM C173 or C231 correlations only. A new or modified specification requirement with specific tailoring options for its use would be required. Additional requirements to the "Proportioning Studies" section should be added to include AVA testing during the trial mixture portion of the project. This additional testing should be similar to the requirements for testing multiple water-cement ratios for concrete property validation at respective air contents and also show the concrete mixture selected can provide stable measurements when monitored by the AVA. While the data shows a good correlation for total air content data collected, use of the AVA for monitoring this concrete property may not be the most efficient or economical testing method for this task.

- A simulated quality control and assurance operation study should be completed to investigate the feasibility of AVA testing with fieldproduced PCC made according to Unified Facilities Criteria Specifications (UFGS 2010): Concrete Pavement for Airfields and Other Heavy Duty Pavements. The investigation should include samples taken from laboratory trial batching in addition to those taken from the construction projects selected.

- A study concerning the effects of different vibratory efforts on AVA results should be conducted since the electric hammer drill provided 
with the stock equipment will be cumbersome to operate in the field. A generator must be supplied to power this electric drill and the location of the cord must be managed. A battery-powered drill would be preferred to a corded drill because of its ease of use and transportability, but battery-powered drills cannot achieve the same performance as the drill provided with the AVA equipment. Current commercially available battery-powered drills (18V) will achieve only 67 percent of the rotational speed as that of a corded drill $(120 \mathrm{~V}, 5.8 \mathrm{~A})$ provided with the AVA. It is expected samples taken with drills of different rotational speeds and the stock AVA sampling bit will produce different AVA air testing results, since different levels of vibration are used. 


\section{References}

American Association of State Highway Transportation Officials (AASHTO). 2004. Standard method of test for air content of freshly mixed concrete by the Chace indicator. Designation T 199. Washington DC: American Association of State Highway Transportation Officials.

2008. Standard method of test for air-void characteristics of freshly mixed concrete by buoyancy change. Designation TP 75. Washington DC: American Association of State Highway Transportation Officials.

American Concrete Institute (ACI). 2009. Standard practice for selecting proportions for normal, heavyweight and mass concrete. Committee document 211.1. Farmington Hills, MI: American Concrete Institute.

ASTM International. 2005a. Standard test method for compressive strength of cylindrical concrete specimens. Designation: C 39. West Conshohocken, PA: ASTM Internaitonal.

. 2006a. Standard specification for air entraining admixtures for concrete. Designation: C 260. West Conshohocken, PA: ASTM International.

2006b. Standard test method for sieve analysis of fine and coarse aggregates. Designation: C 136. West Conshohocken, PA: ASTM International.

. 2007a. Standard practice for making and curing concrete test specimens in the laboratory. Designation: C 192. West Conshohocken, PA: ASTM International.

2007b. Standard specification for concrete aggregates. Designation: C 33. West Conshohocken, PA: ASTM Interanational.

2007e. Standard test method for determination of water (moisture) content of soil by direct heating. Designation: D 4959. West Conshohocken, PA: ASTM International.

2008a. Standard specification for chemical admixtures for concrete. Designation: C 494. West Conshohocken, PA: ASTM International.

2008b. Standard specification for coal fly ash and raw or calcined natural pozzolan for use in concrete. Designation: C 618. West Conshohocken, PA: ASTM International.

2008c. Standard test method for resistance of concrete to rapid freezing and thawing. Designation: C 666. West Conshohocken, PA: ASTM International.

2008d. Standard test method for slump of hydraulic cement concrete. Designation: C 143. West Conshohocken, PA: ASTM International.

2008e. Standard test method for temperature of freshly mixed hydrauliccement concrete. Designation: C 1064. West Conshohocken, PA: ASTM International. 
.2008f. Standard test method for fundamental transverse, longitudinal and torsional resonant frequencies of concrete specimens. Designation: C215. West Conshohocken, PA: ASTM International.

2009a. Standard practice for capping cylindrical concrete specimens. Designation: C 617. West Conshohocken, PA: ASTM International.

2009c. Standard specification for portland cement. Designation: C 150. West Conshohocken, PA: ASTM International.

2009d. Standard test method for density (unit weight), yield, and air content (gravimetric) of concrete. Designation: C 138. West Conshohocken, PA: ASTM International.

. 2009e. Standard test method for air content of freshly mixed concrete by pressure method. Designation: C 231. West Conshohocken, PA: ASTM International.

2009f. Standard test method for air content of freshly mixed concrete by volumetric method. Designation: C 173. West Conshohocken, PA: ASTM International.

. 2010a. Standard practice for sampling freshly mixed concrete. Designation: C 172. West Conshohocken, PA: ASTM International.

.2010b. Standard practice for use of the terms precision and bias in ASTM test methods. Designation: E 177. West Conshohocken, PA: ASTM International.

.2010c. Standard test method for microscopical determination of parameters of the air-void system in hardened concrete. Designation: C 457. West Conshohocken, PA: ASTM International.

Backstrom, J. E. 1956. The air void systems of Highway Research Board Cooperative concretes. Concrete Laboratory Report C-824. Denver, CO: US Department of Interior, Bureau of Reclamation.

Cahill, J., J.C. Dolan, and P.W. Inward. 1994. The identification and measurement of entrained air in concrete using image analysis: Petrography of cementitious materials. ASTM STP 1215. S.M. DeHayes and D. Stark, eds. Philadelphia, PA: American Society for Testing and Materials.

Caliskan, S. 2007. Examining concrete cores by non-destructive techniques. 4th Middle East NDT Conference and Exhibition. Kingdom of Bahrain.

Carlson, J. 2005. Advancement on the application of a flat-bed scanner for hardened portland cement concrete air void analysis. M. S. thesis. Michigan Technological University.

Cordon, W.A. 1966. Freezing and thawing of concrete-mechanisms and control. Monograph No. 3. Detroit, MI: American Concrete Institute.

Crawford, G.L, L.G. Wathne, and J. I. Mullarky. 2003. “A 'fresh' perspective on measuring air in concrete.” Proceedings of the 2003 PCI/FHWA $3^{\text {rd Annual }}$ Symposium on High Performance Concrete. 
Dansk Beton Teknik. 1994. Subtask 2.1: Determination of the air void structure before compaction of the concrete. BRITE EURAM Project BE-3376-89: Quality Assurance of Concrete Based on Testing of the Fresh, Still Plastic Material. Brussels, Belgium: European Union Commission.

Desai, D.H., P.J. Tikalsky, and B.E. Scheetz. 2007. Hardened air in concrete roadway pavements in structure. Report Number FHWA-PA-2007-002-510401-06. Harrisburg, PA: Bureau of Planning and Research, Pennsylvania Department of Transportation.

Distlehorst, J.A. and G.J. Kurgan. 2007. Development of precision statement for determining air void characteristics of fresh concrete with use of air void analyzer. Transportation Research Record. Vol. 2020: 45-9. Electronic.

Federal Highway Administration (FHWA). 2006. Priority, market-ready technologies and innovations: Air Void Analyzer. Washington D.C. PDF file.

Germann Instruments (GI). 2011. AVA. Evanston, IL. PDF file. www.germann.org.

Grove J., G. Fick, T. Rupnow, and F. Bektas. 2008. Material and construction optimization for prevention of premature pavement distress in PCC pavements: Final report. FHWA TPF-5(066). Washington, DC: Federal Highway Administration.

Jana, D. 2007. A round robin test on measurements of air void parameters in hardened concrete by various automated image analysis and ASTM C457 methods. Proceedings of the Twenty-Ninth Conference on Cement Microscopy. Quebec City, PQ, Canada.

Kerkhoff, B. 2002. Benefits of air entrainment in HPC. HPC Bridge Views. Issue 23. September/October 2002: 3. Electronic.

Korhonen, C. 2002. Effect of high doses of chemical admixtures on the freeze-thaw durability of portland cement concrete. ERDC/CRREL TR-02-05. Hanover, NH: U.S. Army Engineer Research and Development Center.

Kosmatka, S. and M.Wilson. 2011. Design and control of concrete mixtures. $15^{\text {th }}$ ed. Skokie, IL: Portland Cement Association.

Lamond, J. F. and J. H. Pielert. 2006. Significance of tests and properties of concrete and concrete-making materials. STP 169D. West Conshohocken, PA: ASTM International.

Magura, D.D. 1996. Air void analyzer evaluation. FHWA-SA-96-062. Washington D.C.: Federal Highway Administration, Office of Technology Applications. U.S. Department of Transportation.

McAbe, W. L., J. C. Smith, and P. Harriot. 2001. Unit operations of chemical engineering. $6^{\text {th }}$ ed. New York: McGraw-Hill.

Mehta, P. K. and P. J.M. Monteiro. 2006. Concrete: Microstructure, properties and materials. 3rd ed. New York: McGraw-Hill. 
Mindess, S., J. F. Young, and D. Darwin. 2003. Concrete. 2nd ed. Upper Saddle River, NJ: Pearson Educational Inc.

Ozyildirim, C. 1991. Comparison of air void content measurements in fresh versus hardened concretes. Publication Number VTRC 90-R23. Charlottesville, VA: Virginia Transportation Research Council, Virginia Department of Transportation.

Ramezanianpour, A. M. and R.D. Hooton. 2010. Evaluation of two automated methods for air void analysis of hardened concrete. Journal of ASTM International, 7(2).

Roberts, L. R. and R. D. Gaynor. 1991. Discussion of paper by Ozyldirim, C., "Comparison of the Air Contents of Freshly Mixed and Hardened Concretes," Cement, Concrete, and Aggregates, Vol. 13, No. 1, pp. 16-17.

St. John, D. A., A. W. Poole, and I. Sims. 1998. Concrete petrography: A handbook of investigative techniques. $1^{\text {st }}$ Ed. New York: John Wiley and Sons Inc.

Tanesi, J. and R. Meininger. 2007. Freeze-thaw resistance of concrete with marginal air content. Transportation Research Record. Vol. 2020: 61-6. Electronic.

Taylor, P. C., S. H. Kosmatka, and G. F. Voigt. 2007. Integrated materials and construction practices for concrete pavement: A state-of-the-practice manual. Publication Number HIF-07-004. Washington, DC: U.S. Department of Transportation, Federal Highway Administration.

Trost, S. 2008. Air void characteristics of Oklahoma Concrete/AVA sources of error. Publication Number: SS-07-110-01. Oklahoma City, OK: Oklahoma Department of Transportation.

Unified Facilities Criteria (UFC). 2001. Pavement design for airfields. UFC 03-260-02. Washington, DC: Construction Criteria Base, National Institute of Building Sciences.

Unified Facilities Guide Specification (UFGS). 2010. Concrete pavement for airfields and other heavy duty pavements. UFGS 32-13-11. Washington, DC: Construction Criteria Base, National Institute of Building Sciences.

Wilson, M. L. 2010. Measurement of air content in concrete. HPC Bridge Views. Issue 61. May/June 2010: 8-10. Electronic.

Wang, K. M. M. Metwally, F. Bektas and J. Grove. 2008. Improving variability and precision of the Air-Void Analyzer (AVA) test results and developing rational specification limits. Publication Number DTFH-61-06-H-00011, W23. Washington, DC: U.S. Department of Transportation, Federal Highway Administration.

Zhang, S., and K. Wang. 2006. Investigation into the effects of materials and mixing procedures on air void characteristics of fresh concrete using air void analyzer (AVA). Journal of ASTM International, 3(10). 


\section{Appendix A: Detailed Material Testing Reports}

This appendix contains the laboratory measured aggregate and cementitious material properties test results for the aggregates used in this study. Additionally, the measured fresh and hardened laboratory measured properties of each concrete batch produced are shown here.

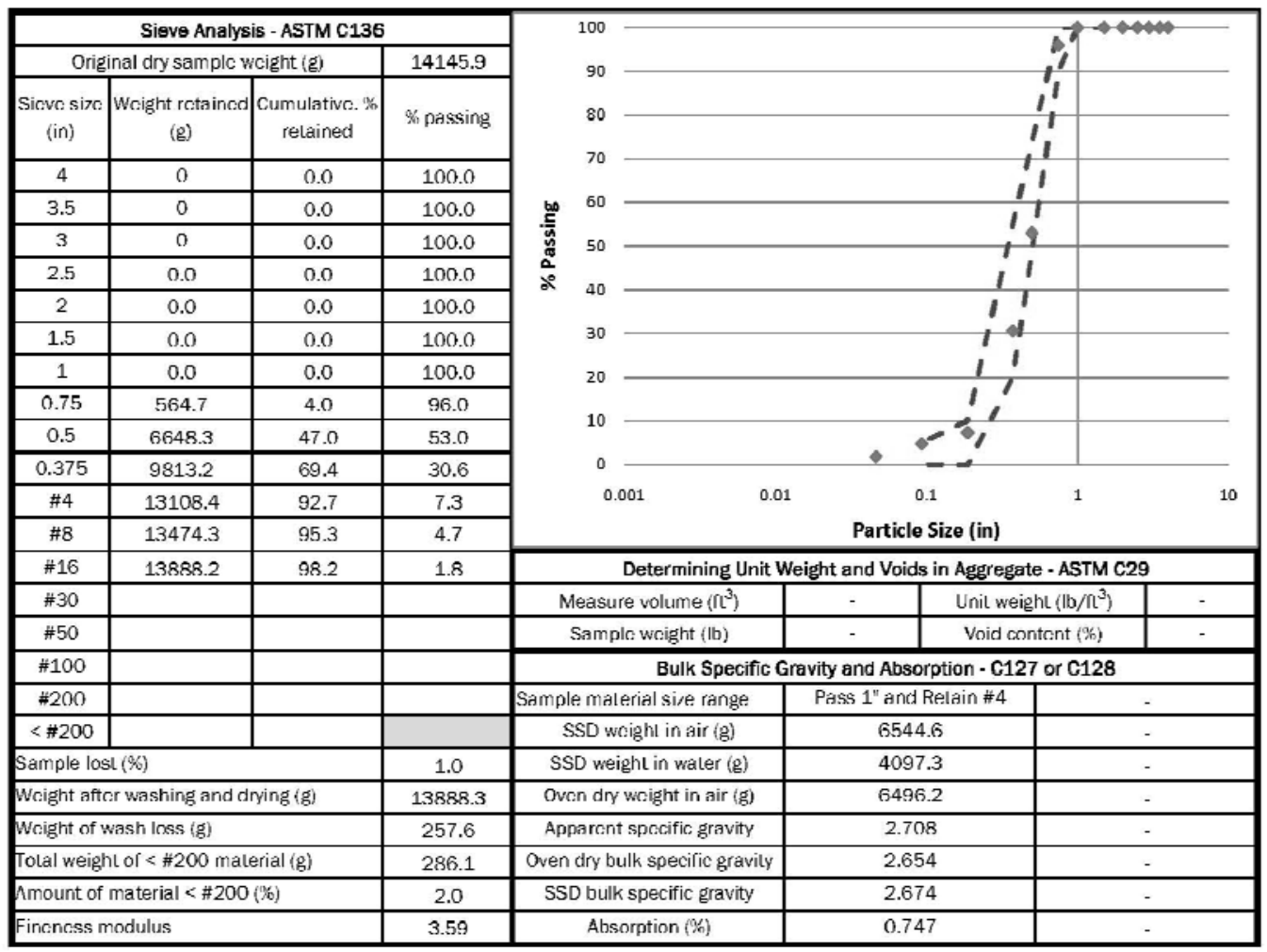

Figure A1. \#67 Limestone test results. 


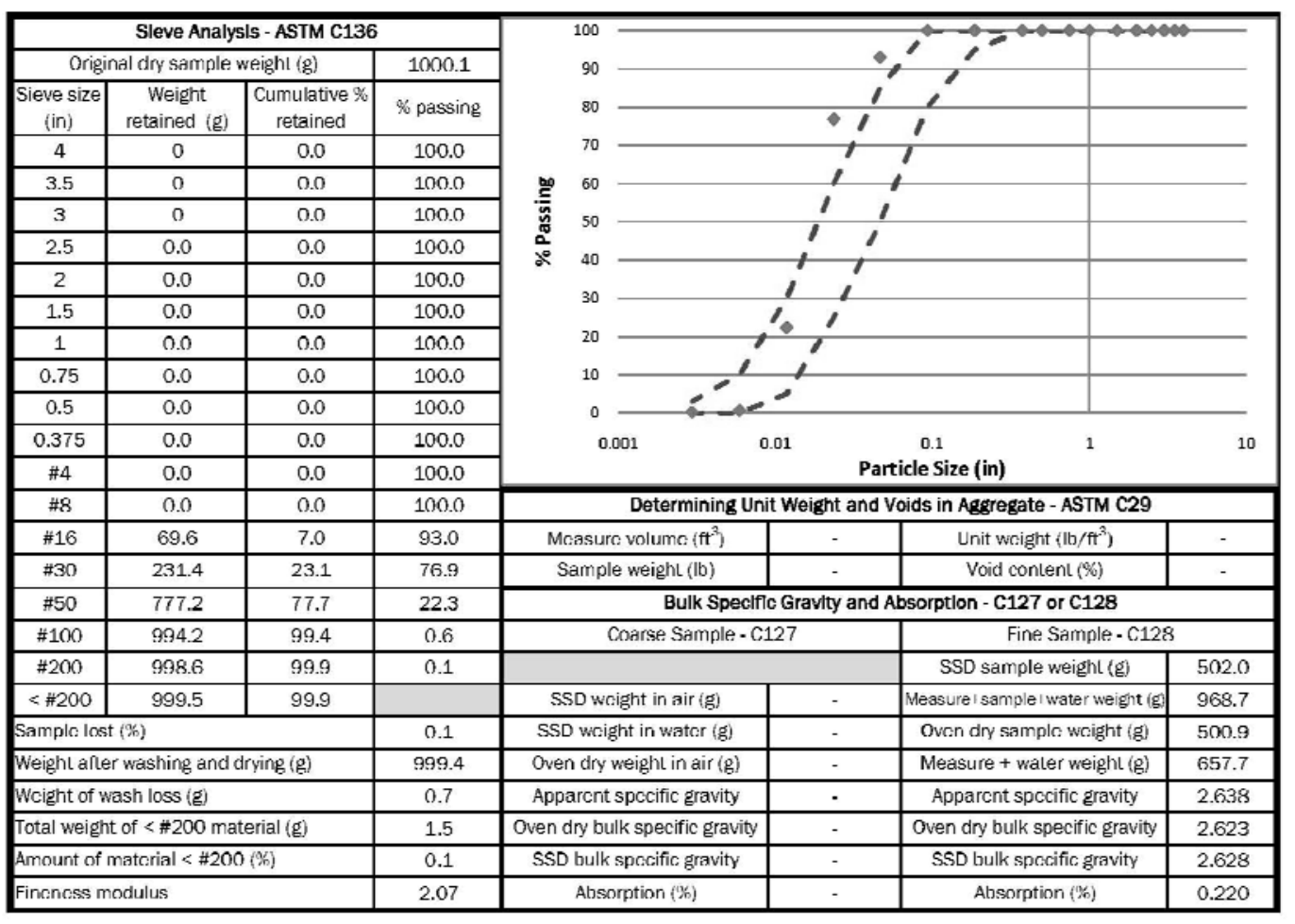

Figure A2. Bagged sand test results.

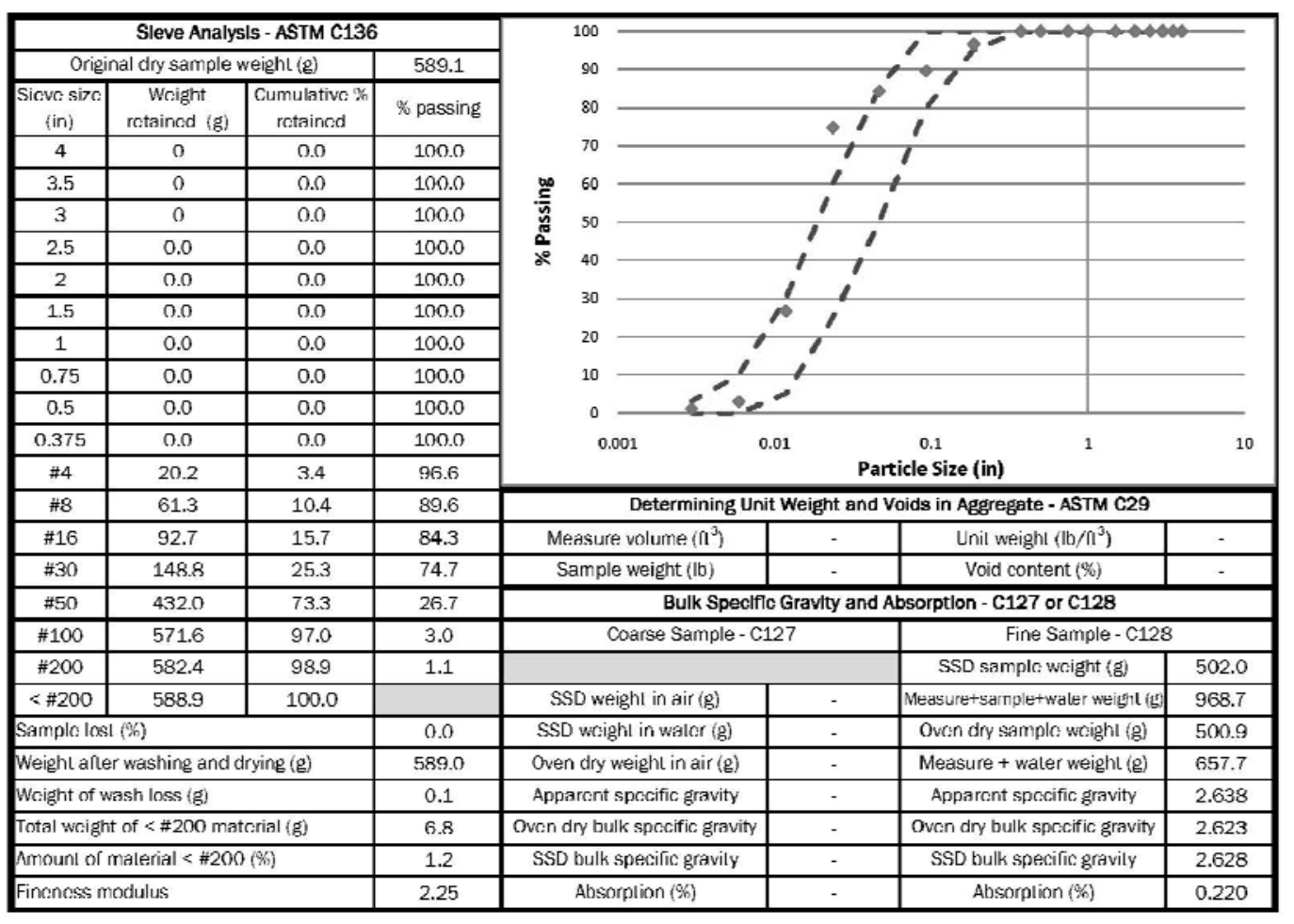

Figure A3. Reclaimed sand test results. 
Phoenix Cement Company

8800 E Chaparral Rd Suite 155

Scottsdale, AZ 85250

\section{SR/LG \\ Salt River Materials Group}

FUNG SNIIDCEMENT

Product: PHOENIX CEMENT TYPE I/II $N$ ASTM C150

\begin{tabular}{|c|c|c|c|c|c|}
\hline \multicolumn{4}{|c|}{ MILL TEST REPORT } & \multicolumn{2}{|c|}{ CHH: :00990 } \\
\hline Lot: $3-3122$ & \multirow[t]{2}{*}{ Results } & \multicolumn{2}{|c|}{$\begin{array}{c}\text { Type II } \\
\text { Speclfications }\end{array}$} & \multicolumn{2}{|c|}{$\begin{array}{c}\text { Type V } \\
\text { Specifications }\end{array}$} \\
\hline \multicolumn{5}{|l|}{ Chemical Analysis (c111) } & \\
\hline Calcium Oxide, $\mathrm{CaO}$ & $64.87 \%$ & -.- & & -.. & \\
\hline Silicon Dioxide, $\mathrm{SiO}_{2}$ & $20.87 \%$ & -.- & & 20.00 & Min \\
\hline Aluminum Oxide, $\mathrm{Al}_{2} \mathrm{O}_{3}$ & $3.79 \%$ & 6.00 & Max & 6.00 & $\operatorname{Max}$ \\
\hline Ferric Oxide, $\mathrm{Fe}_{2} \mathrm{O}_{3}$ & $3.59 \%$ & 6.00 & Max & 6.00 & $\operatorname{Max}$ \\
\hline Magnesium Oxide, MgO & $1.88 \%$ & 6.00 & Max & 6.00 & $\operatorname{Max}$ \\
\hline Sulfur Trioxide, $\mathrm{SO}_{3}$ & $2.83 \%$ \% & 3.00 & Max & 2.30 & Max \\
\hline Loss on Ignition & $1.52 \%$ & 3.00 & $\operatorname{Max}$ & 3.00 & $\operatorname{Max}$ \\
\hline Insoluble Residue & $0.29 \%$ & 0.75 & Max & 0.75 & $\operatorname{Max}$ \\
\hline Alkalis ("\%Na, O $\left.0.658 \% \mathrm{~K}_{2} \mathrm{O}\right)$ & $0.43 \%$ & 0.60 & Max & 0.60 & $\operatorname{Max}$ \\
\hline \multicolumn{6}{|l|}{ Potential Composition } \\
\hline Tricalcium Silicate, $\mathrm{C}_{2} \mathrm{~S}$ & $66 \%$ & --- & & -- & \\
\hline Tricalcium Aluminate, $\mathrm{C}_{\supset} \mathrm{A}$ & $3 \%$ & 8 & Max & 5 & Max \\
\hline Dicaleium Silicate, $\mathrm{C}_{2} \mathrm{~S}$ & $9 \%_{2}$ & -- & & - & \\
\hline $\begin{array}{l}\left(C_{4} A F+2 C_{3} A\right) \\
\text { Heat of Hydration }\end{array}$ & $16 \%$ & -- & & - & \\
\hline \multicolumn{6}{|l|}{ Physical Data } \\
\hline Fineness, Blaine, $\mathrm{CM}_{2} / \mathrm{Gm}$ (c204) & 4460 & 2800 & Min & 2800 & Min \\
\hline Specific Gravity (c100) & 3.15 & $\ldots$ & & - & \\
\hline Autoclave Expansion (c151) & $-0.01 \%$ & 0.80 & Max & 0.80 & Max \\
\hline $\begin{array}{l}\text { Air Content (c105) } \\
\text { Compressive Strength, } \operatorname{Lb} s / \mathrm{In}^{2} \text { (:L109) }\end{array}$ & $6.70 \%$ & 12.00 & Max & 12.00 & $\operatorname{Max}$ \\
\hline 1 Day & 2830 & --- & & - & \\
\hline 3 Days & 5620 & 1450 & Min & 1160 & Min \\
\hline 7 Days & 6460 & 2470 & Min & 2180 & Min \\
\hline \multicolumn{6}{|c|}{ Time of Setting: Vicat $x \times$ Gillmore $\quad(c 191 /(\mathrm{Cr} 6)$} \\
\hline Initial set & $1: 50$ & $0: 45$ & Min & $0: 45$ & Min \\
\hline Final set & $3: 50$ & $6: 15$ & Max & $6: 15$ & $\operatorname{Max}$ \\
\hline ASTM C1038 (ii) 14 days) & $0.002 \%$ & -.. & & 0.020 & - Max \\
\hline 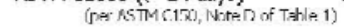 & & & & & \\
\hline
\end{tabular}

All tests have been made in strict accordance with the current standards of the American Society for Testing and Materials covering the type of material specified.

$$
\begin{aligned}
& \text { Comporate Headquarters } \\
& \text { } 0 \mathrm{U} \text { Chupartul Rd, Sle } 15
\end{aligned}
$$

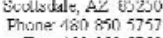

$$
\begin{aligned}
& \text { Faro: } 1808505758 \\
& \text { Cement Mamufacturing } \\
& 1 \text { Nisement Plant R. }
\end{aligned}
$$

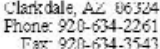

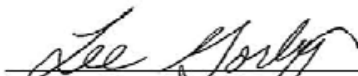

Lee Gorby, Quality Assurgate Manager

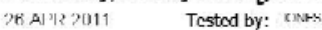

Figure A4. Portland cement mill testing report. 


\section{SR/LG \\ Salt River Materials Group}

Salt River Materials Group

Phoenix Cement Company

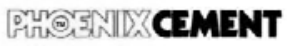

Scottsdale, AZ 85250

Product: Class F Fly Ash, Four Comers Fly Ash ASTM C 618

\begin{tabular}{|c|c|c|}
\hline POZ & EPORT & \\
\hline Lot: 6052 & Recults & pecificatio \\
\hline 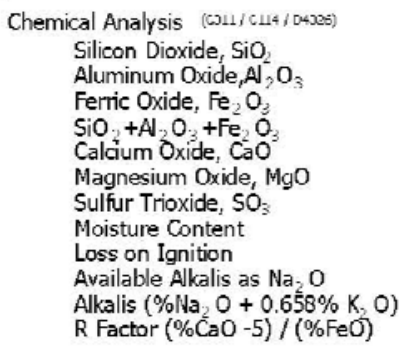 & $\begin{array}{r}24.60 \% \\
4.16 \% \\
90.20 \% \\
1.59 \% \\
1.10 \% \\
0.16 \% \\
0.03 \% \\
0.32 \% \\
0.22 \% \\
1.88 \% \\
-0.82 \%\end{array}$ & 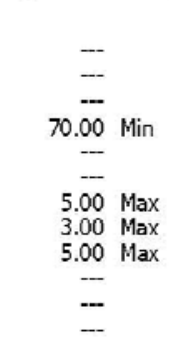 \\
\hline
\end{tabular}

Physical Analysis

Fineness, amount retained on

\#325 sieve, \% (MA:1) $\quad 25.40 \quad 34.00 \mathrm{Max}$ variation, points from average

Density, $\mathrm{g} / \mathrm{cm}^{-1}$ (c18)

Variation from average, $\%$

1.19

1.96

$5.00 \operatorname{Max}$

Strength Activity Index

$0.01 \quad 5.00 \mathrm{Max}$

with Portland Cement (c311/(civy)

at 7 days, \% of cement control

at 28 days, $\%$ of cement control 84.82

$80.41 \quad 75 . \overline{00} \quad$ Min

Water Requirement (coll

$\%$ of cement control

96.69

105.00 Max

or contraction, \%

$-0.01$

$0.80 \operatorname{Max}$

All tests have been made in strict accordance with the current standards of the American Society for Testing and Materials covering the type of material specified.

$$
\begin{aligned}
& \text { Corporate Headquarter } \\
& \text { cen E Chuparul Rd, Slc 1: } \\
& \text { sculludale, Az } 6523 \\
& \text { Phone: 180 850 } 7757
\end{aligned}
$$

Four Corners Fly Ash Facility $I^{2} O B_{0.06} 100$ Fhine: 50559888657
Fare 50559888533

San Jum Fly Ash Facility

3an Juan Gonersting Static Walerilow, NMU U/421 thone: $209-5353-1246$
Fare $5055 \% 87517$

T.scalante Tly Ash Fadlity CRis/ I O BCx 620
Trwill, NM 87403 Fhone: $505-205-4590$

Gallup Fly Ash Facllty Gallup, NM 87303

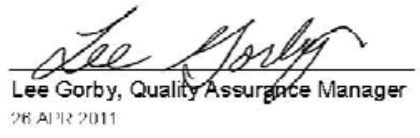

Figure A5. Fly ash mill testing report. 
Grace Concrete Products

DARAVAIR 1000

Air-entraining admixture

ASTM C260

\section{Product Description}

Daravair ${ }^{\circ} 1000$ is a liquid air-entraining admixture that provides freeze-thaw resistance, yield control, and finishability performance across the full range of concrete mix designs. Daravair 1000 is a clean, light-orange product designed to generate specification-quality air systems. Based on a high-grade saponified rosin formulation, Daravair 1000 is chemically similar to vinsol-based products, but with increased purity and supply dependability. Daravair 1000 weighs approximately $8.5 \mathrm{lbs} / \mathrm{gal}$ $(1.02 \mathrm{~kg} / \mathrm{L}$ ). Daravair 1000 does not contain intentionally added chloride.

\section{Uses}

Daravair 1000 air-entraining admixture may be used wherever the purposeful entrainment of air is required by concrete specifications. Formulated to perform across the entire spectrum of production mixes, Daravair 1000 generates quality, freeze-thaw resistant air systems in concrete conditions that include the following:

- Low slump

- Paving

- Central mix

- Extruded slip form

- Mixes containing hot water and accelerators

- Precast

\section{Product Advantages}

- Rapid air build suitable for short mix cycles

- Can be used in wide spectrum of mix designs
- High cement factor

- Fly ash and slag

- Superplasticizers

- Manufactured sands

Performance

Air is incorporated into the concrete by the mechanics of mixing and stabilized into millions of discrete semi-microscopic bubbles in the presence of a specifically designed airentraining admixture such as Daravair 1000 . These air bubbles act much like flexible ball bearings increasing the mobility, or plasticity and workability of the concrete. This can permit a reduction in mixing water with no loss of slump. Placeability is improved. Bleeding, plastic shrinkage and segregation are minimized.

Through the purposeful entrainment of air, Daravair 1000 markedly increases the durability of concrete to severe exposures particularly to freczing and thawing. It has also demonstrated a remarkable ability to impart resistance to the action of frost and de-icing salts as well as sulfate, sea and alkaline waters.

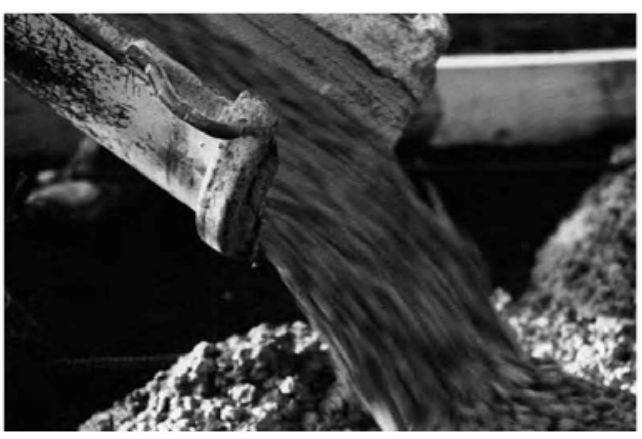

Figure A6. Air entraining admixture manufacturer's information. 


\section{Addition Rates}

There is no standard addition rate for Daravair 1000 . The amount to be used will depend upon the amount of air required for job conditions, usually in the range of 4 to $8 \%$. Typical factors which might influence the amount of air-entraining admixture required are temperature, cement, sand gradation, and the use of extra fine materials such as fly ash and microsilica. Typical Daravair 1000 addition rates range from $1 / 2$ to $3 \mathrm{fl} \mathrm{oz} / 100 \mathrm{lbs}$ ( 30 to $200 \mathrm{~mL} / 100 \mathrm{~kg}$ ) of cement. Pretesting of concrete should be performed to confirm dosage rates required to achieve desired concrete performance.

The air-entraining capacity of Daravair 1000 is usually increased when other concrete admixtures are contained in the concrete, particularly water-reducing admixtures and water-reducing retarders. This may allow up to $2 / 3$ reduction in the amount of Daravair 1000 required.

\section{Mix Adjustment}

Entrained air will increase the volume of the concrete making it necessary to adjust the mix proportions to maintain the cement factor and yield. This may be accomplished by a reduction in water requirement and aggregate content.

\section{Compatibility with Other}

Admixtures and Batch

Sequencing

Daravair 1000 is compatible with most Grace admixtures as long as they are added separately to the concrete mix. In general, it is recommended that Daravair 1000 be added to the concrete mix near the beginning of the batch sequence for optimum performance, preferably by "dribbling" on the sand. Different sequencing may be used if local testing shows better performance. Please see Grace
Technical Bulletin TB-0110, Admixture Dispenser Discharge Line Location and Sequencing for Concrete Batching Operations for further recommendations. Daravair 1000 should not be added directly to heated water.

Pretesting of the concrete mix should be performed before use, and as conditions and materials change in order to assure compatibility, and to optimize dosage rates, addition times in the batch sequencing and concrete performance. Please consult your Grace representative for guidance.

\section{Packaging \& Handling}

Daravair 1000 is available in bulk, delivered by metered tank trucks and in $55 \mathrm{gal}$ ( $210 \mathrm{~L}$ ) drums. Daravair 1000 will freeze at about $30^{\circ} \mathrm{F}\left(-1^{\circ} \mathrm{C}\right)$ but its air-entraining properties are completely restored by thawing and thorough mechanical agitation.

\section{Dispensing Equipment}

A complete line of accurate automatic dispensing equipment is available. These dispensers can be located to discharge into the water line, the mixer, or on the sand.

\section{Specifications}

Concrete shall be air entrained concrete, containing 4 to $8 \%$ entrained air. The air contents in the concrete shall be determined by the pressure method (ASTM Designation C231) or volumetric method (ASTM Designation $\mathrm{C173)}$. The air-entraining admixture shall be a completely neutralized rosin solution, such as Daravair 1000, as manufactured by Grace Construction Products, or equal, and comply with Standard Specification for Air-Entraining Admixtures ( $\triangle$ STM Designation $\mathrm{C260}$ ). The air-entraining admixture shall be added at the concrete mixer or batching plant at approximately $1 / 2$ to $3 \mathrm{fl} \mathrm{oz} / 100 \mathrm{lbs}$ ( 30 to $200 \mathrm{~mL} / 100 \mathrm{~kg}$ ) of cement, or in such quantities as to give the specified air contents.

\section{www.graceconstruction.com}

North American Customer Service: 1-877-4AD-MIX1 (1-877-423-6491)

Daravair is a regislered lrademark of W. R. Grace \& Co,-Conn.,

We hope ate information here will be helpful. It is based on data and knowlectge considered to be true and acourate and is offered for the users' suggestions in conjunction with our conditions of salle, which apply to all goods supplied by us. No statement, recommendetion or suggession is intended for any use which would infringe any patent or copyright. W. R. Grace \& Co.-Conn., 62 Whiticmore Avenue, Cambridge, MA 02140. In Cenada, Grace Cenada, Inc., 294 Clements Road, West, Ajax, Ontario, Cenada L1S 3C6. 


\section{Grace Concrete Products}

\section{ADVA 140M}

High-range water-reducing admixture

ASTM C191 Typo A and F, and ASTM C1017 Typo I

\section{Product Description}

1

Al) VA* $140 \mathrm{M}$ is a high-range

watcr-reducing admixfure based on polycarboxylate technology specifically formulated to meet ADVA the needs of the concrete industry. AI)VA $14(\mathrm{M}$ M meets the requirements of ASTM C494 as a Type A and F, and ASTM C1017 Type I. One gallon weighs approximately $8.8 \mathrm{lbs}(1.1 \mathrm{~kg} / \mathrm{L})$ and does not contain intentionally added chloride. It is a low viscosity liquid that has been formulated by the mamfinethrer for use as received.

\section{Uses}

ADVA $140 \mathrm{M}$ las heen used sueeessfully in a wide variety of concrete applications lơ high-slump, low water-to-cementitious ratio concrete requiring a high-range water reducer to flatwork in residential applications reqmiring a mid-range water reduecr. AIJVA $140 \mathrm{M}$ produces conerete with execllent workgbilit characteristics for high slump and moderate slump concrete.

\section{Product Advantages}

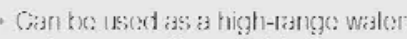
reducer as well as a mid rance wator roducer providing production tlexibility

- Consistent air entrainment

Consistent performance across cement chemistries

- Provides a superior combination of long slump lifo with noear noutrat sel lime:

- Concreder firishess cessily wilhoul stickiness, tearing or spotty set characteristics
ADVA 140M is ideal for use in any concrete where it is desired to keep the water/cementitious ratio to a minimmm and still achieve the high strength and degree of workability necessary to provide easy placement and consolidation. ADVA 140M will also tluidize concrete making it ideal for tremie concreting or other applications where high slumps are desired.

\section{Addition Rates}

Addition rates of AIJVA $140 \mathrm{M}$ can vary with iy ne of malerials and application. The addition rate ean range between 2 odew1 and 20 oz/ew1 $(130 \mathrm{~mL} / 100 \mathrm{~kg}$ and $1300 \mathrm{~mL} / 100 \mathrm{~kg}$ ) of cement.

Typical addition rates are:

- Iligh-range water reducer-9 to $16 \mathrm{oz} / \mathrm{cwt}$ $(590$ to $1040 \mathrm{~mL} / 100 \mathrm{~kg}$ )

- Mid-range water reducer-5 to ? $\mathrm{nz} / \mathrm{cwt}$ $(32510590 \mathrm{~mL} / 100 \mathrm{~kg})$

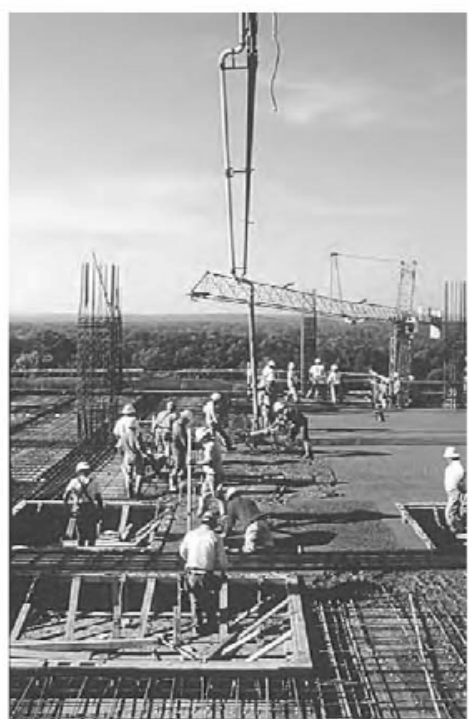

Figure A7. Air entraining admixture manufacturer's information. 
Optimal addition rates will depend on other concrete mixture components, job conditions, and desired performance characteristics. At a given water/cementitious ratio, the slump required for placement can be controlled by varying the addition rate. Should job site conditions require using more than recommended addition rates, please consult your Grace representative.

Compatibility with Other Admixtures and Batch Sequencing

ADVA $140 \mathrm{M}$ is compatible with most Grace admixtures as long as they are added separately to the concrete mix. However, ADVA products are not recommended for use in concrete containing naphthalene-based admixtures including Daracem 19 and Daracem 100 , and melamine-based admixtures including Daracem ML 330 and Daracem 65. In general, it is recommended that ADVA $140 \mathrm{M}$ be added to the concrete mix near the end of the batch sequence for optimum performance. Different sequencing may be used if local testing shows better performance. Please see Grace Technical Bulletin TB-0110, Admixture Dispenser Discharge Line Location and Sequencing for Concrete Batching Operations for further recommendations. ADVA 140M should not come in contact with any other admixture before or during batching, even if diluted in mix water.

Pretesting of the concrete mix should be performed before use and as conditions and materials change in order to assure compatibility with other admixtures, and to optimize dosage rates, addition times in the batch sequencing and concrete performance. For concrete that requires air entrainment, the use of an ASTM C260 air-entraining agent (such as Daravair ${ }^{*}$ or Darex product lines) is recommended to provide suitable air void parameters for freeze-thaw resistance. Please consult your Grace representative for guidance.

\section{Packaging \& Handling}

ADVA $140 \mathrm{M}$ is available in bulk, delivered by metered tank trucks, in 275 gal $(1040 \mathrm{~L})$ disposable totes, and in 55 gal $(208 \mathrm{~L})$ drums. It will begin to freeze at approximately $32^{\circ} \mathrm{F}$ $\left(0^{\circ} \mathrm{C}\right)$, but will return to full strength after thawing and thorough agitation.

In storage, and for proper dispensing, $\mathrm{ADVA}$ $140 \mathrm{M}$ should not experience prolonged exposure below $32^{\circ} \mathrm{F}\left(0^{\circ} \mathrm{C}\right)$ nor above $132^{\circ} \mathrm{F}\left(55^{\circ} \mathrm{C}\right)$.

\section{Dispensing Equipment}

A complete line of accurate, automatic dispensing equipment is available.

ADVA 140M ASTM C494 Type F High-Range Water Reducer Test Data

\begin{tabular}{|l|c|c|c|c|}
\hline \multirow{2}{*}{} & \multicolumn{2}{|c|}{ US Units } & \multicolumn{2}{c|}{ Metric } \\
\cline { 2 - 5 } & Control & ADVA 140M & Control & ADVA 140M \\
\hline Cement $(\mathrm{pcy})\left(\mathrm{kg} / \mathrm{m}^{3}\right)$ & 517 & 517 & 307 & 307 \\
\hline Coarse aggregate $(\mathrm{pcy})\left(\mathrm{kg} / \mathrm{m}^{3}\right)$ & 1944 & 1944 & 1153 & 1153 \\
\hline Fine aggregate $(\mathrm{pcy})\left(\mathrm{kg} / \mathrm{m}^{3}\right)$ & 1144 & 1214 & 679 & 720 \\
\hline Water $(\mathrm{pcy})\left(\mathrm{kg} / \mathrm{m}^{3}\right)$ & 235 & 201 & 140 & 119 \\
\hline w/cm & 0.455 & 0.389 & 0.455 & 0.389 \\
\hline Slump (inches) (mm) & 3.75 & 3.75 & 95 & 95 \\
\hline Plastic air $(\%)$ & 5.5 & 5.5 & 5.5 & 5.5 \\
\hline Compressive strength & & & & \\
1 day (psi) (MPa) & 1860 & 2750 & 12.8 & 19.0 \\
7 day (psi) (MPa) & 4520 & 5850 & 31.2 & 40.3 \\
28 day (psi) (MPa) & 5440 & 6640 & 37.5 & 45.8 \\
\hline Initial set time (hr:min) & $4: 02$ & $4: 18$ & $4: 02$ & $4: 18$ \\
\hline Length change 28 day (\%) & -0.031 & -0.024 & -0.031 & -0.024 \\
\hline Freeze-thaw resistance (RDME \%) & 92 & 96 & 92 & 96 \\
\hline
\end{tabular}

\section{www.graceconstruction.com}

North American Customer Service: 1-877-4AD-MIX1 (1-877-423-6491)

ADVA, the ADVA logo, Daracem, Daravair and Darex are regislered irademerks of W. R. Grace \& Co.-Conm.

We hope ane information here will be helppul. Eis is based on data and knowledge considered to be ine and acoarate and is offered for the users' suggestions in conjunction with our conditions of sale, which apply to all goods supplied by us. No statement, recommendation or suggesion is intended for any use which would infringe any patent or copyright. W. R. Grace \& Co.-Conn., 62 Whitemore Avenue, Cambridge, MA 02140 . In Cenada, Grace Cenada, Inc.. 294 Clements Road, West, Ajax, Ontario, Cenada L1S 3 C6.

This product may he cowered by patents or patents pencing.
DC-B1B $\quad$ Prinled in U.S.A. Copyright 2007. W. R. Grace \& Co.-Corn. 
Table A1. Measured fresh and hardened concrete properties.

\begin{tabular}{|c|c|c|c|c|c|}
\hline \multirow[b]{2}{*}{ Mixture } & \multirow[b]{2}{*}{ Batch } & \multirow[b]{2}{*}{ Slump, in. } & \multirow[b]{2}{*}{ Temperature, ${ }^{\circ} \mathrm{F}$} & \multicolumn{2}{|c|}{ Average Compressive Strength, psi } \\
\hline & & & & 28 day & 90 day \\
\hline \multirow{5}{*}{1} & 1 & 2.75 & 69 & 7440 & 7200 \\
\hline & 2 & 0.25 & 68 & 5910 & 6810 \\
\hline & 3 & 0.25 & 69 & 6810 & 7030 \\
\hline & 4 & 1 & 67 & 6970 & 7200 \\
\hline & 5 & 0.75 & 68 & 6850 & 7230 \\
\hline \multirow{5}{*}{2} & 1 & 1 & 70 & 6710 & 7650 \\
\hline & 2 & 2.25 & 66 & 6980 & 7120 \\
\hline & 3 & 1.5 & 66 & 6820 & 7110 \\
\hline & 4 & 1.25 & 66 & 6290 & 6570 \\
\hline & 5 & 1.5 & 67 & 7150 & 7490 \\
\hline \multirow{5}{*}{3} & 1 & 5.75 & 67 & 5910 & 5230 \\
\hline & 2 & 4.25 & 67 & 5700 & 5710 \\
\hline & 3 & 7 & 69 & 5510 & 5670 \\
\hline & 4 & 5.75 & 68 & 5800 & 6160 \\
\hline & 5 & 5 & 68 & 5440 & 5810 \\
\hline \multirow{5}{*}{4} & 1 & 7.5 & 65 & 4980 & 5260 \\
\hline & 2 & 7.25 & 67 & 4630 & 5190 \\
\hline & 3 & 7 & 67 & 4780 & 4890 \\
\hline & 4 & 6.5 & 72 & 4510 & 5060 \\
\hline & 5 & 7 & 72 & 4700 & 4420 \\
\hline \multirow{5}{*}{5} & 1 & 1.5 & 72 & 6620 & 7810 \\
\hline & 2 & 1.25 & 70 & 6870 & 7870 \\
\hline & 3 & 1.5 & 66 & 7220 & 7830 \\
\hline & 4 & 1 & 64 & 6770 & 7770 \\
\hline & 5 & 1 & 63 & 6880 & 6350 \\
\hline \multirow{5}{*}{6} & 1 & 1.25 & 60 & 6370 & 6860 \\
\hline & 2 & 1.25 & 60 & 6170 & 6840 \\
\hline & 3 & 2.25 & 66 & 7090 & 7440 \\
\hline & 4 & 3 & 66 & 6970 & 7100 \\
\hline & 5 & 2.25 & 66 & 6870 & 6530 \\
\hline \multirow{5}{*}{7} & 1 & 3 & 66 & 4840 & 5150 \\
\hline & 2 & 3.75 & 66 & 4750 & 5170 \\
\hline & 3 & 2.75 & 66 & 4030 & 5080 \\
\hline & 4 & 3 & 64 & 4130 & 4470 \\
\hline & 5 & 3.25 & 64 & 3760 & 4780 \\
\hline
\end{tabular}




\begin{tabular}{|c|c|c|c|c|c|}
\hline \multirow[b]{2}{*}{ Mixture } & \multirow[b]{2}{*}{ Batch } & \multirow[b]{2}{*}{ Slump, in. } & \multirow[b]{2}{*}{ Temperature, ${ }^{\circ} \mathrm{F}$} & \multicolumn{2}{|c|}{ Average Compressive Strength, psi } \\
\hline & & & & 28 day & 90 day \\
\hline \multirow{5}{*}{8} & 1 & 5.75 & 62 & 3660 & 4050 \\
\hline & 2 & 6.25 & 62 & 4180 & 4700 \\
\hline & 3 & 5 & 62 & 3670 & 4480 \\
\hline & 4 & 3.75 & 62 & 3440 & 3940 \\
\hline & 5 & 3 & 60 & 3840 & 4640 \\
\hline \multirow{5}{*}{9} & 1 & 1.5 & 61 & 6130 & 6590 \\
\hline & 2 & 1.25 & 61 & 6040 & 7240 \\
\hline & 3 & 1.5 & 62 & 5660 & 6490 \\
\hline & 4 & 1.25 & 62 & 5450 & 6530 \\
\hline & 5 & 1 & 62 & 5310 & 7130 \\
\hline \multirow{5}{*}{10} & 1 & 1.25 & 64 & 5450 & 7030 \\
\hline & 2 & 1.5 & 64 & 4700 & 6660 \\
\hline & 3 & 1.5 & 64 & 5170 & 6730 \\
\hline & 4 & 2 & 68 & 5580 & 6010 \\
\hline & 5 & 2.5 & 68 & 6090 & 7990 \\
\hline \multirow{5}{*}{11} & 1 & 2.25 & 66 & 4020 & 4780 \\
\hline & 2 & 3 & 64 & 3950 & 5120 \\
\hline & 3 & 2.5 & 64 & 4580 & 5620 \\
\hline & 4 & 2.75 & 65 & 4610 & 6200 \\
\hline & 5 & 2 & 70 & 4530 & 6400 \\
\hline \multirow{5}{*}{12} & 1 & 2.5 & 70 & 3740 & 4950 \\
\hline & 2 & 4.5 & 70 & 3540 & 4270 \\
\hline & 3 & 4 & 72 & 3160 & 4280 \\
\hline & 4 & 3.5 & 72 & 3440 & 4340 \\
\hline & 5 & 3.25 & 72 & 3340 & 4220 \\
\hline
\end{tabular}


Table A2. ASTM C666-A testing data.

\begin{tabular}{|c|c|c|c|c|c|c|}
\hline \multirow{2}{*}{\begin{tabular}{|l} 
Mixture \\
Design
\end{tabular}} & \multirow[b]{2}{*}{ Batch } & \multirow{2}{*}{$\begin{array}{l}\text { Design Air } \\
\text { Content, \% }\end{array}$} & \multicolumn{4}{|c|}{ Final Recorded Data Point } \\
\hline & & & Cycles & Relative Dynamic Modulus, \% & Mass Loss, $\%$ & Durability Factor \\
\hline \multirow{5}{*}{1} & 1 & \multirow{5}{*}{3} & 23 & 32.5 & 0.46 & 2 \\
\hline & 2 & & 23 & 29.7 & 0.59 & 2 \\
\hline & 3 & & 10 & 23.5 & 0.37 & 1 \\
\hline & 4 & & 23 & 41.1 & 0.45 & 3 \\
\hline & 5 & & 23 & 57.1 & 0.27 & 2 \\
\hline \multirow{5}{*}{2} & 1 & \multirow{5}{*}{4} & 23 & 57.5 & 0.36 & 4 \\
\hline & 2 & & 48 & 44.2 & 0.45 & 7 \\
\hline & 3 & & 48 & 40.6 & 0.54 & 6 \\
\hline & 4 & & 23 & 52.0 & 0.37 & 4 \\
\hline & 5 & & 23 & 74.0 & 0.40 & 6 \\
\hline \multirow{5}{*}{3} & 1 & \multirow{5}{*}{6} & 257 & 55.9 & 2.15 & 48 \\
\hline & 2 & & 221 & 59.5 & 2.27 & 44 \\
\hline & 3 & & 257 & 58.9 & 2.69 & 50 \\
\hline & 4 & & 291 & 58.6 & 3.30 & 57 \\
\hline & 5 & & 257 & 53.7 & 3.02 & 46 \\
\hline \multirow{5}{*}{4} & 1 & \multirow{5}{*}{8} & 108 & 46.2 & 0.14 & 17 \\
\hline & 2 & & 291 & 55.9 & 3.18 & 54 \\
\hline & 3 & & 304 & 64.2 & 3.51 & 64 \\
\hline & 4 & & 291 & 58.6 & 1.97 & 57 \\
\hline & 5 & & 304 & 64.0 & 1.36 & 64 \\
\hline \multirow{5}{*}{5} & 1 & \multirow{5}{*}{3} & 10 & 65.0 & 0.36 & 2 \\
\hline & 2 & & 10 & 65.6 & 0.32 & 2 \\
\hline & 3 & & 23 & 36.2 & 0.59 & 3 \\
\hline & 4 & & 23 & 38.0 & 0.63 & 3 \\
\hline & 5 & & 10 & 49.7 & 0.54 & 2 \\
\hline \multirow{5}{*}{6} & 1 & \multirow{5}{*}{4} & 23 & 59.7 & 2.54 & 5 \\
\hline & 2 & & 10 & 63.9 & 0.59 & 2 \\
\hline & 3 & & 10 & 61.6 & 0.36 & 2 \\
\hline & 4 & & 23 & 25.7 & 0.58 & 2 \\
\hline & 5 & & 10 & 57.9 & 0.04 & 2 \\
\hline \multirow{5}{*}{7} & 1 & \multirow{5}{*}{6} & 236 & 65.8 & 2.19 & 52 \\
\hline & 2 & & \begin{tabular}{|l|}
177 \\
\end{tabular} & 67.1 & 1.61 & 40 \\
\hline & 3 & & 236 & 65.6 & 2.53 & 52 \\
\hline & 4 & & 10 & 68.4 & 0.23 & 2 \\
\hline & 5 & & 10 & $\begin{array}{l}73.4 \\
\end{array}$ & 0.24 & 2 \\
\hline
\end{tabular}




\begin{tabular}{|c|c|c|c|c|c|c|}
\hline \multirow{2}{*}{$\begin{array}{l}\text { Mixture } \\
\text { Design }\end{array}$} & \multirow[b]{2}{*}{ Batch } & \multirow{2}{*}{$\begin{array}{l}\text { Design Air } \\
\text { Content, \% }\end{array}$} & \multicolumn{4}{|c|}{ Final Recorded Data Point } \\
\hline & & & Cycles & Relative Dynamic Modulus, \% & Mass Loss, $\%$ & Durability Factor \\
\hline \multirow{5}{*}{8} & 1 & \multirow{5}{*}{8} & 201 & 65.4 & 2.37 & 44 \\
\hline & 2 & & 95 & 81.2 & 0.34 & 26 \\
\hline & 3 & & 223 & 61.1 & 1.25 & 45 \\
\hline & 4 & & 201 & 60.9 & 1.52 & 41 \\
\hline & 5 & & 177 & 75.7 & 1.31 & 45 \\
\hline \multirow{5}{*}{9} & 1 & \multirow{5}{*}{3} & 10 & 66.4 & 0.27 & 2 \\
\hline & 2 & & 10 & 60.7 & 0.32 & 2 \\
\hline & 3 & & 1 & 101.1 & 0.09 & 0 \\
\hline & 4 & & 1 & 99.2 & 0.13 & 0 \\
\hline & 5 & & 1 & 99.4 & 0.09 & 0 \\
\hline \multirow{5}{*}{10} & 1 & \multirow{5}{*}{4} & 34 & 70.7 & 0.22 & 8 \\
\hline & 2 & & 10 & 86.7 & 0.23 & 3 \\
\hline & 3 & & 34 & 76.1 & 0.36 & 9 \\
\hline & 4 & & 10 & 86.1 & 0.18 & 3 \\
\hline & 5 & & 10 & 63.9 & 0.27 & 2 \\
\hline \multirow{5}{*}{11} & 1 & \multirow{5}{*}{6} & 59 & 64.6 & 0.14 & 13 \\
\hline & 2 & & 95 & 68.9 & 0.33 & 22 \\
\hline & 3 & & 236 & 60.9 & 3.80 & 48 \\
\hline & 4 & & 201 & 61.8 & 2.50 & 41 \\
\hline & 5 & & 201 & 68.3 & 3.96 & 46 \\
\hline \multirow{5}{*}{12} & 1 & \multirow{5}{*}{8} & 201 & 64.7 & 3.39 & 43 \\
\hline & 2 & & 152 & 67.3 & 2.06 & 34 \\
\hline & 3 & & 260 & 60.7 & 3.69 & 53 \\
\hline & 4 & & 260 & 64.4 & 3.30 & 56 \\
\hline & 5 & & 152 & 70.9 & 2.49 & 36 \\
\hline
\end{tabular}




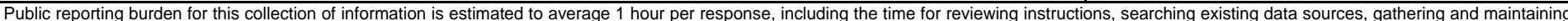

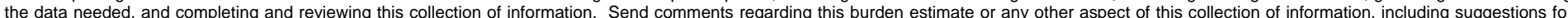

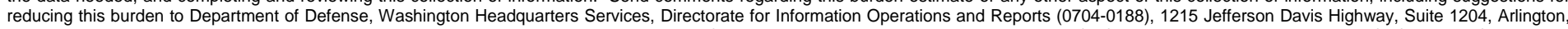

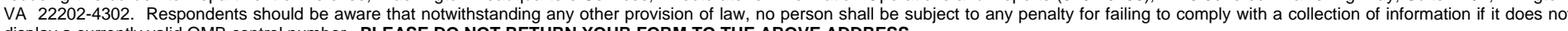
display a currently valid OMB control number. PLEASE DO NOT RETURN YOUR FORM TO THE ABOVE ADDRESS.
1. REPORT DATE (DD-MM-YY)
July 2013

\section{TITLE AND SUBTITLE}

Evaluation of the Air Void Analyzer
3. DATES COVERED (From - To)

5a. CONTRACT NUMBER

5b. GRANT NUMBER

5c. PROGRAM ELEMENT NUMBER

5d. PROJECT NUMBER

5e. TASK NUMBER

5f. WORK UNIT NUMBER

8. PERFORMING ORGANIZATION REPORT NUMBER

ERDC/GSL TR-13-31

U.S. Army Engineer Research and Development Center

Geotechnical and Structures Laboratory

3909 Halls Ferry Road

Vicksburg, MS 39180

9. SPONSORING / MONITORING AGENCY NAME(S) AND ADDRESS(ES)

10. SPONSOR/MONITOR'S ACRONYM(S)

Headquarters, Air Force Civil Engineer Support Agency

Tyndall Air Force Base, FL 32403-5319

11. SPONSOR/MONITOR'S REPORT NUMBER(S)

\section{DISTRIBUTION I AVAILABILITY STATEMENT}

Approved for public release; distribution is unlimited.

\section{SUPPLEMENTARY NOTES}

\section{ABSTRACT}

The U.S. Army Engineer Research and Development Center (ERDC) conducted an evaluation of the Air Void Analyzer (AVA) to determine the machine's ability to accurately and precisely measure the air void structure of freshly prepared portland cement concrete (PCC). This evaluation consisted of producing multiple batches of PCC in the laboratory and measuring each batch's air void structure with the AVA and other commonly used ASTM International testing procedures. A statistical analysis was conducted on sixty batches of concrete, covering a range of entrained air and fly ash contents. Air contents and fly ash replacement ranged from 3 to 8 percent and 0 to 20 percent, respectively. The freeze-thaw resistance of the PCC produced was also evaluated to verify the machine's ability to reveal poorly performing mixtures.

The laboratory evaluation was conducted from May 2011 to January 2012. Laboratory mixtures were batched and concrete specimens were prepared and tested at the ERDC Materials Testing Center. A certified petrographer determined the air void structures were in accordance with ASTM C457. A statistical analysis of the air void structure measurements taken by the AVA was completed using the results of five ASTM International standard test methods.

This report summarizes the laboratory performance of the AVA, and the pertinent conclusions from the testing performed.

Recommendations for implementation and future testing are provided.

\begin{tabular}{|c|c|c|c|c|c|}
\hline \multicolumn{2}{|c|}{ 15. SUBJECT TERMS } & \multicolumn{2}{|l|}{ Air Void Analyzer } & \multicolumn{2}{|c|}{ Entrapped air } \\
\hline \multicolumn{2}{|l|}{ Aggregate } & \multicolumn{2}{|l|}{ Air Void System } & \multicolumn{2}{|c|}{ Mixture design } \\
\hline \multicolumn{2}{|l|}{ Air content } & \multicolumn{2}{|l|}{ Entrained air } & \multicolumn{2}{|c|}{ Portland cement concrete } \\
\hline \multicolumn{3}{|c|}{ 16. SECURITY CLASSIFICATION OF: } & $\begin{array}{l}\text { 17. LIMITATION } \\
\text { OF ABSTRACT }\end{array}$ & $\begin{array}{l}\text { 18. NUMBER } \\
\text { OF PAGES }\end{array}$ & $\begin{array}{l}\text { 19a. NAME OF RESPONSIBLE } \\
\text { PERSON: }\end{array}$ \\
\hline $\begin{array}{l}\text { a. REPORT } \\
\text { Unclassified }\end{array}$ & $\begin{array}{l}\text { b. ABSTRACT } \\
\text { Unclassified }\end{array}$ & $\begin{array}{l}\text { c. THIS PAGE } \\
\text { Unclassified }\end{array}$ & Unclassified & 105 & $\begin{array}{l}\text { 19b. TELEPHONE NUMBER (include } \\
\text { area code) }\end{array}$ \\
\hline
\end{tabular}

